\title{
Welfare and Equity Impacts of Cross-Border Factor Mobility in Bangladesh: A General Equilibrium Analysis
}

\author{
Sharif M. Hossain \\ Nobuhiro Hosoe
}

January 2019

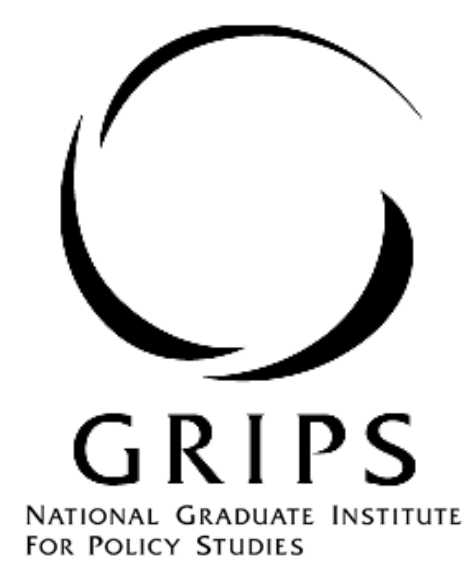

National Graduate Institute for Policy Studies

7-22-1 Roppongi, Minato-ku,

Tokyo, Japan 106-8677 


\title{
Welfare and Equity Impacts of Cross-Border Factor Mobility in Bangladesh: A General Equilibrium Analysis
}

\author{
Sharif M. Hossain ${ }^{\mathrm{a}, \mathrm{b}, \mathrm{c}, 1}$ \\ and \\ Nobuhiro Hosoe ${ }^{b}$ \\ ${ }^{\text {a }}$ Research Fellow, Japan Society for the Promotion of Science (JSPS) \\ ${ }^{\mathrm{b}}$ National Graduate Institute for Policy Studies (GRIPS), Japan \\ ${ }^{\mathrm{c}}$ Department of Economics, Jagannath University, Bangladesh
}

\begin{abstract}
Bangladesh is one of the top remittance recipient countries in the world and it is the second largest source of the country's foreign exchange earnings. However, in recent years, remittance inflows into Bangladesh have declined steadily because of real income reductions of migrants. This trend in income has increased the number of returning migrants, making domestic employment less secure. To address this issue, we develop a recursive dynamic CGE model for Bangladesh that describes the allocation of employment between domestic and foreign labor markets in response to a foreign wage premium, competition between local firms and multinational enterprises in the readymade garments (RMG) sector, and distributional impacts of factor mobility on different household groups. Our simulation results show that returning migrants reduce household welfare by lowering wages and increasing unemployment, particularly for unskilled workers in the domestic labor market. Using counteractive policy options, we examine the impacts of FDI promotion in the RMG sector and of a human-capital development program. Based on our results, we conclude that the former policy minimizes the negative impacts of foreign labor market shocks, while a combination of both policies is more equitable.
\end{abstract}

Key words: Factor mobility, migration, remittances, foreign direct investment, computable general equilibrium analysis.

JEL Classification Code: C68, F21, F22, O15

${ }^{1}$ Corresponding author. 7-22-1 Roppongi, Minato, Tokyo 106-8677, Japan. E-mail: smhossain@ gmail.com.

* It is gratefully acknowledged that this study was supported by the JSPS KAKENHI Grants (18J11669 and $16 \mathrm{~K} 03613)$ 


\section{Welfare and Equity Impacts of Cross-Border Factor Mobility in Bangladesh: A General Equilibrium Analysis}

\section{Introduction}

Recent decades have witnessed a considerable intensification of global economic integration. Cross-border trade in goods and services has increased substantially through bilateral and multilateral free trade agreements (FTAs), leading to higher economic growth and improved welfare, particularly in the member countries. FTAs used to cover mainly crossborder movement of goods and services, but now also involve factor mobility, typically in the forms of labor migration and foreign direct investment (FDI). As traditional trade theories have viewed that the abundance of factors determines trade patterns (Heckscher-Ohlin model), cross-border factor mobility also matters in the recently globalizing world, as labor migrates from poor to rich countries, and capital moves from rich to poor countries.

Inbound labor migration to rich countries can relax labor supply constraints on growth and increase economic mass to exploit economies of scale. Poor countries can use remittance income to reduce poverty among households, earn foreign currency, and acquire skills through returning migrants (ILO/OECD/World Bank, 2015, p. 10). Similarly, as a supplement to domestic investment, FDI can relax the capital-availability constraint in the host countries (Herzer et al., 2008, p. 793). The donor countries can benefit from the availability of cheap labor and intermediate inputs, and by enjoying greater market access of their products. However, problems can also arise. Continued emigration can undermine sustainable development. Rich countries exploit the services of relatively skilled workers that were educated and trained by developing countries using their limited budgets (Beine et al., 2001, p. 276; Hanson, 2009, p. 180). Furthermore, FDI inflows can create severe competition between local firms and multinational enterprises (MNEs) in both output and labor markets in the host countries. Growth of MNEs increases the wages of employees working in export processing zones where most MNEs are located, whereas the wages of workers employed by local firms may be stagnant.

While outward migration can increase the welfare of poor households in the short run, many unskilled migrants miss the opportunities for training and education, which hinders human capital accumulation in the long run. As MNEs are technology and knowledge intensive and thus tend to hire skilled workers, human capital accumulation can create a synergy effect 
with FDI/MNEs. Human capital development to meet the demand for highly skilled workers makes part of the labor force temporarily unavailable, worsening poverty incidence in the short run. In the long run, a wage increase can eradicate poverty and improve income equality. The above-mentioned dilemmas relating to factor mobility and human capital accumulation create two tradeoffs in a poor country: a tradeoff between short-run poverty alleviation with remittances and long-run growth with human capital accumulation, and a tradeoff between competition among local firms and MNEs with the presence of FDI. These tradeoffs are serious in Bangladesh, which faces many constraints: employment opportunities, foreign exchange earnings by remittances, poverty incidence, and human capital quality and availability.

Figure 1: Migration, Remittances and FDI in Bangladesh (1980-2017) [Unit: Million USD and Thousands of Workers]

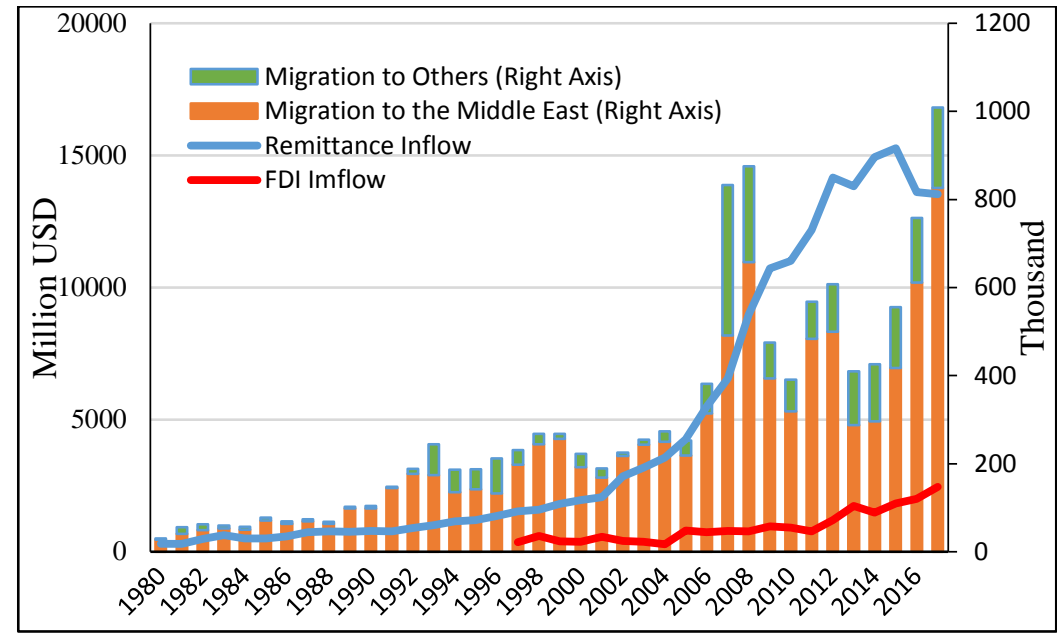

Source: BMET Database and Bangladesh Bank (2017)

Bangladesh is one of the largest remittance recipient countries in the world. Remittances are the second largest source of foreign exchange earnings in Bangladesh, after exports of ready-made garments (RMG), which is the most important manufacturing sector in Bangladesh. From 2007 to 2017, remittances accounted for eight percent of gross domestic product (GDP) and 47 percent of total exports, and funded 34 percent of the country's total import payments (World Bank World Development Indicators). The remittance receipts (Figure 1) enabled Bangladesh to maintain a balance of payments surplus despite facing a continuously growing trade deficit (Abrar and Billah, 2017, p. 148). Remittances contributed significantly to improving household welfare and reducing headcount poverty (World Bank Global Economic Prospect, 2006, p. 120; Raihan et al., 2009, p. 17). However, in recent years, remittance inflows have declined steadily because of real income reductions among migrants working in the 
Middle East (Figure 1). ${ }^{1}$ This is a major risk factor for Bangladesh (IMF, 2017, p. 6).

These income reductions have resulted in an increase in the number of returning migrants, which makes domestic employment in Bangladesh less secure. Given this external labor market shock, policy interventions are necessary to mitigate its negative impact on the domestic economy. For example, more job opportunities need to be created by encouraging more FDI. However, inward FDI in Bangladesh is very small at present, less than two percent of GDP (Figure 1). The poor business environment is the main barrier as indicated by the World Bank's Ease of Doing Business Index, in which Bangladesh ranked 176 out of 190 countries in 2017. The returning migrants are most commonly unskilled workers and are therefore more of a threat to the job security of domestic unskilled workers than skilled ones. While the transformation of unskilled workers to skilled ones through human capital development programs is a solution, this skill transformation creates another tradeoff between short-run wage loss and long-run wage increase.

The studies on factor mobility in Bangladesh mainly examined the impacts of remittances and FDI on economic growth and/or poverty. Selvanathan and Selvanathan (2012) used time-series econometric techniques to investigate the causal link between remittances and economic growth and found a unidirectional positive effect from remittances to economic growth in Bangladesh. Hassan et al. (2016), Hassan et al. (2017), and Kumar et al. (2018) argued that the relationship between remittances and GDP growth is not linear but rather nonlinear in Bangladesh. Many other studies (Khan, 2008; Raihan et al., 2009; Moniruzzaman, 2009; Hatemi-J and Uddin, 2014; Raihan et al., 2017) analyzed the impact of remittances on household poverty and found that remittances reduced poverty in Bangladesh. Studies on FDI in Bangladesh (Ahmad, 1990; Alam and Mian, 2006; Kabir, 2007; Quader, 2009; Shimul et al., 2009; Ahmed and Tania, 2010; Islam and Meerza, 2013; Khatun and Ahmad, 2015; Noor, 2016; Dutta et al., 2017) also analyzed its impact on GDP growth and found either a positive effect

\footnotetext{
${ }^{1}$ Several factors can explain the real income reduction among migrant workers in the Middle East. First, the economic weakness in the Middle East, resulting from the oil price shocks, has reduced the job opportunities and wages of migrant workers. Second, strict immigration policies in this region restricted the employment of undocumented migrants in formal sectors with higher wages. Third, high migration costs, as well as the high cost of living relative to the wages of migrants in the Middle East, reduced migrants' average propensity to save and consequently average propensity to remit money out of their savings (Hussain, 2014).
} 
or ambiguous results.

Most of these existing empirical studies are ex-post in nature and used either reducedform econometric techniques or qualitative methods to predict the effects of remittances/FDI on aggregate variables such as GDP, total factor productivity, and poverty incidence. A structural approach is required to predict the effects of a shock in foreign labor markets as well as in FDI promotion and skill transformation, and to describe their synergetic roles in a macroeconomy with those three tradeoffs mentioned above. To the best of our knowledge, very few studies have employed a structural computable general equilibrium (CGE) model to analyze the impacts of remittances and FDI in Bangladesh. Two exceptions are Raihan et al. (2009) and Hossain and Hosoe, (2017), although the former study does not incorporate the labor market for migrant workers and remittances were exogenously determined. The latter study used a static model with a full employment assumption in the labor market to analyze the impact of FDI in the RMG sector in Bangladesh.

In this paper, we examine the impacts of cross-border factor mobility and human capital accumulation on household welfare in level and equity, and the macroeconomy. Our simulation exercises for Bangladesh show that a foreign labor market shock reduces household welfare by inevitably lowering wages and increasing unemployment, particularly for unskilled workers in the domestic labor market. To counteract this negative impact, we consider two policy options. In the first option, we examine the impacts of FDI increases in the RMG sector. In the second option, we analyze the impacts of a human capital development program that transforms unskilled workers to skilled, to help them combat the domestic wage fall. Based on our simulation results, we conclude that the former policy minimizes the negative impacts of returning migrants on the domestic labor market and consequently on household welfare, while a combination of both policies is more equitable and favorable toward poor households.

The reminder of the paper is organized as follows. Section 2 describes the methodological approach, data, and simulation scenarios. The results of the simulations are discussed in Section 3, while Section 4 draws conclusions. 


\section{Methodology and Data}

\subsection{The Model}

We develop a recursive dynamic CGE model for Bangladesh based on the static model of Hossain and Hosoe (2017). Our model distinguishes 15 sectors, including two subsectors in the RMG sector (Table 1), eight household groups (Table 2), and three factors of production: unskilled labor, skilled labor, and capital. The income of these households is generated from factor income, government transfers, and foreign remittances, which reflects these households' characteristics (Figure 2). Among these eight household groups, urban highly educated household generates most of their income from skilled labor wages, while the urban poorly educated household does so from unskilled labor wage. The rural nonagricultural rich household depends heavily on capital income. The rural agricultural large household generates considerable amounts of income from land. ${ }^{2}$ Other households generate most of their income from their unskilled labor wages. ${ }^{3}$

Table 1: Sectoral Aggregation

\begin{tabular}{ll}
\hline Sector & Abbreviation \\
\hline Agriculture & AGR \\
Cotton cultivation & COT \\
Mining \& quarrying & MIN \\
Food products & FOD \\
Textile & TEX \\
Ready-made garments hosting local firms & Local-RMG \\
Ready-made garments hosting MNEs & MNE-RMG \\
Yarn industry & YRN \\
Paper, printing \& publishing & PPP \\
Basic chemical & CHM \\
Metal, machinery \& equipment & MME \\
Other manufacturing & OMC \\
Construction & CON \\
Power & POW \\
Trade, transport \& communications & TTC \\
Services & SVC \\
\hline
\end{tabular}

\footnotetext{
${ }^{2}$ In the following simulation analysis, we combine land with capital.

${ }^{3}$ There are only minor differences in consumption patterns among households.
} 
Table 2: Definition of Household Types

\begin{tabular}{ll}
\hline Household type & Description \\
\hline Urban & \\
\hline Highly educated & Head has more than 8 years of schooling \\
Poorly educated & Head has 1-8 years of schooling \\
\hline Rural & \\
\hline Nonagricultural rich & Not engaged in agricultural activities and owns more than 0.5 acres of land \\
Nonagricultural poor & Not engaged in agricultural activities and owns fewer than 0.5 acres of land \\
Agricultural large & Agricultural households who own more than 2.49 acres of land \\
Agricultural small & Agricultural households who own 0.5-2.49 acres of land \\
Agricultural marginal & Agricultural households who own up to 0.49 acres of land \\
Agricultural landless & Agricultural households who have no land \\
\hline
\end{tabular}

Figure 2: Share of Income Generating Factors in Total Household Income

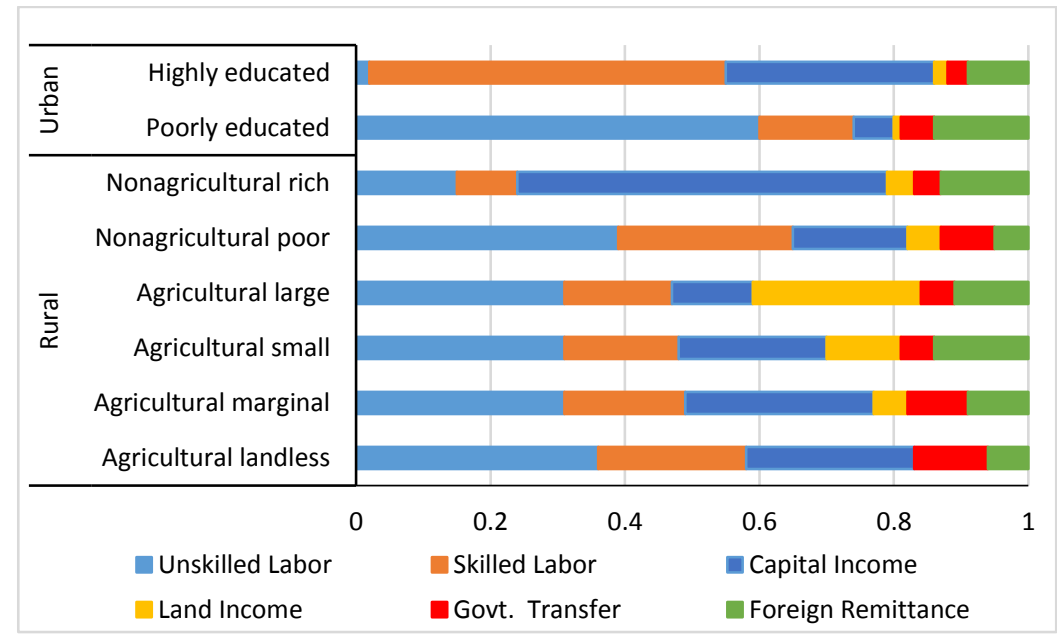

The model is extended in the following three ways. First, the RMG sector is split into two subsectors, local firms and MNEs, based on the capital ownership. This feature enables us to analyze the impacts of international capital mobility in the form of FDI. Second, we elaborate labor supply by household by incorporating (voluntary) unemployment and endogenous allocation of the workforce between domestic and foreign labor markets in response to the foreign wage premium. This extension allows us to examine how a reduction in migrant workers' earnings in the foreign labor market affects their migration decision and domestic labor supply. Finally, we extend it to a dynamic model to examine the tradeoffs between physical and human capital accumulation in the short run and long run in the presence of FDI inflows and international labor mobility, which cannot be analyzed with a static model.

For the second extension, we assume that a household obtains utility by consuming a composite good, composed of various goods and services, and by enjoying leisure (Figure 3 ). 
The substitution between these two endogenously determines labor supply by each household. Compared with other approaches, such as full employment with a flexible wage rate (neoclassical model) and an institutionally fixed wage rate with unlimited supply of labor (structuralist model), this voluntary unemployment approach allows us to describe the labor market in Bangladesh more flexibly, where many people are jobless even with open job opportunities offering low wages. Voluntary unemployment also explains the relatively high unemployment rate of skilled workers compared with unskilled workers in Bangladesh (Asadullah, 2014). We next describe both the static and dynamic features of our model.

\subsubsection{Structure of the CGE Model within a Period}

The within-period structure of our CGE model is described in Figure 3. In the labor market for the $h$-th labor type (left panel), the $r$-th household makes the decision to supply its skilled and unskilled labor endowments $\left(\right.$ Lab.End $\left._{r, h}\right)$ either to work (Tot.Work $\left.k_{r, h}\right)$ or consume its own leisure ( Leisure $_{r, h}$ ), taking into account the labor wage (label 1 in Figure 3). A constant elasticity of transformation (CET) function is employed to allocate the labor endowments between total workforce and leisure. The $h$-th total workforce (Tot. Work $k_{r, h}$ ) is then allocated between domestic workforce (Dom.Work $k_{r, h}$ ) and foreign workforce $\left(\right.$ For. Work $k_{r, h}$ ) with a CET function (label 2). The $h$-th domestic workforce (Dom. Work $k_{r, h}$ ) is employed in all sectors (both local and MNE sectors). Both skilled and unskilled workers are fully mobile across sectors; domestic capital is used only in the local firm sectors not in the MNE sector. The external sector supplies capital to their affiliates in the MNE-RMG sector in the form of FDI. In the output market for the $i$-th good (right panel), the composite factor $\left(Y_{i}\right)$ is produced by using capital and skilled and unskilled labor with a Cobb-Douglas type production function (label 3). The structure after the composite factor production is similar to the standard CGE model, which describes the economic activities with nested constant elasticity of substitution and transformation (CES and CET) functions. These functions describe the production of gross domestic output $\left(Z_{i}\right)$ (label 4), transformation of gross domestic output into domestic goods $\left(D_{i}\right)$ and exports $\left(E_{i}\right)$ (label 5), and production of Armington composite goods $\left(Q_{i}\right)$ (label 6). As mentioned above, household utility depends on the consumption of composite goods $\left(X_{i, r}^{p}\right)$ and own leisure (Leisure $\left.{ }_{r, h}\right)$ from the $h$-th labor endowment (label 7). 
Figure 3: Intratemporal Structure of the CGE Model

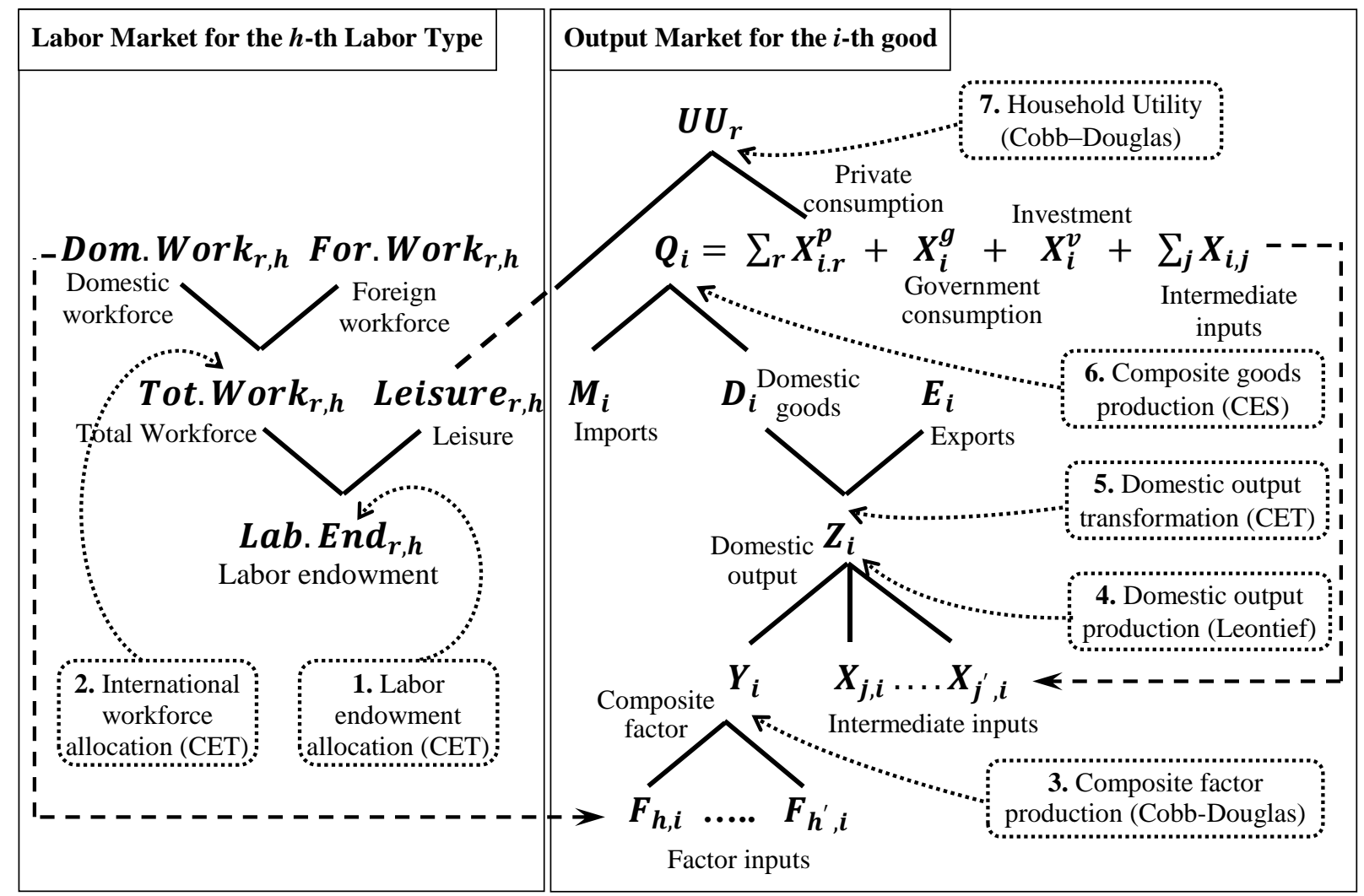

As Hossain and Hosoe (2017) assumed, the difference between the local-RMG and MNE-RMG sectors lies in the ownership of the capital they use. We assume that the MNERMG sector is 100 percent export-oriented in final demand and that foreign capital is not substitutable with domestic capital. Their production technology, such as capital-labor ratio and intermediate input coefficients, is assumed to be common.

\subsubsection{Dynamic Structure}

We modify the static model of Hossain and Hosoe (2017), by adding recursive dynamics. Government consumption is set as exogenous within a period, but growing at the rate of population growth rate $(p o p)$. The government generates its revenue from various indirect taxes and a lump-sum direct tax on household income. Total tax revenue is proportionately used for government consumption, subsidies, transfers to households, and savings. Government fiscal balance is achieved through the lump-sum direct taxes. Household income depends on labor wages, returns to capital, government transfers, and remittances.

The $h$-th labor endowment is given at the beginning of each period but grows at the population growth rate pop, Lab. End $d_{r, h, t+1}=(1+p o p) . L a b . E n d_{r, h, t}$. Both skilled and 
unskilled workers are fully mobile across sectors. The private savings by the $r$-th household $\left(S_{r, t}^{p}\right)$ and government savings $\left(S_{t}^{g}\right)$ are generated with constant propensities to save $\left(s s_{r}^{p}\right.$ and $\left.s s^{g}\right)$, but foreign savings $\left(S_{t}^{f}\right)$ are assumed to be exogenous and growing at the population growth rate. The foreign exchange rate $\left(\varepsilon_{t}\right)$ is endogenously determined to keep the current account balance unchanged. Savings are used to purchase various investment goods $\left(X_{i, t}^{v}\right)$, which are used to produce composite investment goods that are allocated across sectors. Sectoral investment in the $j$-th sector $\left(I I_{j, t}\right)$ is determined by expected returns to capital under myopic expectations, à la Hosoe (2014).

Unlike the local firm sectors, investment in the MNE sector $\left(I I_{j_{-} M N E, t}\right)$ is financed by the external sector and is exogenous. The return to foreign capital from the MNE sector is captured by the external sector, not by any of the domestic agents. Capital is accumulated with new investment after its depreciation with a rate of dep as: $K K_{j, t+1}=(1-d e p) . K K_{j, t}+I I_{j, t}$. Capital is a putty-clay type and sector specific after its installation.

\subsection{Model Estimation}

Our model is calibrated to the Bangladesh Social Accounting Matrix (SAM) for 2012 with Armington elasticities of substitution and transformation $\left(\sigma_{i_{-}}\right.$all and $\left.\psi_{i_{-} a l l}\right)$ provided by the Global Trade Analysis Project (GTAP) version 9 database. The elasticity of transformation for international labor allocation $\left(\chi_{r, h 2}\right)$ is assumed to be 1.2, following David and Marouani (2015). In our model, the exogenous variables, such as labor endowment $\left(L F_{r, h, t}\right)$, government consumption $\left(X_{i, t}^{g}\right)$, foreign savings $\left(S_{t}^{f}\right)$, and foreign direct investment $\left(I I_{j_{-} M N E, t}\right)$, are assumed to grow at the population growth rate so that the model can generate a balanced growth path for the business-as-usual (BAU) path. The population growth rate is assumed to be 1.1 percent, considering the population growth in Bangladesh in 2016 (World Bank World Development Indicators). We assume the rate of return to capital, ror $=5$ percent; capital depreciation rate, $\operatorname{dep}=4$ percent; and the elasticity parameter in the investment function, $\zeta=$ 1, following Hosoe (2014). ${ }^{4}$ We adjust the investment and government consumption data for

\footnotetext{
${ }^{4}$ To check the robustness of our simulation results with respect to these assumed parameters we conduct sensitivity analyses, which are shown in Appendix A. The details of the investment function and its parameters are explained in Appendix B. These Appendixes are available upon request.
} 
the above-mentioned BAU growth path, as the investment reported in the original SAM is not necessarily consistent with the required investment to generate the BAU growth path.

The Bangladesh SAM reports wages, but not leisure consumption or unemployment for the eight household groups. Assuming common unemployment rates among rural and urban household groups, we estimate the unemployed labor endowment of each household group using the unemployment rates reported in the Quarterly Labor Force Survey (QLFS, 2017) of Bangladesh for year 2015-16. According to the QLFS (2017), the unemployment rates in rural areas are 7.88 and 2.74 percent for skilled and unskilled workers, respectively, whereas in urban areas these rates are 6.91 and 2.80 percent, respectively. These figures may be quite small compared with unemployment rates commonly observed in developing countries. An alternative estimate of the graduate unemployment rate of 47 percent is provided in an economist intelligence report (British Council, 2014, p. 10). The difference between these two estimates can be attributed largely to the differences in the samples and definition of unemployment incidence. As there is no other official unemployment data with a wide coverage, we use the QLFS estimate to construct our model.

\subsection{Simulation Scenarios}

We set three scenarios of cross-border factor mobility and human capital accumulation for Bangladesh. Simulation 1 assumes a one percent wage decline for migrant workers in the foreign labor market. This is an exogenous shock that Bangladesh may face. To counteract this, we consider two policy measures in our scenarios. Simulation 2 assumes a 25 percent yearly increase of FDI inflow into the MNE-RMG sector, in addition to the shock assumed in simulation 1. Simulation 3 assumes a hypothetical human resource development program, provided to 25,000 unskilled workers to transform them into skilled workers so that they can earn a skill premium, in addition to the shocks assumed in simulation 2 . We run our model with these shocks for 10 consecutive periods. Their backgrounds are discussed below.

\subsubsection{Migrant Workers' Wage Decline}

From 2013 to 2017, overall remittances flowing into Bangladesh fell, on average, by 0.7 percent per year (Figure 1). This was partly because of increased unemployment and the declining wages of undocumented low-skilled migrants in the Middle East (Hussain, 2014), and partly because of deteriorating nonmonetary benefits for migrant workers (i.e., food and accommodation, free air tickets to work and to visit family members during holidays, free visa 
extension arrangements). For example, migration costs to Saudi Arabia rose, on average, from 200,000 Bangladeshi taka (BDT) in 2000 to 600,000 BDT in 2016 (Palma, 2016). These changes reduced migrants' earnings and ability to remit. Based on the trend in Figure 1, we assume a one percent decline in migrants' wages throughout the simulation period.

\subsubsection{Increase in FDI Inflow}

In simulation 2, we assume that the FDI stock in the MNE-RMG sector is doubled in Bangladesh in 10 years (Figure 4). This target can be contextualized with the recent policy reforms to attract FDI. The government is aiming to improve the country's attractiveness as an FDI destination in order to become a top 100 FDI host country (The Independent, 2018). To measure attractiveness, the World Bank's Ease of Doing Business Index is often used. Several empirical studies (Wei, 2000; Aizenman and Spiegel, 2006; Jayasuriya, 2011; Zhang, 2012; Duval and Utoktham, 2014; Corcoran and Gillanders, 2015) identified a positive association between this index and the amount of FDI inflow. Corcoran and Gillanders (2015) found that a one place improvement in rank is associated with a 0.56 percent FDI stock increase, on average. This implies that achieving the target rank of 100 in Bangladesh would increase the FDI stock by around 43 percent. As Zhang (2012) found, this relationship between the index and FDI is much stronger for poorly ranked countries such as Bangladesh, which was ranked 176 out of 190 countries in 2017. We investigate to what extent this increase in FDI could vitalize Bangladesh's economy and offset the negative shock in remittances.

\section{Figure 4: FDI Stock in the Textile and RMG Sectors [Unit: Million USD]}

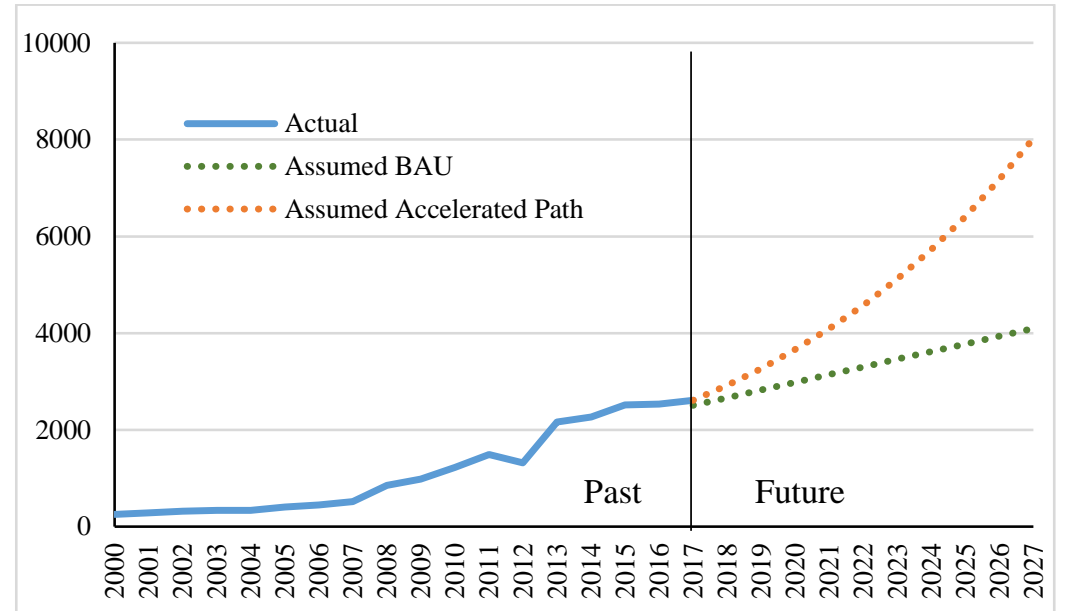

Note: Bangladesh Bank (2017) for the actual FDI stock data.). The BAU and accelerated FDI growth paths are constructed using the authors' assumptions. 
To double the FDI stock in 10 years, Bangladesh must increase the FDI (stock)-GDP ratio from the current ratio of 5.8 percent (UNCTAD, 2018/World Bank World Development Indicators) to 11.6 percent. This 10 -year target is reasonable considering the current FDI stock in the RMG sector, where MNEs produce only five percent of total RMG output (Kee, 2014, p. 39). The target is also consistent with the experiences of other South and Southeast Asian countries, although they have achieved higher positions in the FDI host ranking and the World Bank's Ease of Doing Business Index. For example, the FDI (stock)-GDP ratios of Vietnam (rank 82), Malaysia (rank 23), Indonesia (rank 91), and India (rank 130) are 57.8 percent, 44.4 percent, 24.5 percent, and 14.5 percent, respectively. ${ }^{5}$ This is the rationale of our assumption of a doubling in the FDI stock in the RMG sector over 10 years. This translates into a 25 percent annual increase in FDI in our simulation period.

\subsubsection{Human Capital Accumulation}

A three-year-long hypothetical education and training program is assumed to upgrade unskilled workers to skilled ones. Each year, this program accepts 25,000 unskilled workers among the eight household groups. The trainees are selected based on their unskilled labor endowment. ${ }^{6}$ The unskilled workers assigned to the program leave the labor markets for three years and are transformed into skilled workers, who can earn a skill premium of 148 percent over the unskilled workers, equivalent to 10,206 BDT per worker per month. ${ }^{7}$ Such an education and training program involves pecuniary costs, other than the opportunity cost of wage losses. For this, we use the per-student cost of public universities in Bangladesh, which is estimated to be 45,605 BDT per year based on the data reported in the Annual Report of University Grant Commission (UGC 2015, pp. 96-129) of Bangladesh. The estimated annual

\footnotetext{
${ }^{5}$ Calculated based on data from UNCTAD (2018) and the World Bank's World Development Indicators.

${ }^{6}$ This class size is chosen arbitrarily. This represents about 0.11 percent of the total labor force.

${ }^{7}$ To compute the changes in endowment income resulting from the proposed program, the share of skilled and unskilled labor in Bangladesh is calculated based on World Bank (2013). These shares are 28.5 percent and 71.5 percent, respectively. Using the data of the working labor force from the Ministry of Finance (2014) and total skilled and unskilled labor wages from the Bangladesh SAM 2012, the average skill premium is calculated as 10,206 BDT per month per worker.
} 
cost for each batch of trainees amounts to 2,280 million BDT and is assumed to be covered by an additional tax proportional to household income. ${ }^{8}$

\section{Simulation Results}

\subsection{Simulation 1: Impact of Migrant Workers' Wage Fall}

The one percent wage rate fall in the foreign labor market for Bangladeshi migrants would affect the migration decision and labor allocation between the domestic and foreign markets. The returning migrants would make labor more readily available in the domestic market, and therefore, would expand the output in many sectors (Figure 5). The RMG sectors, which are the most export-oriented, would experience substantial output increases because of abundant labor supply, along with export growth from the currency depreciation following the remittance loss from the returning migrants. The percentage change in output in the MNE-RMG sector is slightly below that of the local-RMG sector as MNEs' production is constrained by the FDI, which is exogenously determined by the external sector. Trade, transport, and communications, other manufacturing, textiles, and yarn industries would expand significantly because of their backward linkage to the RMG sectors and their high labor intensity, by which they can benefit from the increased labor supply of the returning migrants (Figure 5).

Figure 5: Output [Deviation from BAU, Billion BDT]

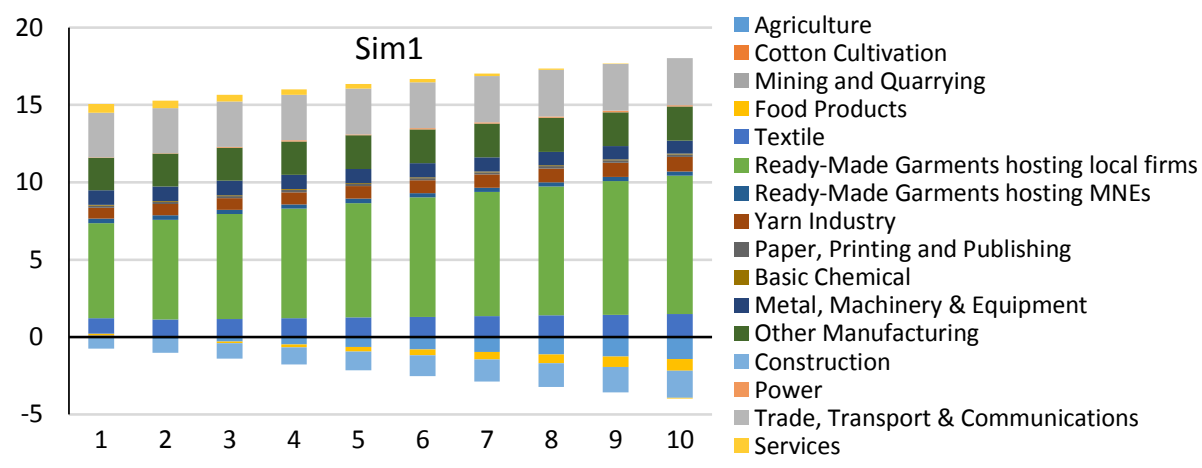

\footnotetext{
${ }^{8}$ This additional tax is only as large as 0.02 percent of household income. Therefore, this assumption is not critical in our simulation analysis.
} 

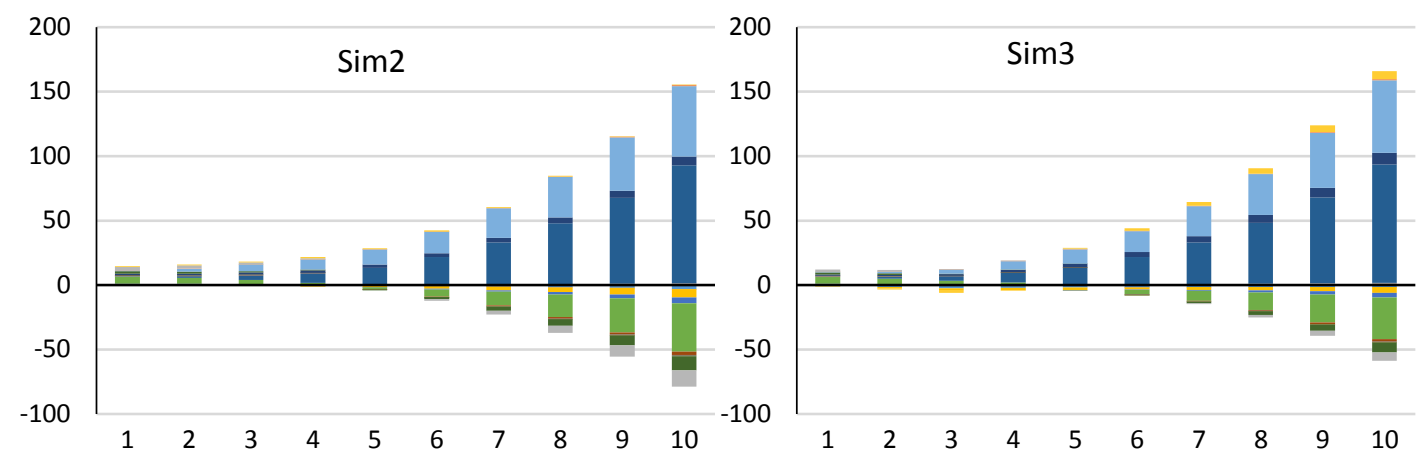

Figure 6: Domestic and Foreign Employment, and Leisure of Unskilled Workers [\% Change from BAU Total Endowment]

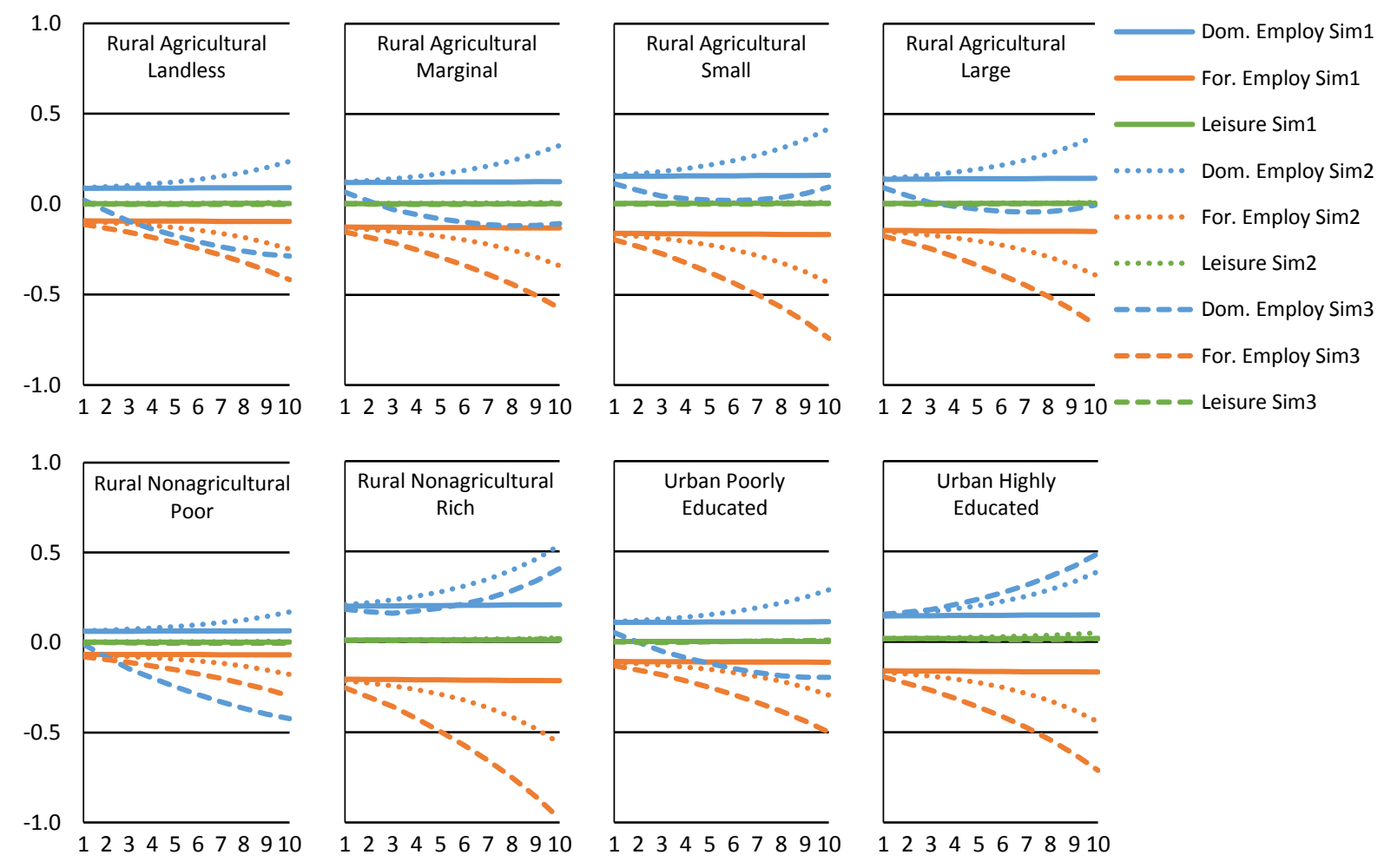


Figure 7: Domestic and Foreign Employment, and Leisure of Skilled Workers [\% Change from BAU Total Endowment]
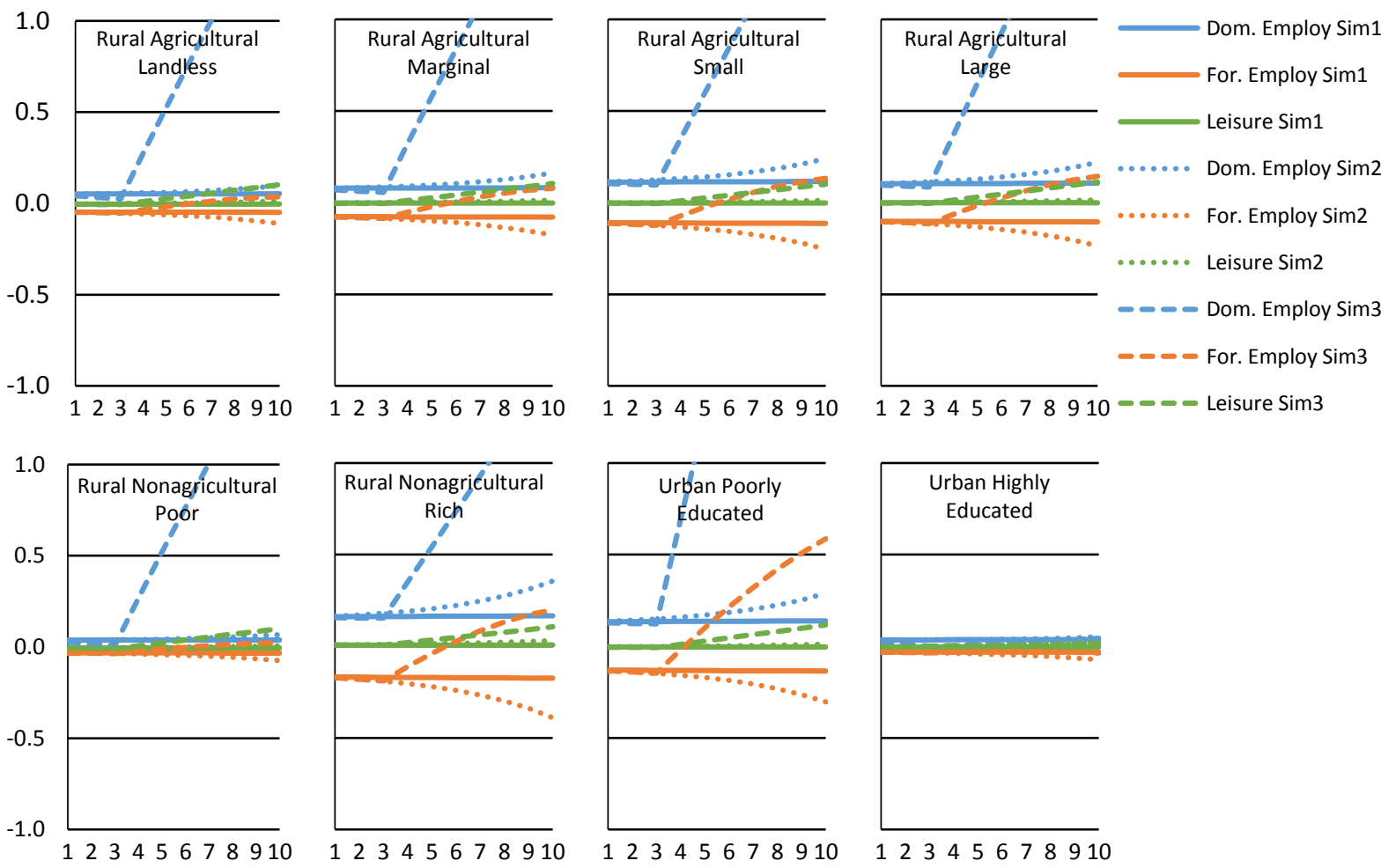

The foreign wage fall of migrants would lower the employment in the foreign labor market and increase that in the domestic labor market, for both unskilled and skilled workers (Figures 6 \& 7). Most, but not all, of the returning migrant workers would employed in the domestic labor market, for all household groups. The differences in the foreign labor endowment by household group determine the amount of unemployment in each group. As most of the out-migrants are unskilled, their domestic return would lower the wage rate in the domestic unskilled labor market by around 0.2 percent (Figure 8). In contrast, skilled workers would be affected only marginally.

Figure 8: Changes in Domestic Labor Wage [Deviation from BAU, \% Change]
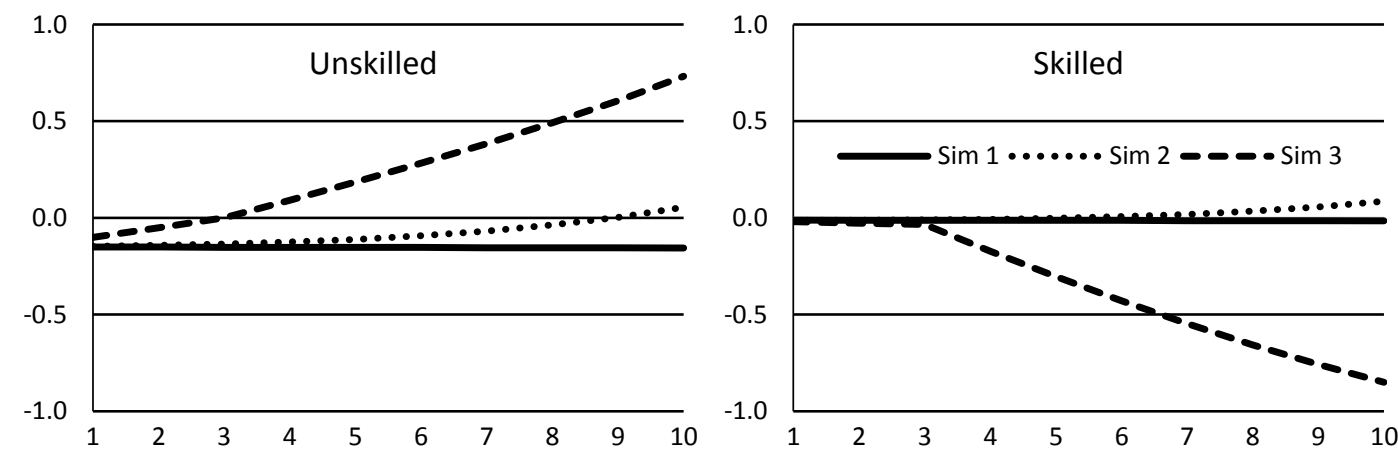
Figure 9: GDP and GNP [Deviation from BAU, \% Change]
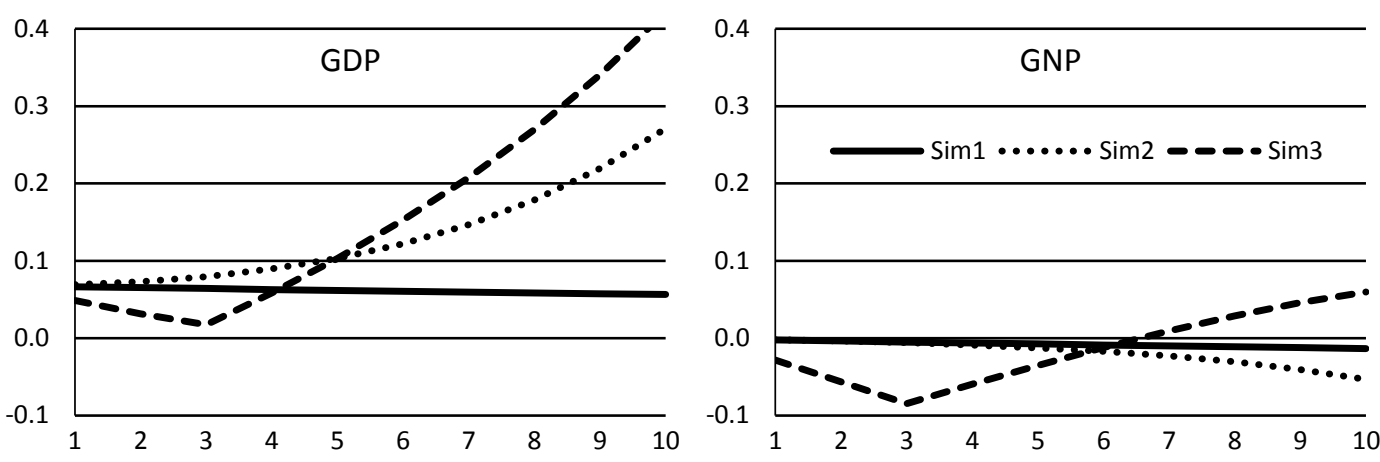

In simulation 1, the country's GDP would increase by around 0.06 percent because of the returning migrants (Figure 9). However, GNP is predicted to fall slightly by around 0.01 percent because of the loss of the foreign wage premium. Consequently, all household groups would suffer from a reduction in welfare, measured using equivalent variation (taking account of both composite good consumption and leisure consumption) (Figure 10). Their dependence on remittance income determines the magnitude of the welfare loss. For example, as the rural nonagricultural rich and the urban less-educated households are dependent heavily on remittance income, they suffer most seriously among the eight household groups from the shock.

\section{Figure 10: Household Welfare [EV in Billion BDT]}

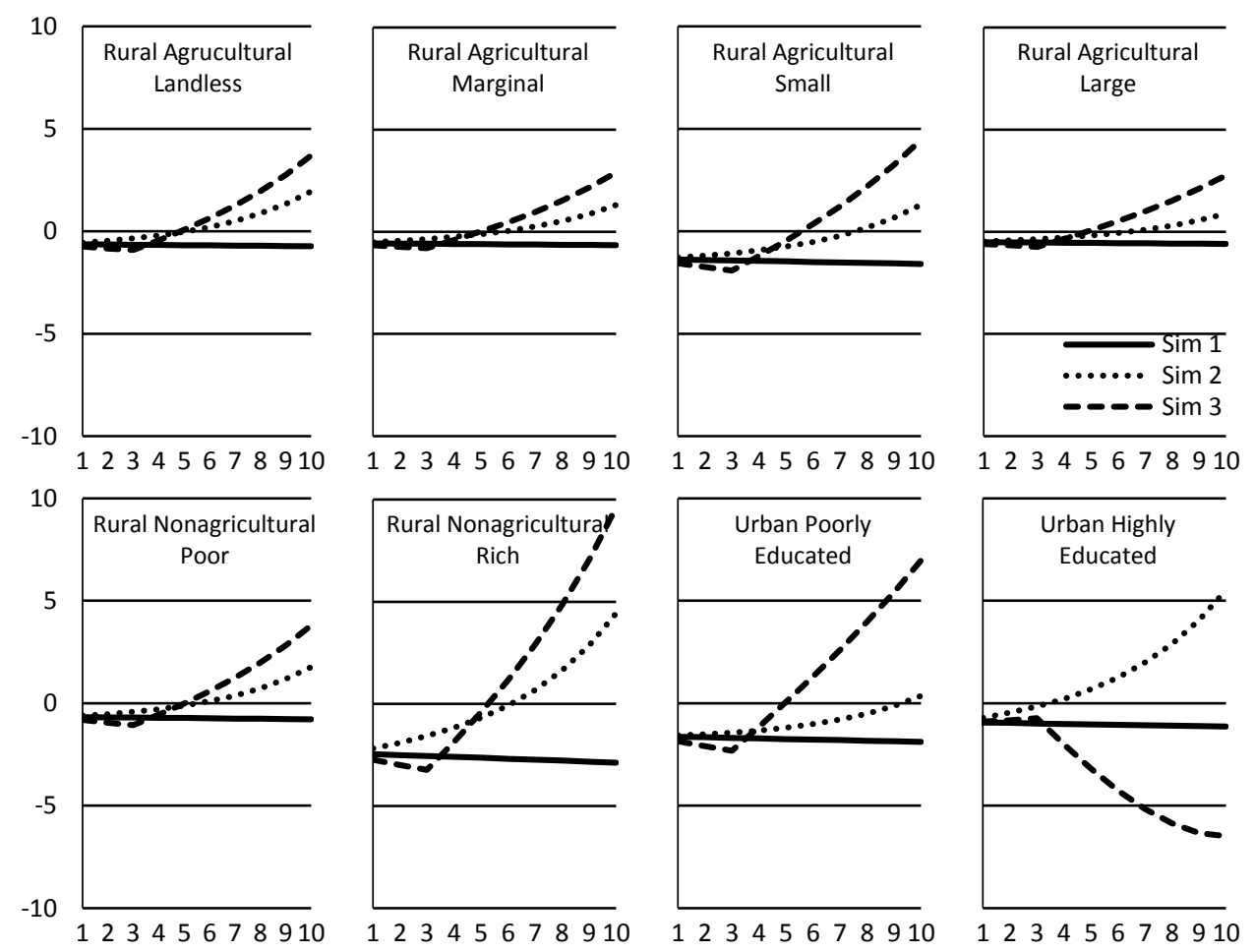




\subsection{Simulation 2: Effect of FDI Promotion}

In Simulation 2, we examine a policy to promote FDI in order to offset the negative impacts of the foreign labor market shock on the domestic economy. The increase in FDI would affect output in the local-RMG and MNE-RMG sectors in opposite ways. While production by MNEs would expand significantly, local firms would experience a contraction by facing competition with MNEs in output and labor markets (Figure 5). Total RMG production by local firms and MNEs would increase substantially, making the labor market tighter.

The increased FDI creates more domestic job opportunities (Figures 6 \& 7), especially for unskilled workers. This would raise the domestic wages in both the unskilled and skilled labor markets. The effects of the fall in wages of unskilled labor, caused by the foreign labor market shock (simulation 1), would be gradually offset and finally disappear in period 10 (Figure 8). Employment in the foreign labor market would fall further (Figures $6 \& 7$ ) because the rise in the domestic wage rates induces more migrant workers to return home. This wage increase enables households to consume more composite goods and leisure (voluntary unemployment) (Figures $6 \& 7$ ).

In simulation 2, both GDP and GNP would be affected, but in different ways (Figure 9). While the increase in GDP is attributable to the injection of capital through the assumed increase in FDI, GNP would further decrease, although marginally. This is because of the return of more migrant workers. As mentioned above, some of them leave the labor market, and thus do not contribute to GNP. In terms of welfare, the negative impact of the foreign labor market shock would disappear following FDI promotion (Figure 10). However, this takes several periods. Among the eight types of households, urban highly educated household would reach the BAU level quickly in period 4, whereas the urban less educated household would at the very end of our simulation period. Others would reach the BAU level by period 7. The distribution of gains from the FDI promotion favors the richest rural and urban household groups in terms of both speed and level. Next, we investigate another policy intervention aimed at accelerating the recovery and more equitable welfare allocation.

\subsection{Simulation 3: Impact of Human Capital Accumulation}

From a distributional perspective, the policy intervention in simulation 2 favors the richest household groups; therefore, a more equitable policy option is required. As the poor household groups depend mainly on the unskilled labor wage, the policy should be targeted 
toward them to ensure an equitable distribution of gains. In simulation 3, we consider a human resource development program that transforms unskilled workers into skilled workers. Our results show that this intervention would reduce output marginally in the short run until period 3 (Figure 5), because it makes part of the unskilled labor endowment unavailable during the training period. This unskilled labor shortage causes an increase in the unskilled wage (Figure 8). When the transformed skilled workers reenter the job market from period 4 , the skilled labor market would experience a sharp fall in the wage rate.

The increase in the unskilled labor wage rate would again induce a return of unskilled migrants (Figure A2). The seven households, which were originally endowed with rich unskilled labor, would benefit from the skill development program significantly (Figure 7). In period 10, the domestic employment of skilled workers would increase by around two percent, which is larger than the skilled wage rate fall about one percent. Thus, the wage income from skilled workers would increase. Incidentally, the domestic skilled wage rate fall would also increase outward migration of skilled workers in a long run (Figure 7).

In simulation 3, GDP and GNP would fall in the short run until period 4 as part of the labor force is unavailable, but increase in the long run because of the human capital accumulation (Figure 9). The GDP and GNP gains in simulation 3 are larger than those in simulation 2 in and after period 6 and period 7, respectively. All but the urban highly educated household would worse off in simulation 3 than in simulation 2 in the short run, but better off in the long run (Figure 10). Thanks to the intervention, their recovery from the foreign labor market shock would be accelerated by five periods. Notably, the distribution of welfare would be more favorable toward poorer household groups. The urban highly educated household would, however, suffer from the sharp fall in the skilled wage of around 0.8 percent (Figure 8).

As the gains in seven types of households are achieved at the expense of the one household, we need to evaluate carefully the overall impact of the human capital development program. In Bangladesh, the income share of the richest five percent group has reached 24.6 percent (Ministry of Finance, 2014, p. 200). This is consistent with the urban highly educated household earning 24.4 percent of total household income as reported in the SAM that we used for our CGE model development. The second richest group's income is 13.4 percent smaller than that of the richest (Ministry of Finance, 2014, p. 199). Therefore, the richest group, the urban highly educated household, suffers but its income level would remain larger than those of the second richest group. 


\section{Conclusion}

This paper studies the impacts of cross-border factor mobility and human capital accumulation on the macroeconomy and household welfare in terms of levels and equitability in Bangladesh. Our simulation results suggest that a one percent wage fall in the foreign labor market causes a movement of workers from foreign to domestic labor markets by affecting the migration decision of households. The returning migrants would lower the unskilled labor wage by around 0.2 percent. The skilled labor wage would also fall, although marginally. The availability of workers in the domestic market would raise the country's GDP by 0.06 percent. However, GNP would fall by around 0.01 percent because of the loss of the foreign wage premium that they earned abroad. All household groups would suffer a welfare deterioration. The more heavily they depend on remittance income, the more they would suffer.

To minimize these negative impacts of the foreign labor market shock, we examine the effectiveness of two counteractive policy options. In the first policy, we examine the impacts of FDI promotion in the MNE-RMG sector. Our results show that increased FDI would further raise domestic wages for both unskilled and skilled labor and would increase the number of returning migrants. While GDP would increase with FDI promotion, GNP would remain relatively stable, because of the return of more migrant workers, who benefit from the domestic wage rise. The negative welfare impact of the foreign labor market shock would gradually disappear with FDI promotion. However, the distribution of gains from the FDI promotion favors the richest household groups. To ensure an equitable distribution of gains, we consider a human resource development program in the second policy option. Transforming unskilled workers into skilled workers accelerates the recovery from the negative foreign labor market shock and achieves a more favorable distribution toward poor household groups.

Our study has certain limitations. First, we consider only voluntary unemployment, even though involuntary unemployment exists in Bangladesh, mainly in the areas with low levels of economic activity. These unemployed people in the economically disadvantaged areas are not mobile and generally unwilling to migrate to the economic zones that offer greater job opportunities. They also suffer from a lack of labor market information. As we examine factor mobility in the form of labor migration and FDI promotion, which mainly affects employment in the economic zones, involuntary unemployment is largely unaffected. Second, we increase FDI inflow into the RMG sector exogenously, assuming a target level of the FDI stock, in one of our alternative policy experiments. Adding endogenous FDI determination with response to 
some policy variables of regulatory reform could be an interesting extension of this study. Third, we examine the impacts of FDI only in the RMG sector because of data availability constraints for the other sectors in Bangladesh. An effective survey on sales and sourcing patterns of MNEs in other capital thrust sectors in Bangladesh would allow replication of our modeling framework to examine the impacts of FDI in those sectors. This type of extension is necessary to identify potential emerging sectors in Bangladesh. 


\section{References}

Abrar, C. R., and M. Billah (2017), "Challenges of Labour Recruitment for Overseas Employment: The Bangladesh Experience", in S. I. Rajan (ed.), South Asia Migration Report 2017: Recruitment, Remittances and Reintegration, London and New York: Routledge, pp. $147-163$.

Ahmad, S. (1990), "Foreign Capital Inflow and Economic Growth: A Two Gap Model for the Bangladesh Economy", Bangladesh Journal of Development Studies, vol. 18, no. 1, pp. 55-78.

Ahmed, M. G., and F. Tania (2010), "Determinants of, and the Relationship between FDI and Economic Growth in Bangladesh", Bonn Econ Discussion Paper, no. 2010, 1. Bonn Graduate School of Economics (BGSE), University of Bonn.

Aizenman, J., and M. M. Spiegel (2006), "Institutional Efficiency, Monitoring Costs, and the Investment Share of FDI", Review of International Economics, vol. 14, no. 4, pp. 683-697.

Alam, Q., and M. Mian (2006), "Foreign Direct Investment and Development: The Bangladesh Scenario", Monash Business Review, vol. 2, no. 1, pp. 1-9

Asadullah, M. N. (2014), “Is Graduate Unemployment Rate Really 47\%”, The Daily Star, May 01, available: https://www.thedailystar.net/is-graduate-unemployment-rate-really-47-22302, accessed: December 15, 2018.

Bangladesh Bank (2017), Foreign Direct Investment (FDI) in Bangladesh: Survey Report January-June 2017 , available: https://www.bb.org.bd/pub/halfyearly/fdisurvey/fdisurveyjanjun2017.pdf, accessed: February $25,2018$.

Beine, M., F. Docquier, and H. Rapoport (2001), "Brain Drain and Economic Growth: Theory and Evidence", Journal of Development Economics, vol. 64, no. 1, pp. 275-289.

BMET Database, Bureau of Manpower, Employment and Training, Ministry of Expatriates' Welfare and Overseas Employment, Government of the People's Republic of Bangladesh, available at: http://www.bmet.gov.bd/BMET/stattisticalDataAction, accessed: January 01, 2018. 
British Council (2014), High University Enrolment, Low Graduate Employment: Analysing the Paradox in Afghanistan, Bangladesh, India, Nepal Pakistan and Sri Lanka, An Economist Intelligence Unit Report for the British Council, available: https://www.britishcouncil.in/sites/default/files/british_council_report_2014_jan.pdf, accessed: October 01, 2018.

Corcoran, A., and R. Gillanders (2015), "Foreign Direct Investment and the Ease of Doing Business", Review of World Economics, vol. 151, no. 1, pp. 103-126.

David, A., and M. A. Marouani (2015), "Migration and Employment Interactions in a Crisis Context: The Case of Tunisia”, Economics of Transition, vol. 23, no. 3, pp. 517-564.

Dutta, C. B., M. Z. Haider, and D. K. Das (2017), "Dynamics of Economic Growth, Investment and Trade Openness: Evidence from Bangladesh", South Asia Journal of Macroeconomics and Public Finance, vol. 6, no. 1, pp. 82-104.

Duval, Y., and C. Utoktham (2014), "Impact of Trade Facilitation on Foreign Direct Investment", ESCAP Trade and Investment Division, TID Working Paper, no. 04/14, Bangkok, available: http://www.unescap.org/publications, accessed: November 22, 2016.

Hanson, G. H. (2009), “The Economic Consequences of the International Migration of Labor”, Annual Review of Economics, vol. 1, pp. 179-208.

Hassan, G. M., M. Chowdhury, and M Bhuyan (2016), "Growth Effects of Remittances in Bangladesh: Is there a U-Shaped Relationship?”, International Migration, vol. 54, no. 5, pp. $105-121$.

Hassan, G. M., and S. Shakur (2017), "Nonlinear Effects of Remittances on Per Capita GDP Growth in Bangladesh", Economies, vol. 5, no. 3, pp. 1-11.

Hatemi-J, A., and G. S. Uddin (2014), "On the Causal Nexus of Remittances and Poverty Reduction in Bangladesh", Applied Economics, vol. 46, no. 4, pp. 374-382.

Herzer, D., S. Klasen, F. Nowak-Lehmann D. (2008), "In Search of FDI-led Growth in Developing Countries: The Way Forward”, Economic Modelling, vol. 25, pp. 793-810. 
Hosoe, N. (2014), “Japanese Manufacturing Facing Post-Fukushima Power Crisis: A Dynamic Computable General Equilibrium Analysis with Foreign Direct Investment”, Applied Economic, vol. 46, no. 17, pp. 2010-2020.

Hossain, S. M., and N. Hosoe (2017) "Foreign Direct Investment in the Ready-Made Garments Sector of Bangladesh: Macro and Distributional Implications", GRIPS Discussion Paper 17-10, DOI: http://doi.org/10.24545/00001598

Hussain, Z. (2014) "Explaining the Recent Decline in Remittances in Bangladesh" available: http://blogs.worldbank.org/endpovertyinsouthasia/explaining-recent-decline-remittancesbangladesh, accessed: December 22, 2017.

ILO/OECD/World Bank (2015), "The Contribution of Labour Mobility to Economic Growth", Joint paper for G20 Labour and Employment Ministers' Meeting Ankara, Turkey, 3-4 September.

IMF (2017), "Bangladesh: 2017 Article IV Consultation-Press Release; Staff Report”, IMF Country Report, no. 17/147, Washington DC: International Monetary Fund.

Islam, M. S., and S. I. A. Meerza (2013), “Trade, Foreign Direct Investment and Economic Growth Linkages in Selected South Asian Countries", in S. Ahmed (ed.), Foreign Direct Investment, Trade and Economic Growth: Exploring Challenges and Opportunities, New Delhi: Routledge, pp. 101-112.

Jayasuriya, D. (2011), “Improvements in the World Bank's Ease of Doing Business Rankings: Do they Translate into Greater Foreign Direct Investment Inflow?", Policy Research Working Paper, no. 5767, The World Bank, available: http://documents.banquemondiale.org/curated/fr/789351468331750147/pdf/WPS5787.pdf, accessed: October 30, 2016.

Kabir, M. (2007), “Is Foreign Direct Investment Growth-Enhancing in Bangladesh?”, BIISS Journal, vol. 28, no. 2, pp. 101-119.

Kee, H. L. (2014), "Local Intermediate Inputs and the Shared Supplier Spillovers of Foreign Direct Investment", Policy Research Working Paper, no. 7050, Washington DC: The World Bank. 
Khan, M. W. R. (2008), The Micro Level Impact of Foreign Remittances on Incomes in Bangladesh: A Measurement Approach Using the Propensity Score, Dhaka: Centre for Policy Dialogue.

Khatun, F., and M. Ahmad (2015), "Foreign Direct Investment in the Energy and Power Sector in Bangladesh: Implications for Economic Growth", Renewable and Sustainable Energy Reviews, vol. 52, pp. 1367-1377.

Kumar, R. R., P. J. Stauvermann, N. N. Kumar, and S. J. H. Shahzad (2018), "Revisiting the Threshold Effect of Remittances on Total Factor Productivity Growth in South Asia: A Study of Bangladesh and India”, Applied Economics, vol. 50, no. 26, pp. 2860-2877.

Ministry of Finance (2014), Bangladesh Economic Review 2014, Government of the People's Republic of Bangladesh.

Moniruzzaman, M. (2009), The Economics of Migrants' Remittances in Bangladesh, Dhaka: Muktachinta Prokashona.

Noor, A. T. (2016), "Contribution of Foreign Direct Investment to Economic Growth in Bangladesh", International Journal of Management and Commerce Innovations, vol. 4, no. 2, pp. 592-603.

Palma, P. (2016), "Migration Cost Goes Up, Wages Not So", The Daily Star, December 09, https://www.thedailystar.net/frontpage/migration-cost-goes-wages-not-so-1327447, accessed June 18, 2018.

QLFS (2017), Quarterly Labor Force Survey Bangladesh 2015-16, Bangladesh Bureau of Statistics, Ministry of Planning, Government of Bangladesh.

Quader, M. (2009), "Foreign Direct Investment in Bangladesh: An Empirical Analysis on its Determinants and Impacts", MPRA Paper no. 26134, Munich Personal RePEc Archive.

Raihan, S., B. H. Khondker, G. Sugiyarto, and S. Jha (2009), "Remittance and Household Welfare: A Case Study of Bangladesh", ADB Economics Working Paper, no 189, Manila: Asian Development Bank.

Raihan, S., T Siddiqui, and R. A. Mahmood (2017), "Estimating the Impact of International Remittance on Household Expenditure in Bangladesh", in S. I. Rajan (ed.), South Asia 
Migration Report 2017: Recruitment, Remittances and Reintegration, London and New York: Routledge, pp. 190-208.

Selvanathan, E. A., and S. Selvanathan (2012), "Remittances and Economic Growth: Empirical Evidence from Bangladesh, India and Sri Lanka”, The Journal of Development Studies, vol. 48, no. 8 , pp. 1045-1062.

Shimul, S. N., S. M. Abdullah, and S. Siddiqua (2009), “An Examination of FDI and Growth Nexus in Bangladesh: Engle Granger and Bound Testing Cointegration Approach", BRAC University Journal, vol. 6, no. 1, pp. 69-76.

The Independent (2018), "BIDA Policy to Make Bangladesh a Top Investment Destination”, January 23, available: http://www.theindependentbd.com/arcprint/details/77613/2017-01-23, accessed: December 20, 2018.

UGC (2015), 41th Annual Report (In Bengali), University Grant Commission of Bangladesh, Dhaka.

UNCTAD (2018), World Investment Report 2018: Investment and New Industrial Policies, Geneva: United Nations Conference on Trade and Development.

Wei, S. J. (2000), "How Taxing is Corruption on International Investors?", Review of Economics and Statistics, vol. 82, no. 1, pp. 1-11.

World Bank (2013), "An Assessment of Skills in the Formal Sector Labor Market in Bangladesh: A Technical Report on the Enterprise-Based Skills Survey 2012”, Discussion Paper Series, no. 64, Washington DC: The World Bank.

World Bank, Global Economic Prospect (2006), Global Economic Prospects 2006: Economic Implications of Remittances and Migration, Washington DC: The World Bank.

World Bank, World Development Indicators, Washington DC: The World Bank, available: http://databank.worldbank.org/data/reports.aspx?source=world-development-indicators, accessed: December 18, 2017.

Zhang, H. (2012), “How do Business Regulations Affect Foreign Direct Investment?”, Transnational Corporations Review, vol. 4, no. 2, pp. 97-119. 
Appendix 


\section{Appendix A: Sensitivity Analysis}

The simulation results of CGE analyses often vary depending on the assumptions made about key parameter values. To check the robustness of our results, we perform sensitivity analyses by changing the values of: i) elasticity of transformation in the labor transformation

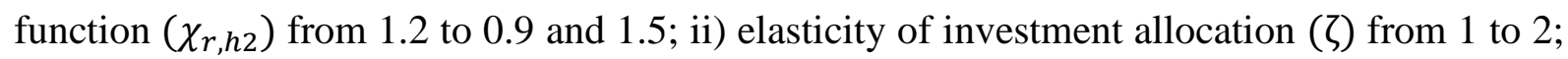
iii) rate of return of capital (ror) from 0.05 to 0.06 ; iv) capital depreciation rate ( $\mathrm{dep}$ ) from 0.04 to 0.05 ; v) population growth rate ( $p o p$ ) from 0.011 to 0.006 ; and vi) unemployment rates to twice as high as their original values.

The alternative parameter values used in our sensitivity analysis produce results similar to our original simulation results shown in the main part. For instance, with a smaller elasticity parameter in the labor transformation function $\left(\chi_{r, h 2}=0.9\right)$, the output expansion would be slightly smaller (Figure A1), because the migration decision and labor allocation between the domestic and foreign labor markets are now less elastic to the foreign wage rate change. As a result, the changes in both domestic and foreign employments would be less affected (Figures A2 \& A3). The wage rate change in the domestic labor market would be slightly smaller in simulation 1, but larger in simulations 2 and 3 with a less elastic labor transformation function (Figure A4). The magnitude of the changes in GDP, GNP, and household welfare would become marginally smaller in the smaller elasticity case (Figures A5 \& A6). The opposite is true in the case of the higher elasticity parameter in the labor transformation function $\left(\chi_{r, h 2}=1.5\right)$ (Figures A7 to A12). Similarly, the impacts of alternative values of $\zeta$, ror, dep, $p o p$, and the rate of unemployment are found to be minimal. 
Figure A1: Output with $\chi_{r, h 2}=0.9$ [Deviation from BAU, Billion BDT]
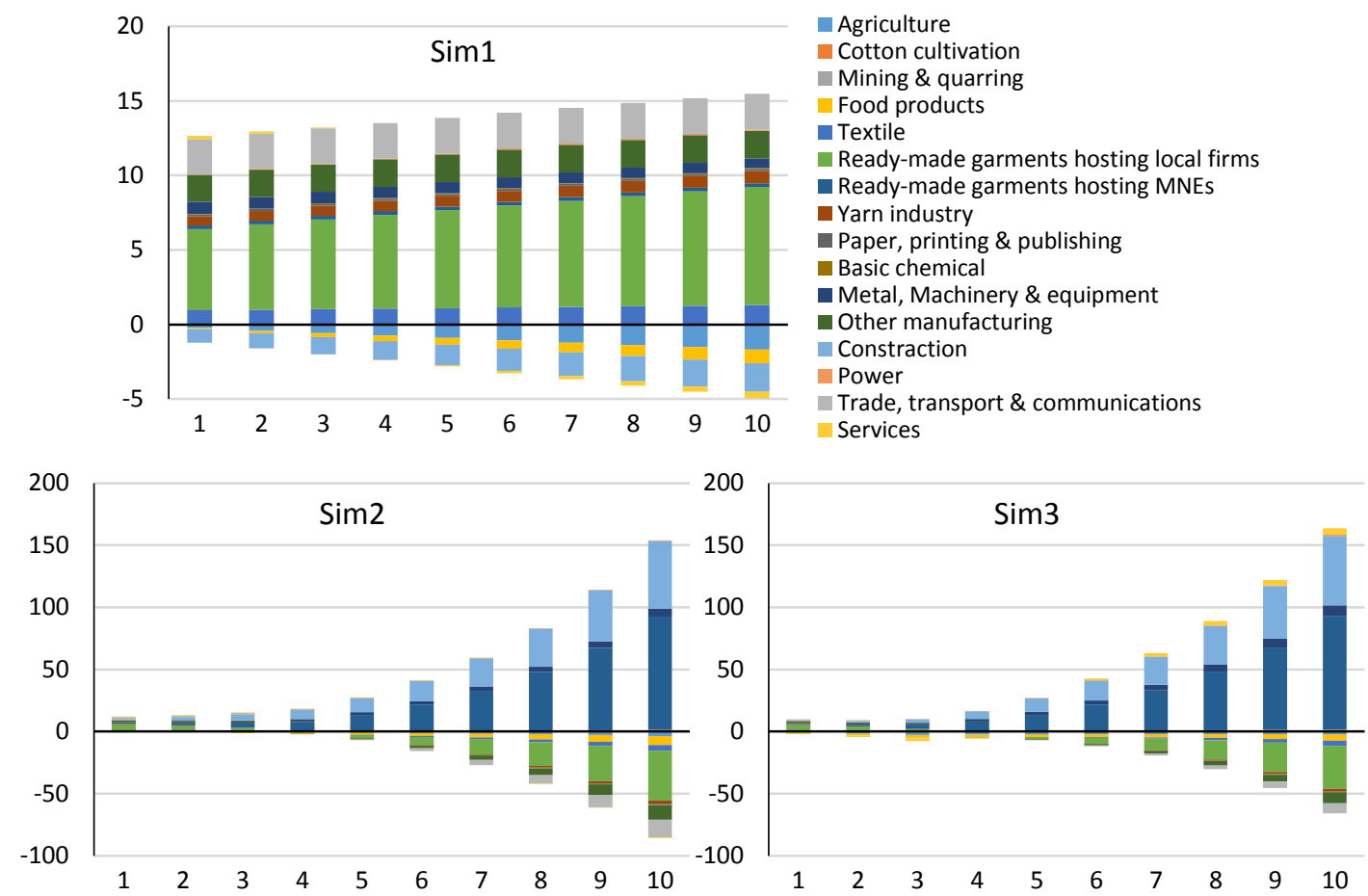

Figure A2: Domestic and Foreign Employment, and Leisure of Unskilled Workers with $\chi_{r, h 2}=0.9$ [\% Change from BAU Total Endowment]
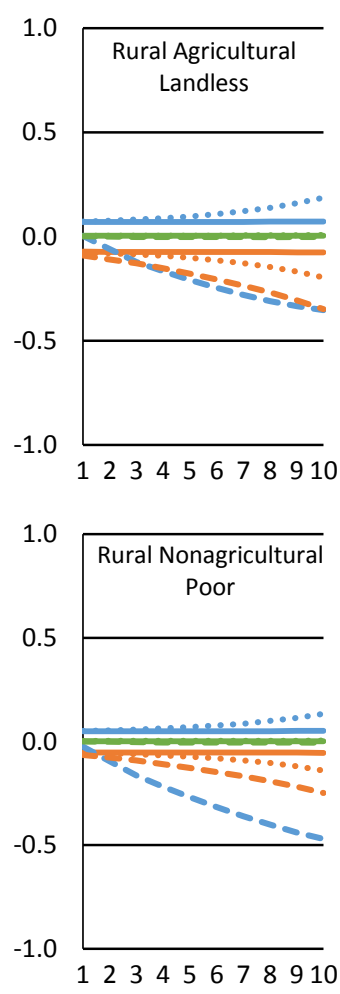
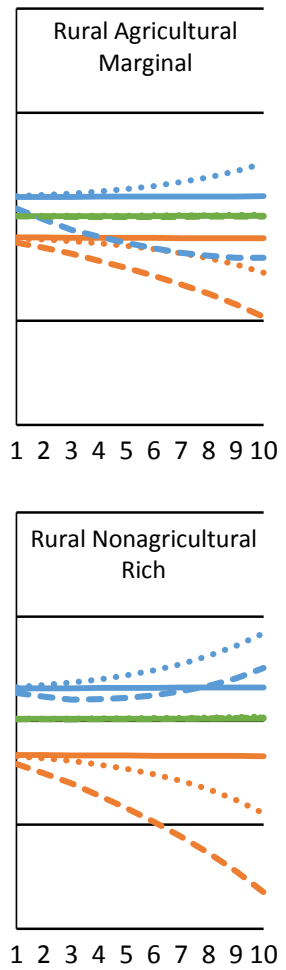
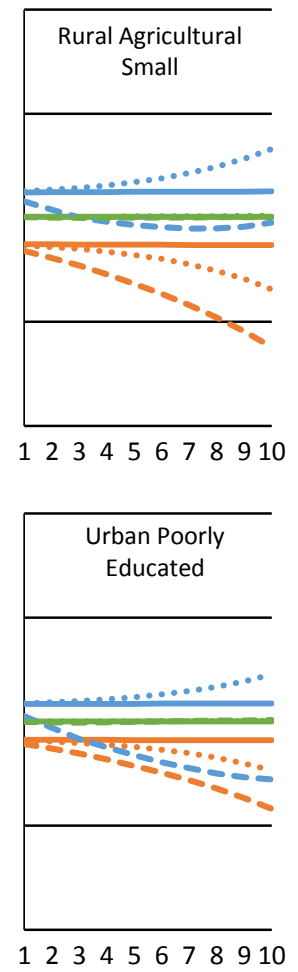
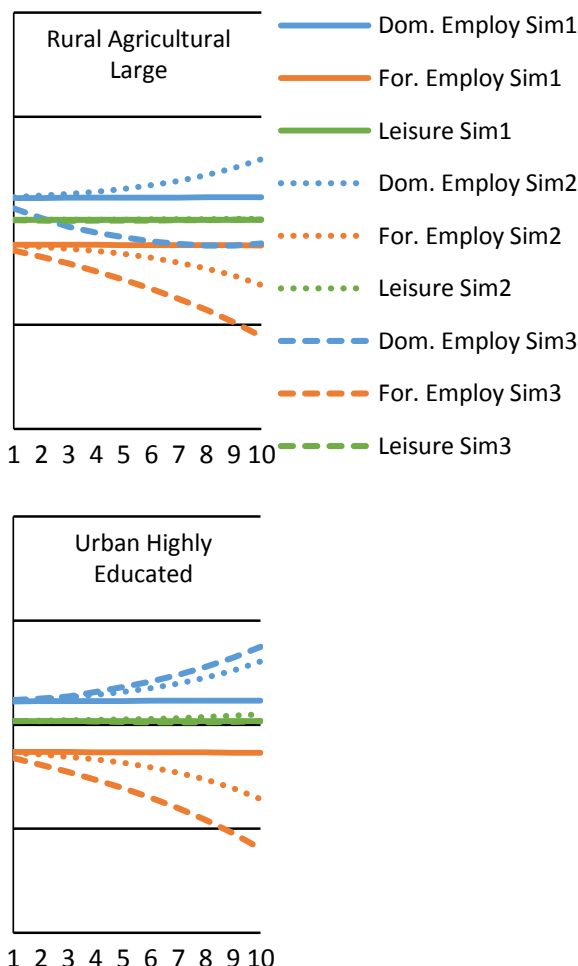
Figure A3: Domestic and Foreign Employment, and Leisure of Skilled Workers with $\chi_{r, h 2}=$ 0. 9 [\% Change from BAU Total Endowment]
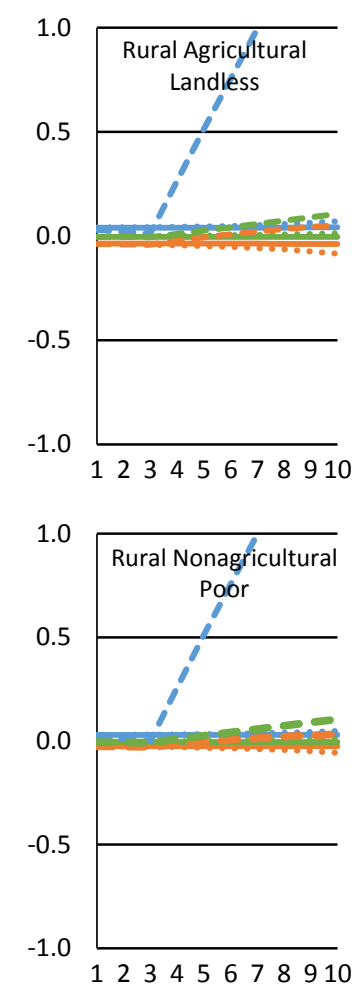
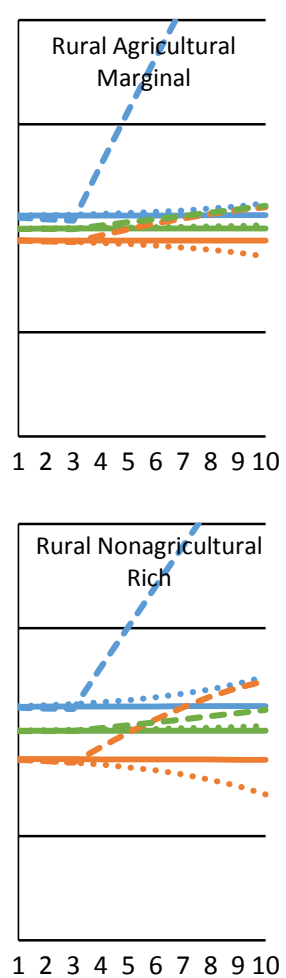
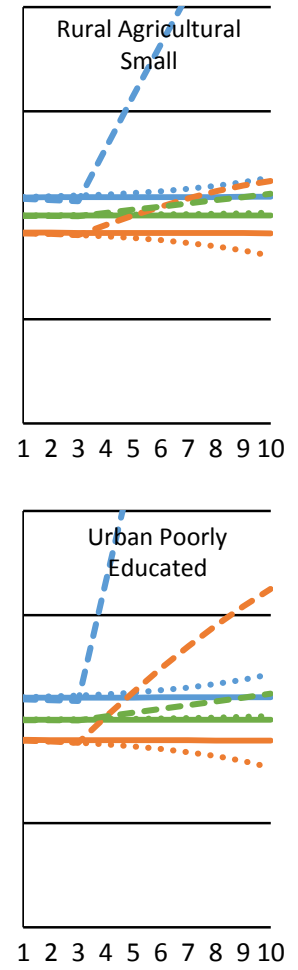
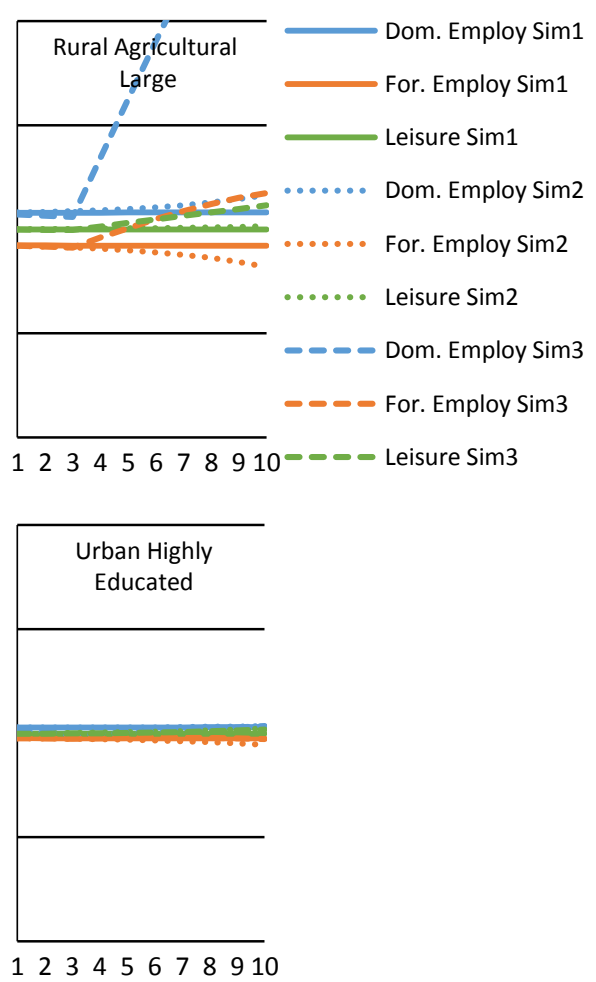

Figure A4: Changes in Domestic Labor Wage with $\chi_{r, h 2}=0.9$ [Deviation from BAU, \%

\section{Change]}
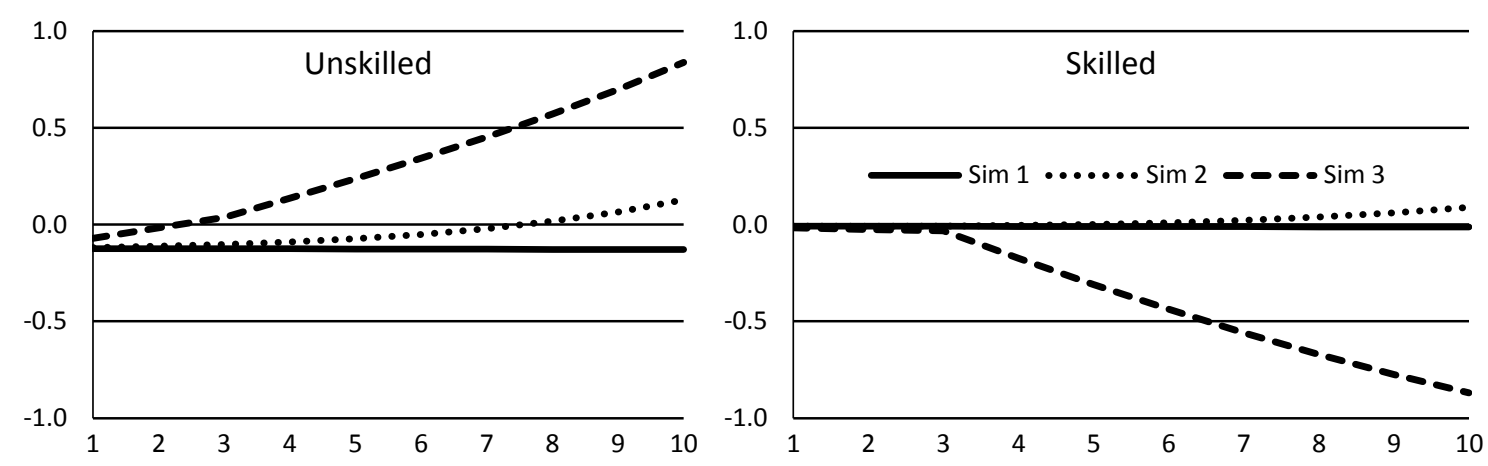
Figure A5: GDP and GNP with $\chi_{r, h 2}=0.9$ [Deviation from BAU, \% Change]
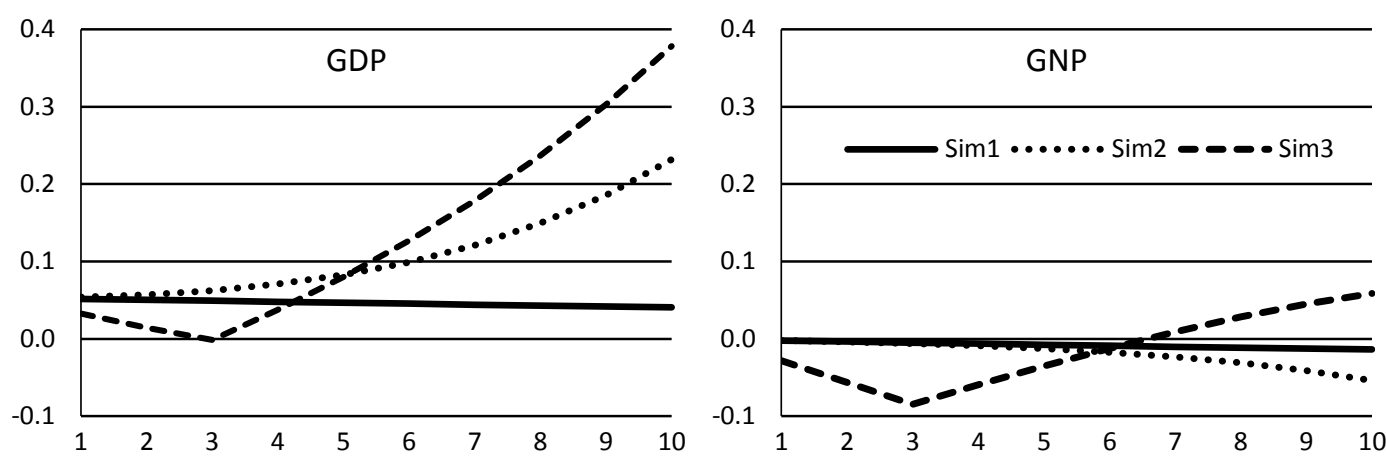

Figure A6: Household Welfare with $\chi_{r, h 2}=0.9$ [EV in Billion BDT]
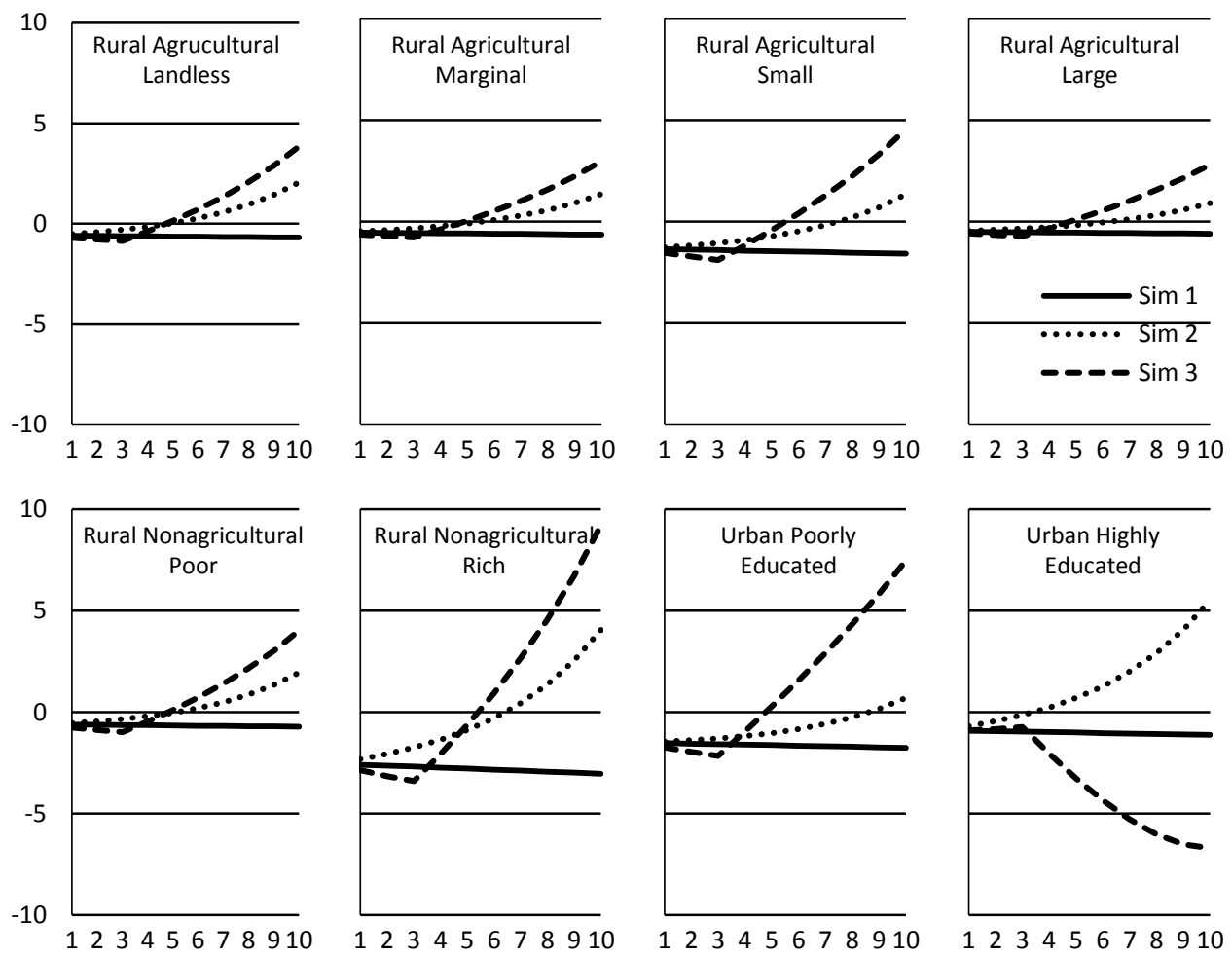
Figure A7: Output with $\chi_{r, h 2}=1.5$ [Deviation from BAU, Billion BDT]
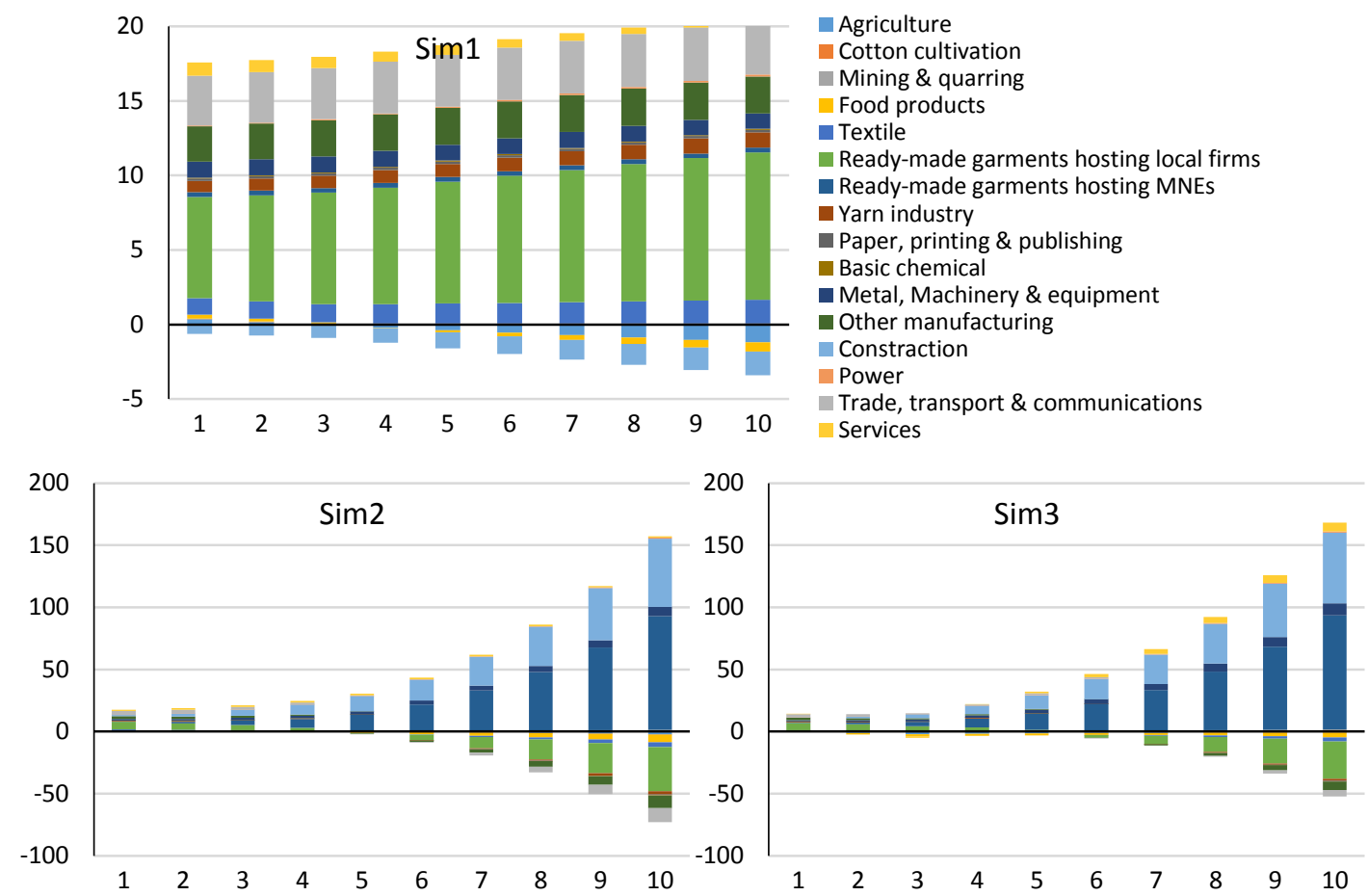

Figure A8: Domestic and Foreign Employment, and Leisure of Unskilled Workers with $\chi_{r, h 2}=1.5$ [\% Change from BAU Total Endowment]
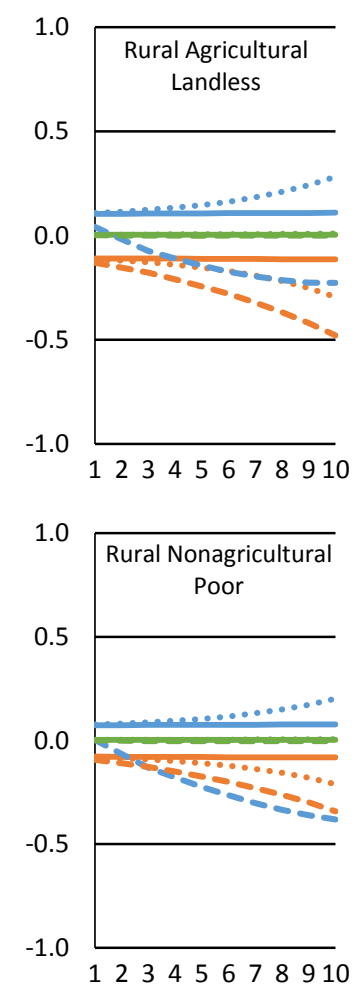
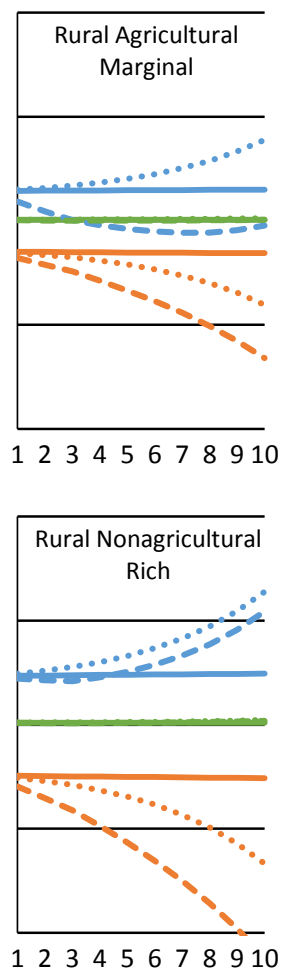
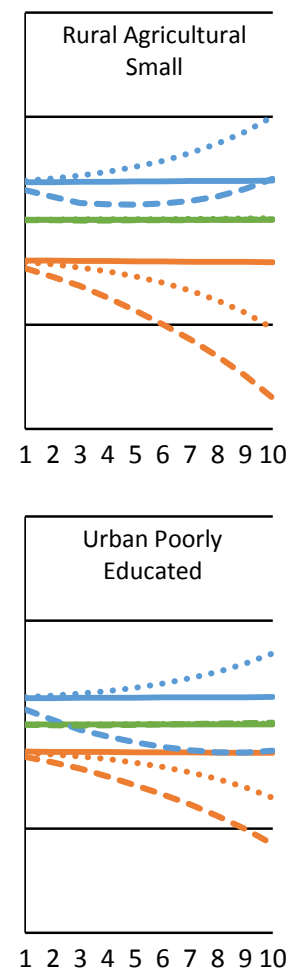
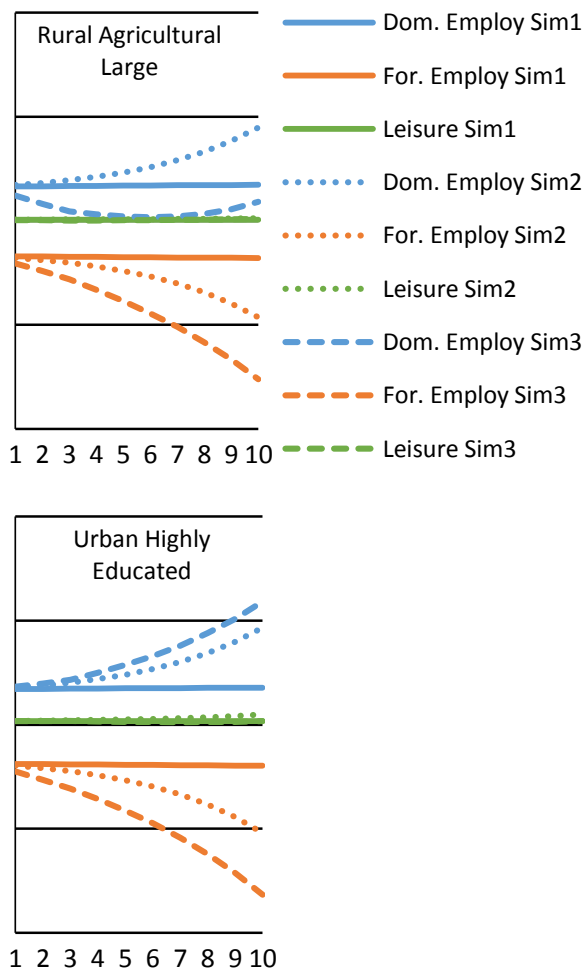
Figure A9: Domestic and Foreign Employment, and Leisure of Skilled Workers with $\chi_{r, h 2}=$ 1. 5 [\% Change from BAU Total Endowment]
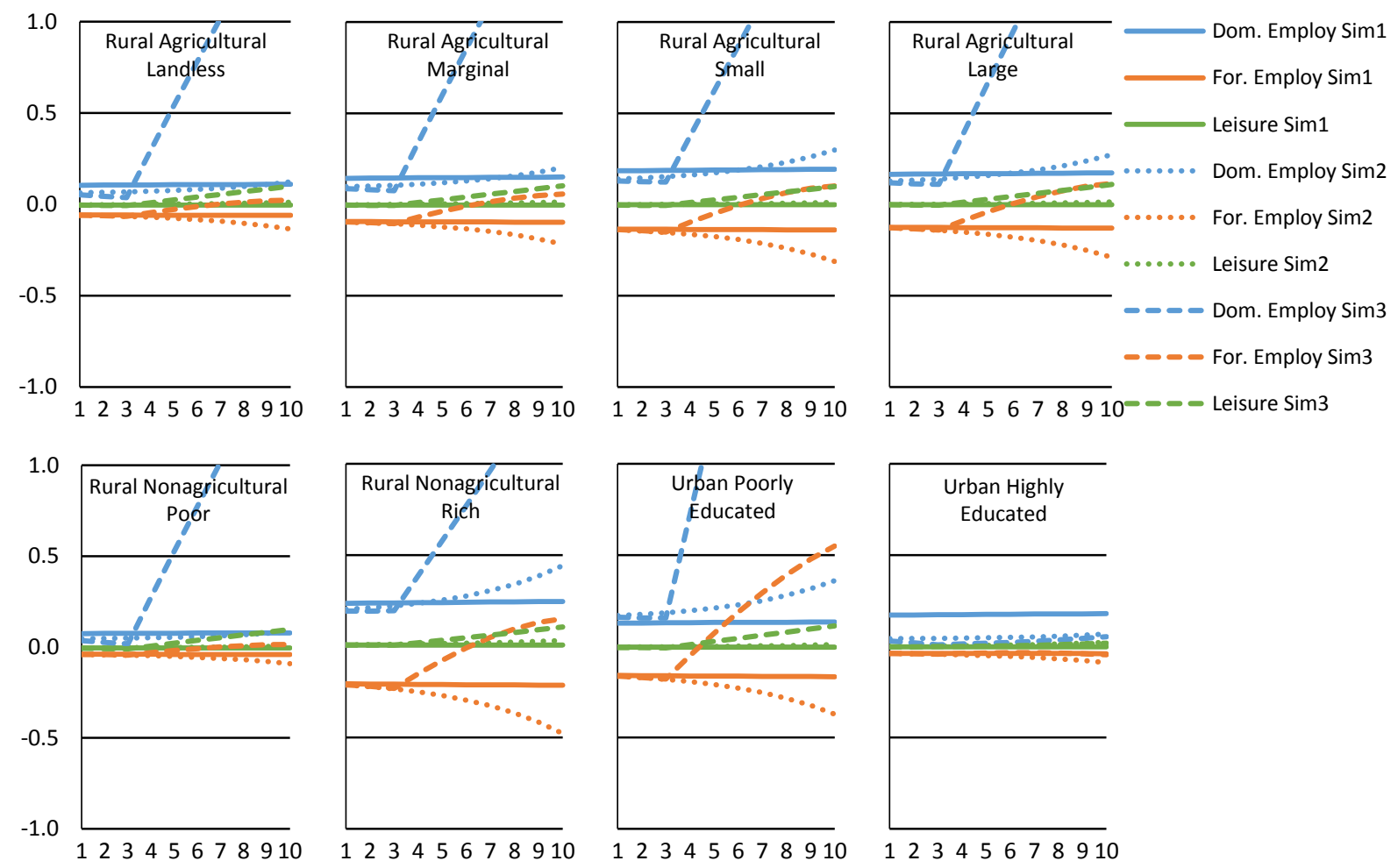

Figure A10: Changes in Domestic Labor Wage with $\chi_{r, h 2}=1.5$ [Deviation from BAU, \% Change]
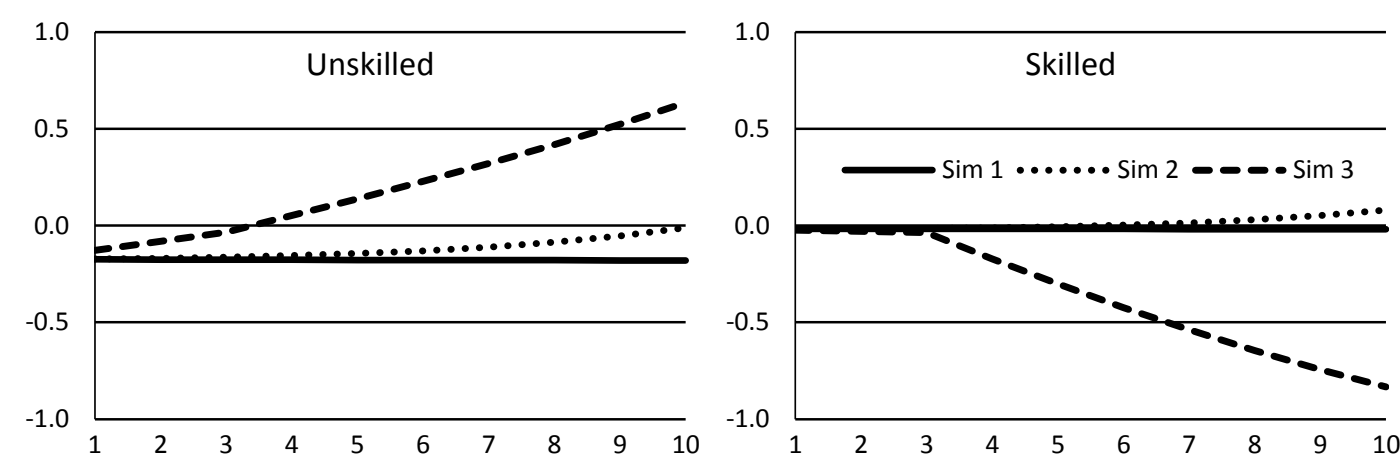
Figure A11: GDP and GNP with $\chi_{r, h 2}=1.5$ [Deviation from BAU, \% Change]
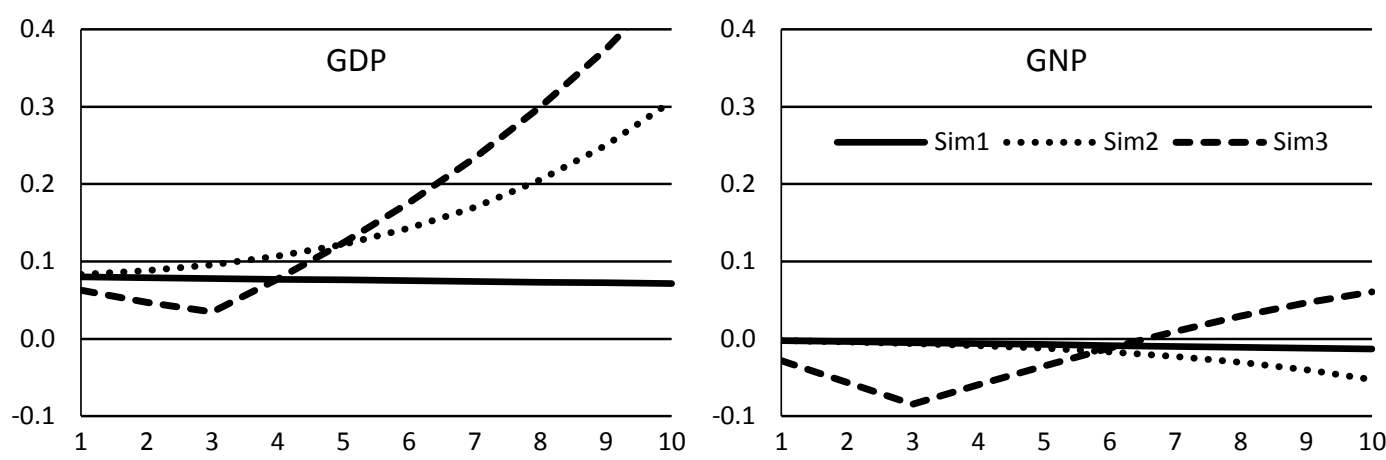

Figure A12: Household Welfare with $\chi_{r, h 2}=1.5$ [EV in Billion BDT]
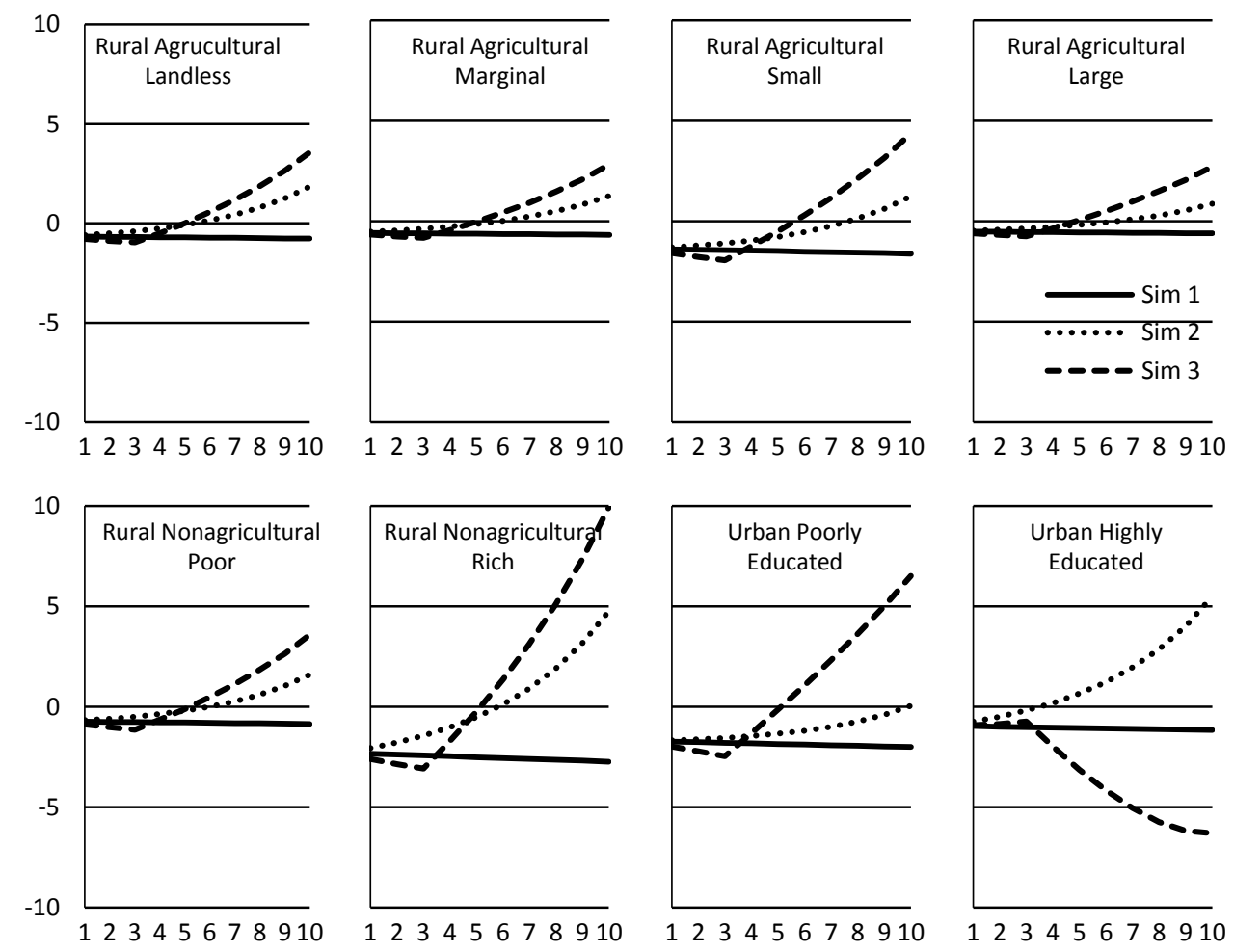
Figure A13: Output with $\zeta=2$ [Deviation from BAU, Billion BDT]
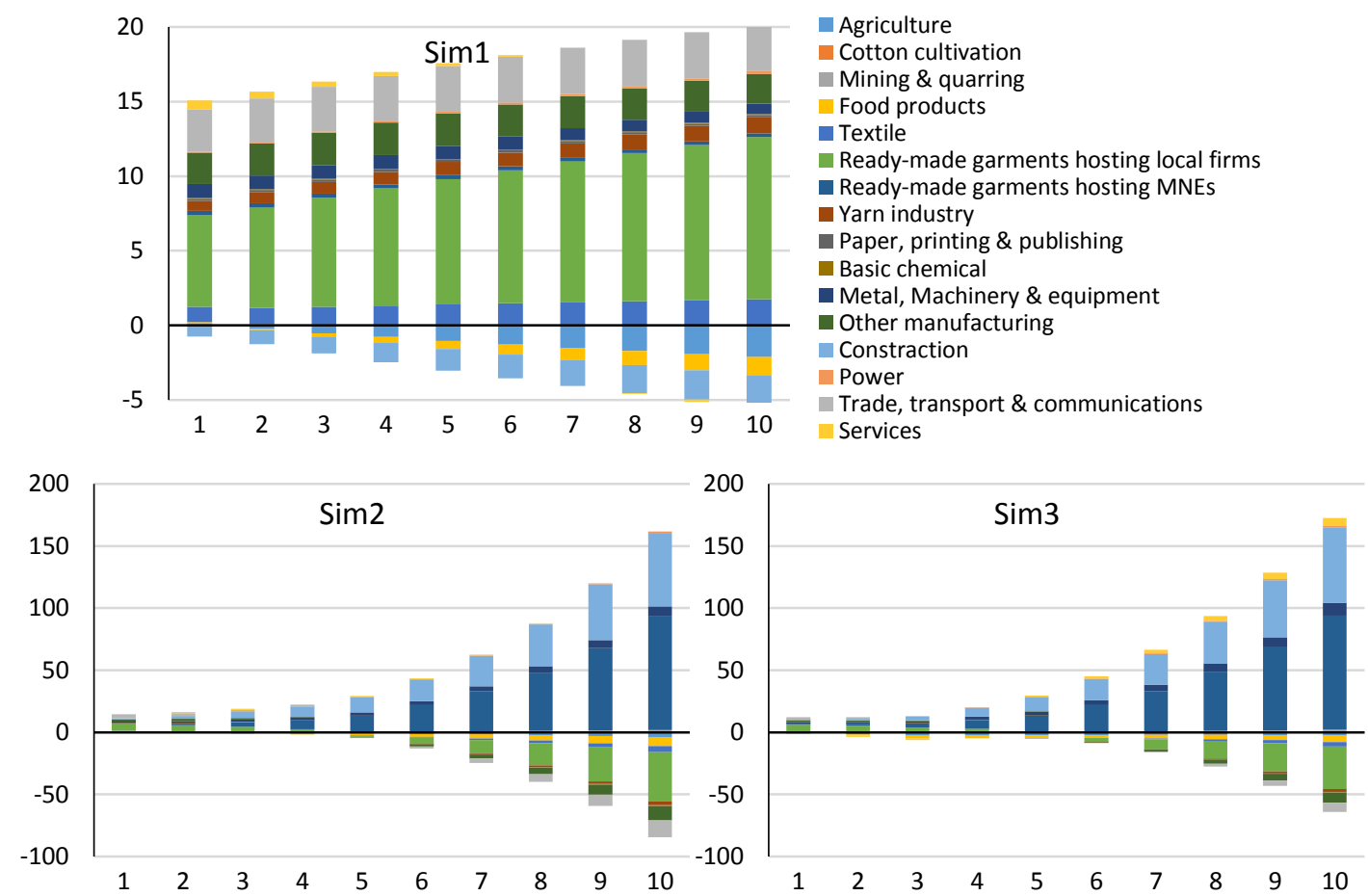

Figure A14: Domestic and Foreign Employment, and Leisure of Unskilled Workers with $\zeta=$ 2 [\% Change from BAU Total Endowment]

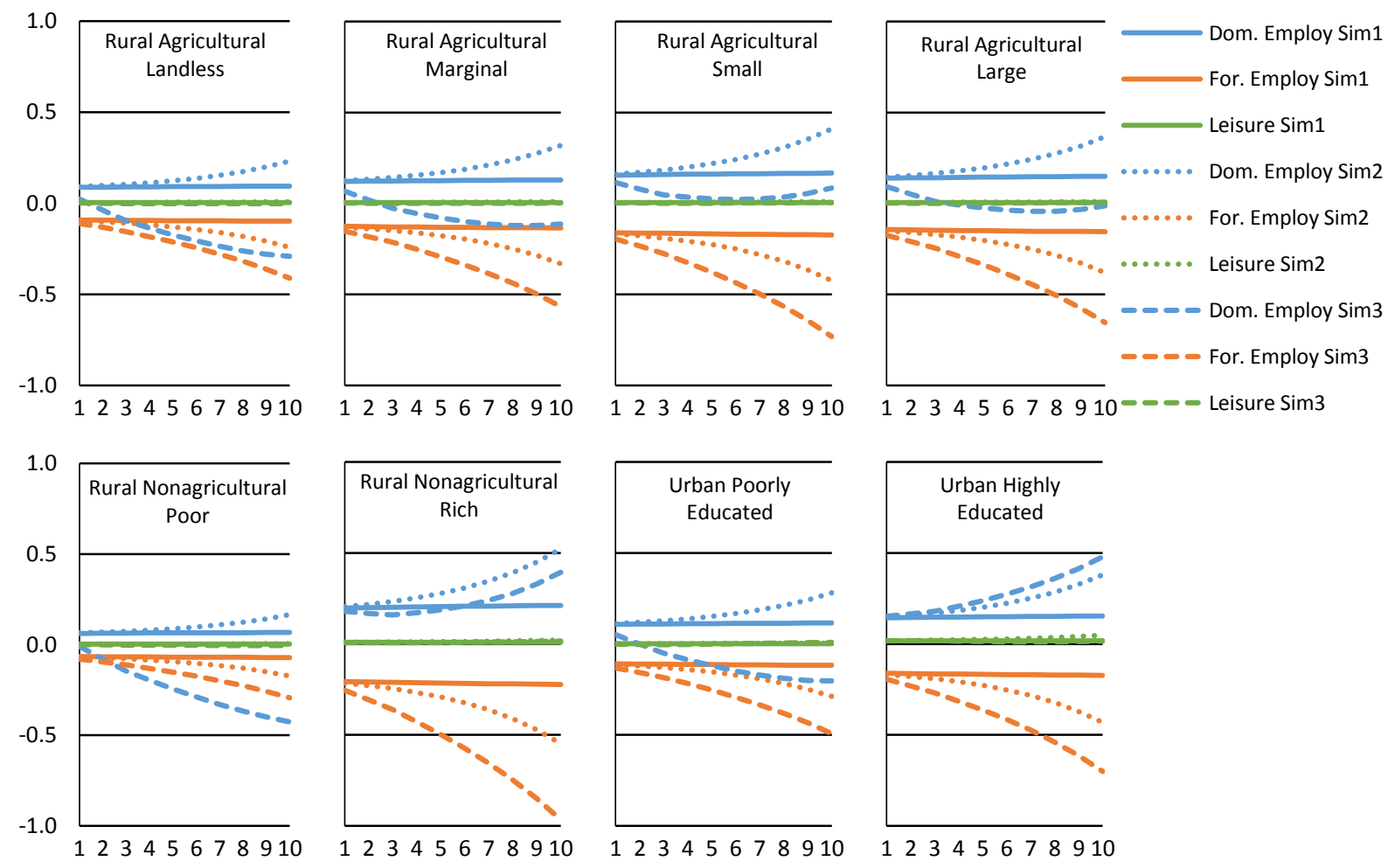


Figure A15: Domestic and Foreign Employment, and Leisure of Skilled Workers with $\zeta=2$ [\% Change from BAU Total Endowment]
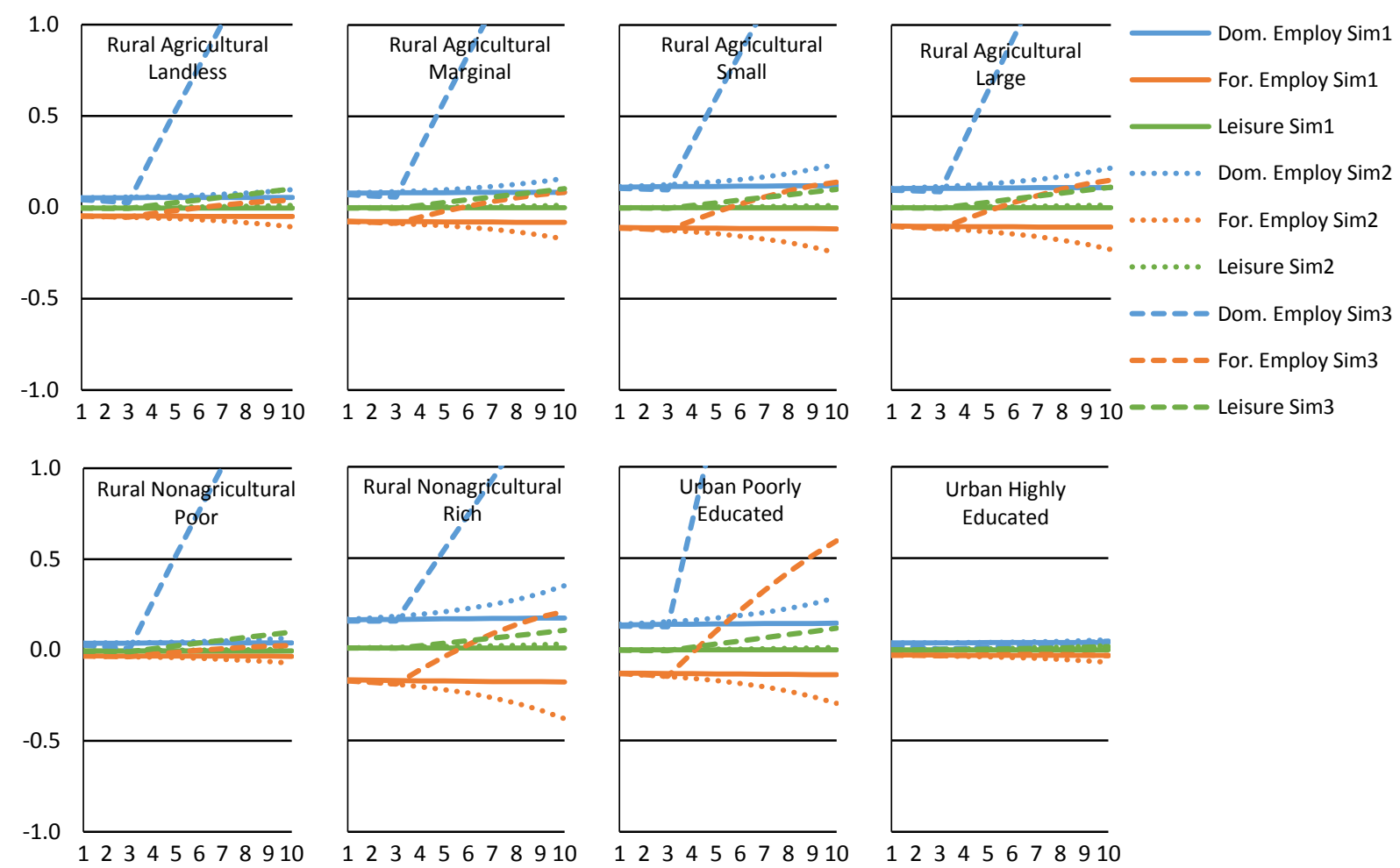

Figure A16: Changes in Domestic Labor Wage with $\zeta=2$ [Deviation from BAU, \% Change]
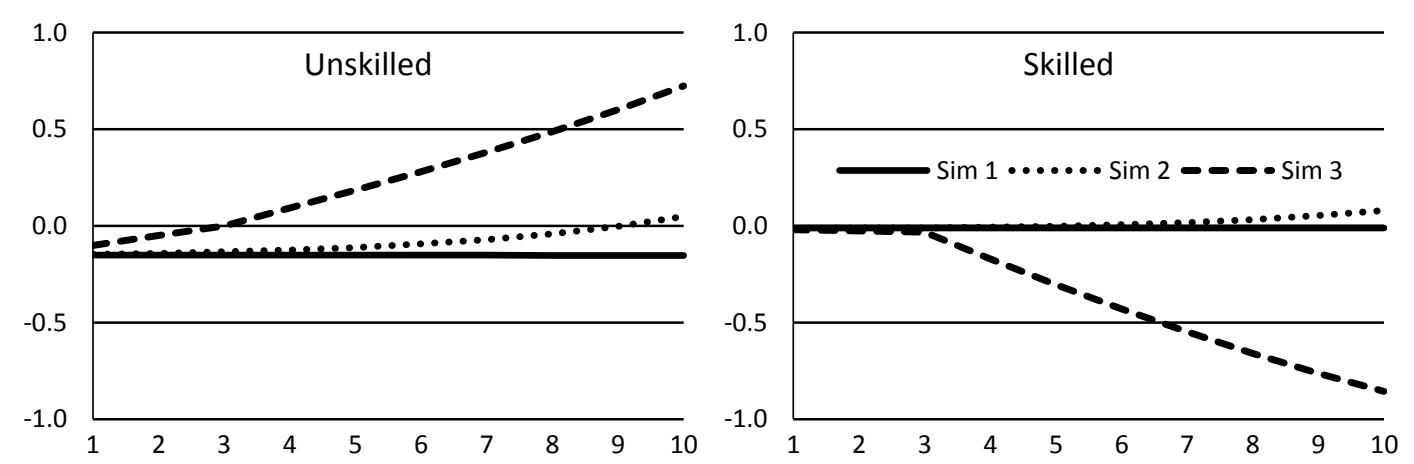
Figure A17: GDP and GNP with $\zeta=2$ [Deviation from BAU, \% Change]
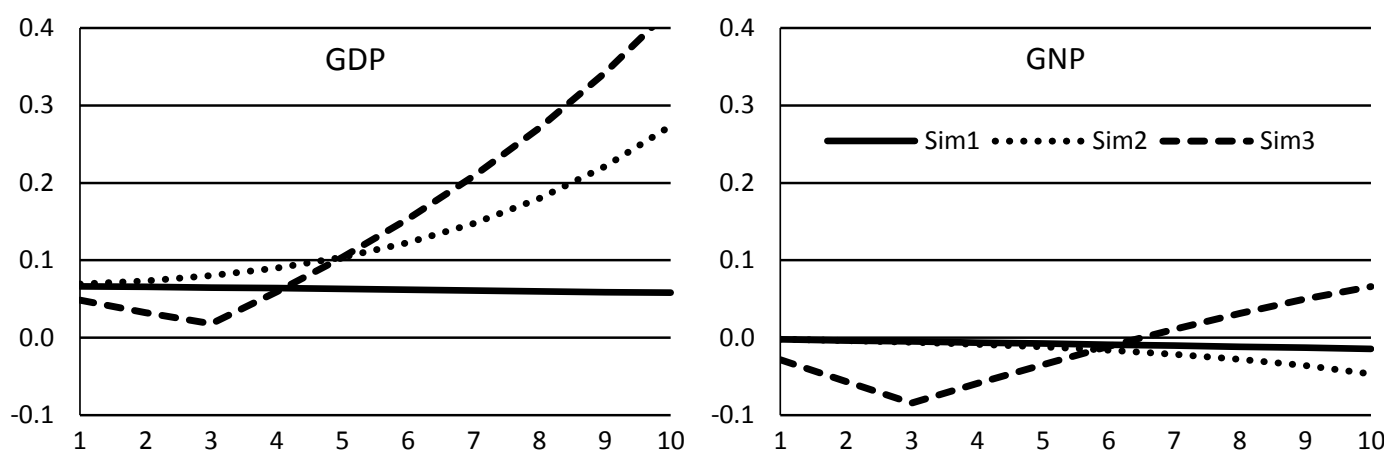

Figure A18: Household Welfare with $\zeta=2$ [EV in Billion BDT]
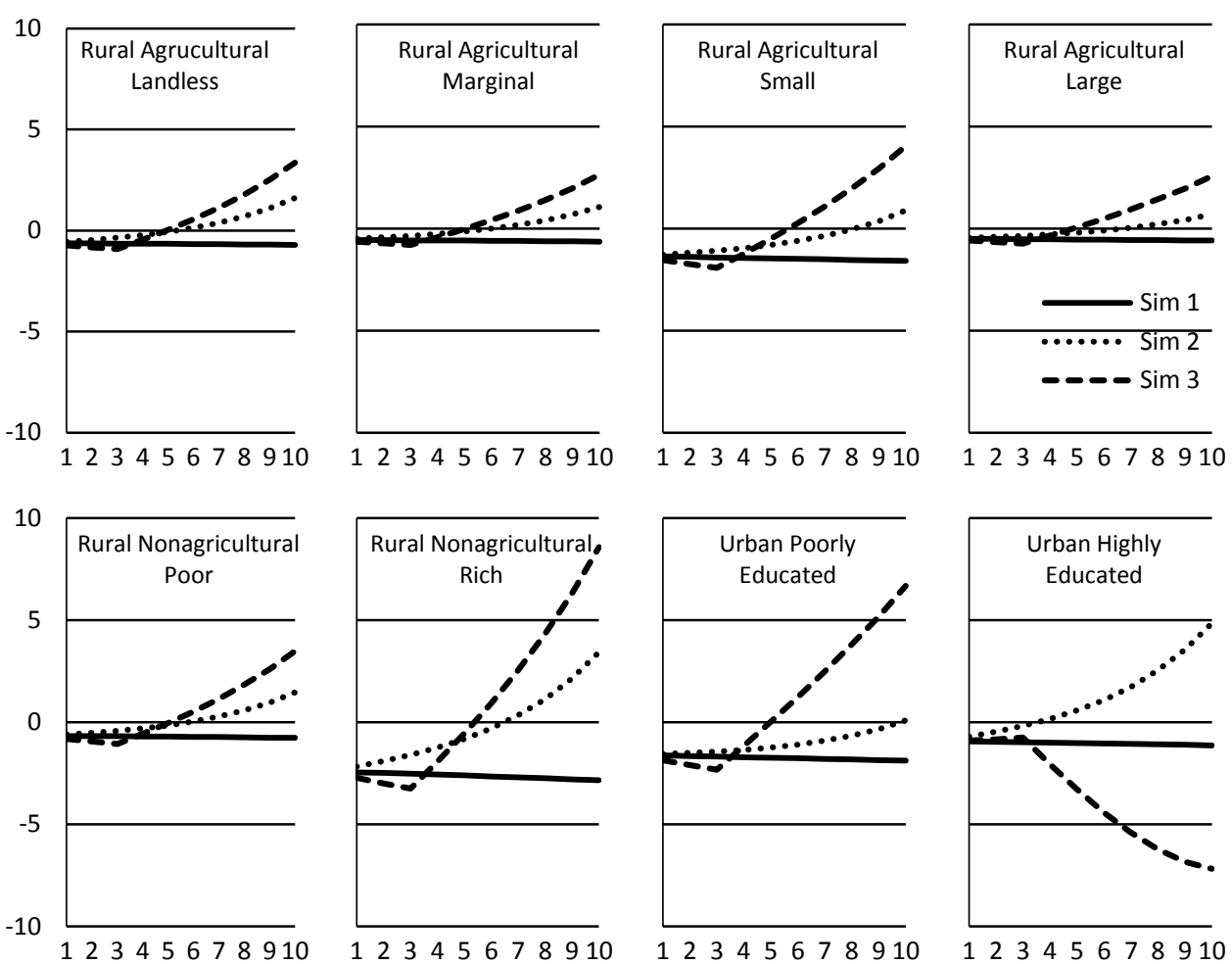
Figure A19: Output with ror $=0.06$ [Deviation from BAU, Billion BDT]
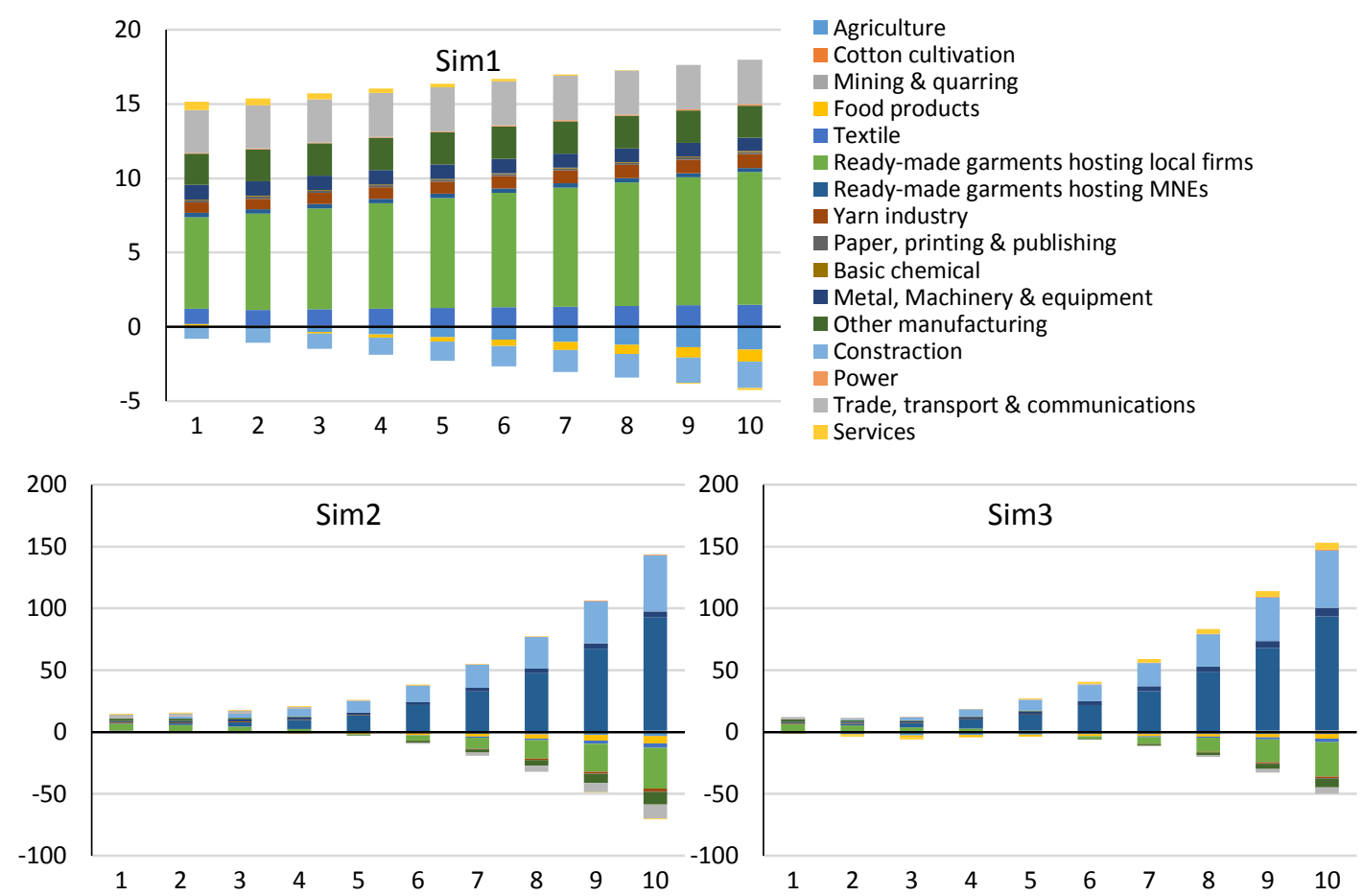

Figure A20: Domestic and Foreign Employment, and Leisure of Unskilled Workers with ror $=0.06$ [\% Change from BAU Total Endowment]
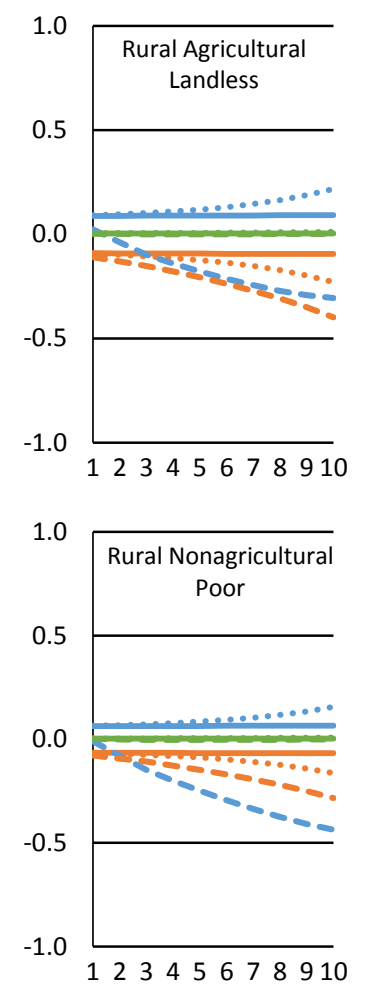
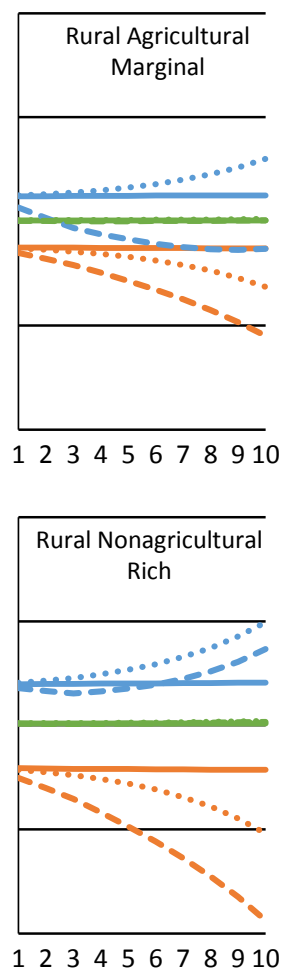
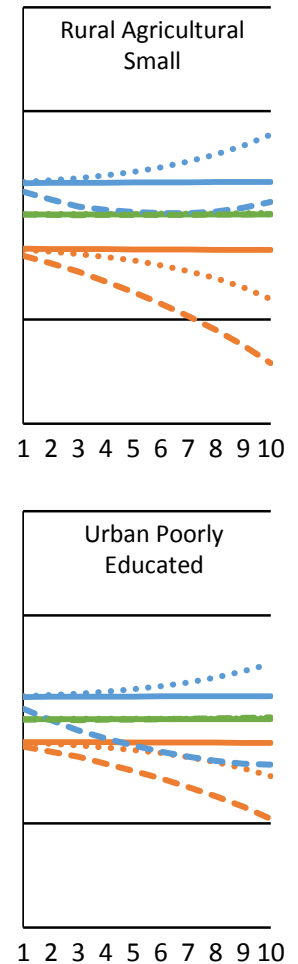
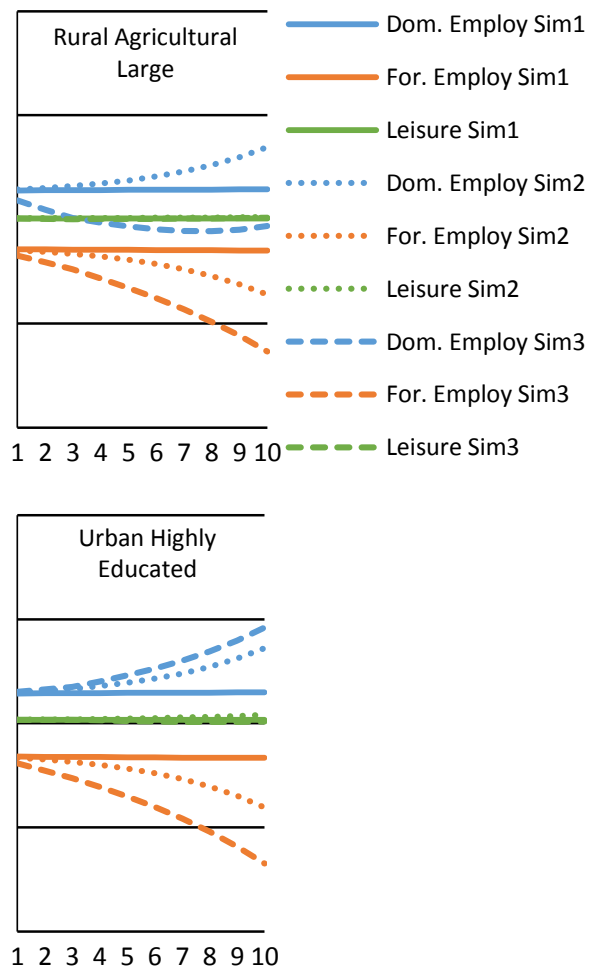
Figure A21: Domestic and Foreign Employment, and Leisure of Skilled Workers with ror = 0.06 [\% Change from BAU Total Endowment]
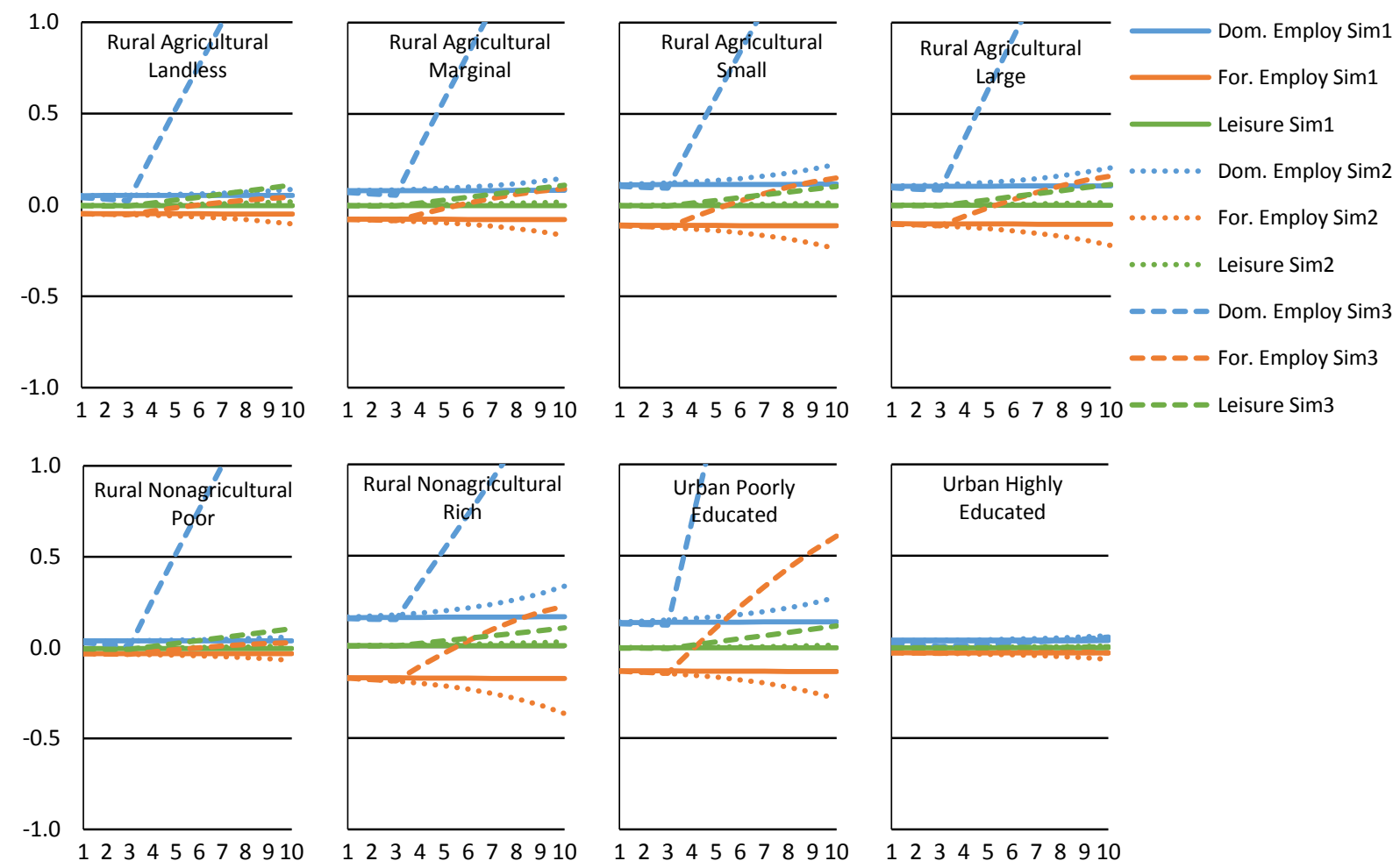

Figure A22: Changes in Domestic Labor Wage with ror $=0.06$ [Deviation from BAU, \% Change]
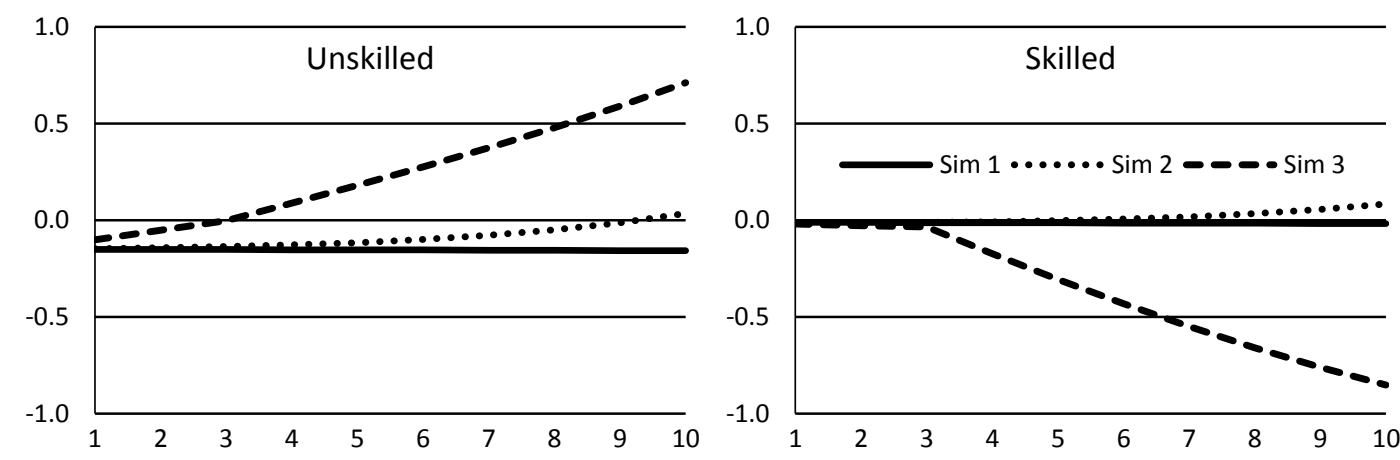
Figure A23: GDP and GNP with ror $=0.06$ [Deviation from $B A U, \%$ Change]
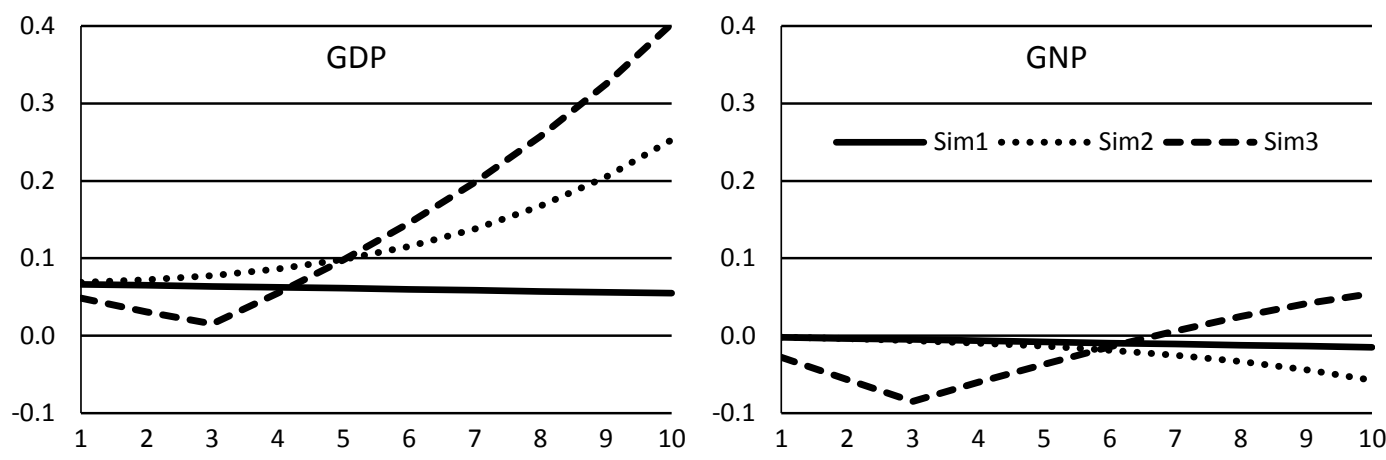

Figure A24: Household Welfare with ror $=0.06[$ EV in Billion BDT]
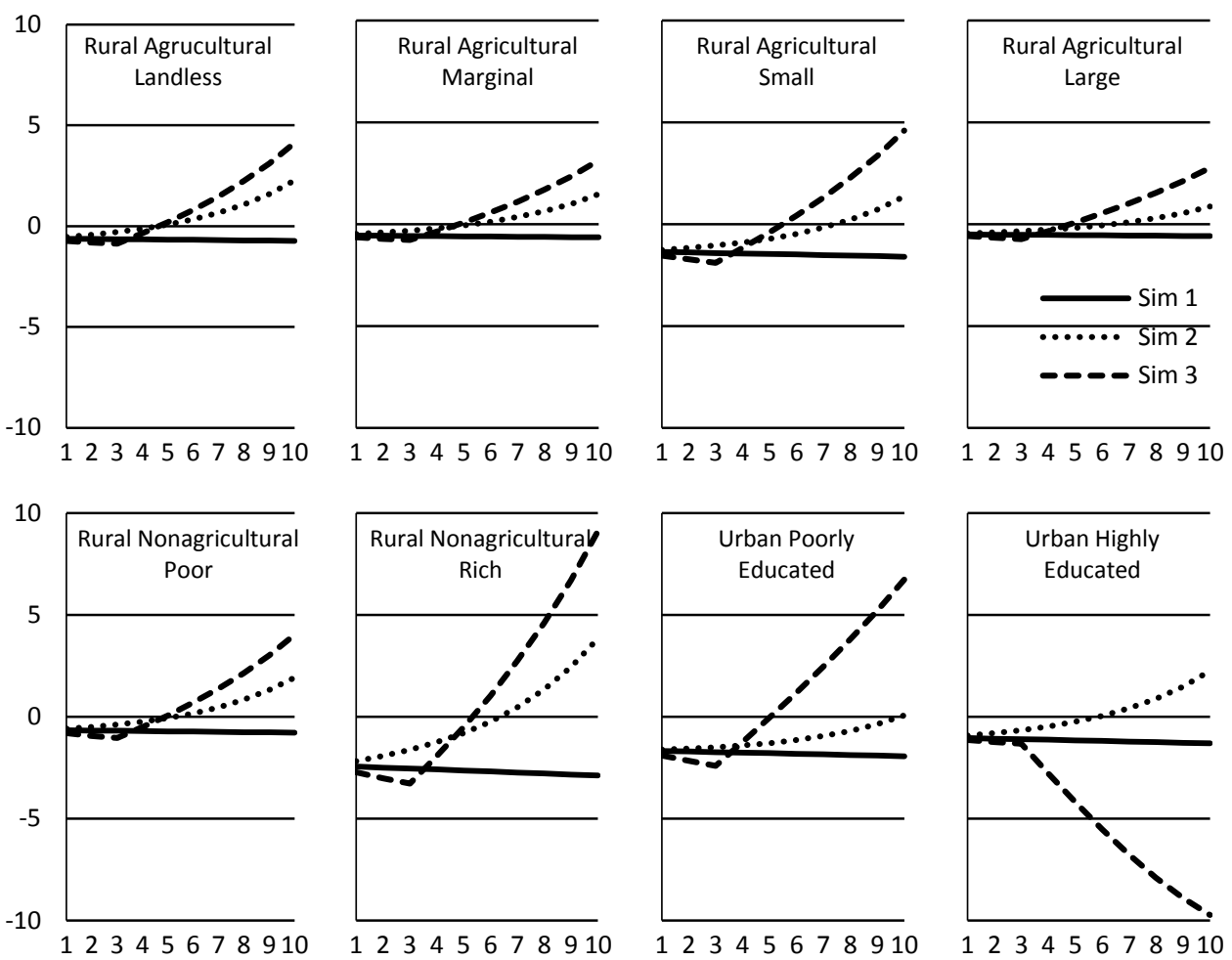
Figure A25: Output with dep $=0.05$ [Deviation from BAU, Billion BDT]
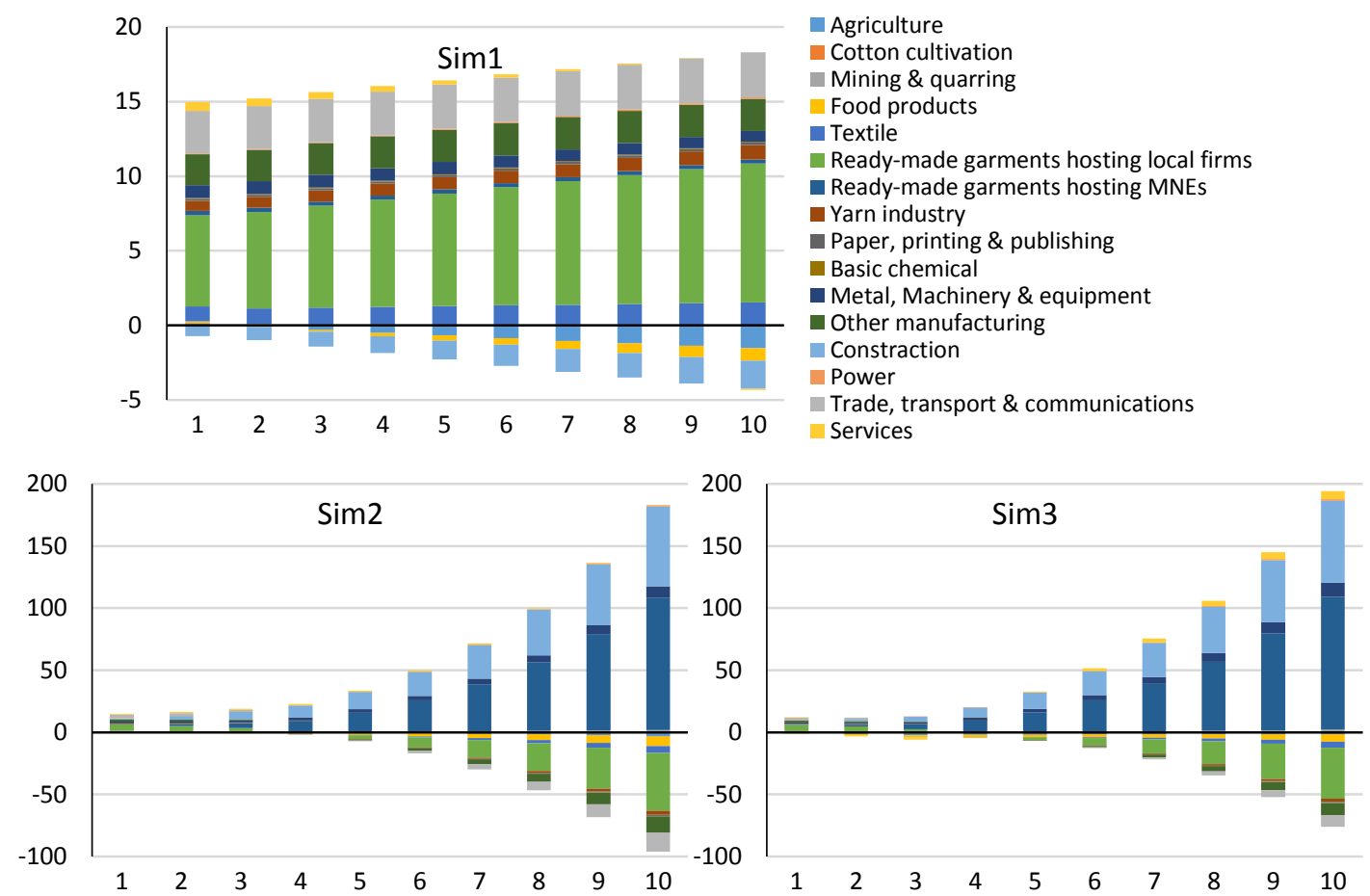

Figure A26: Domestic and Foreign Employment, and Leisure of Unskilled Workers with dep $=0.05$ [\% Change from BAU Total Endowment]
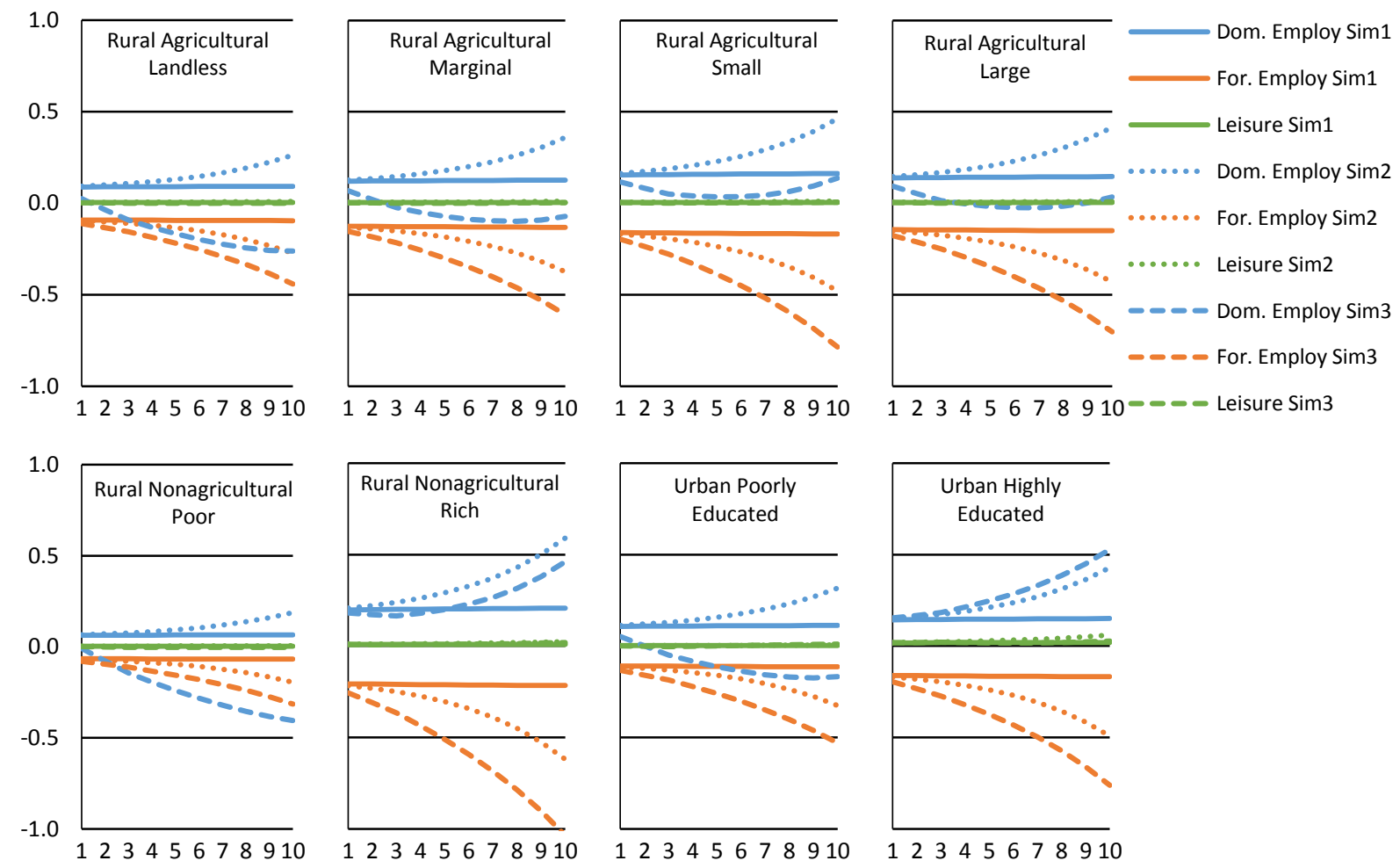
Figure A27: Domestic and Foreign Employment, and Leisure of Skilled Workers with dep = 0.05 [\% Change from BAU Total Endowment]
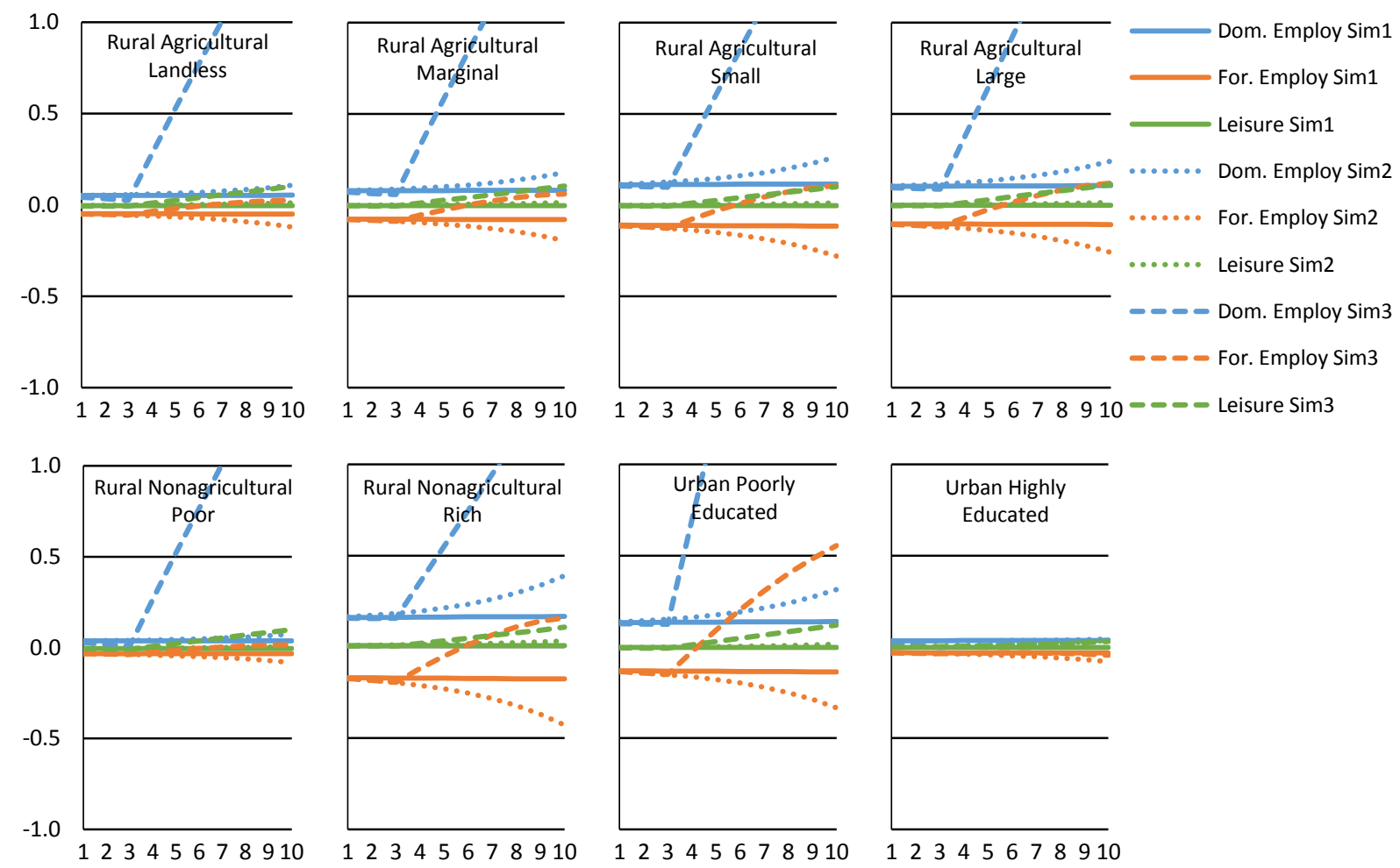

Figure A28: Changes in Domestic Labor Wage with dep $=0.05$ [Deviation from BAU, \%

\section{Change]}
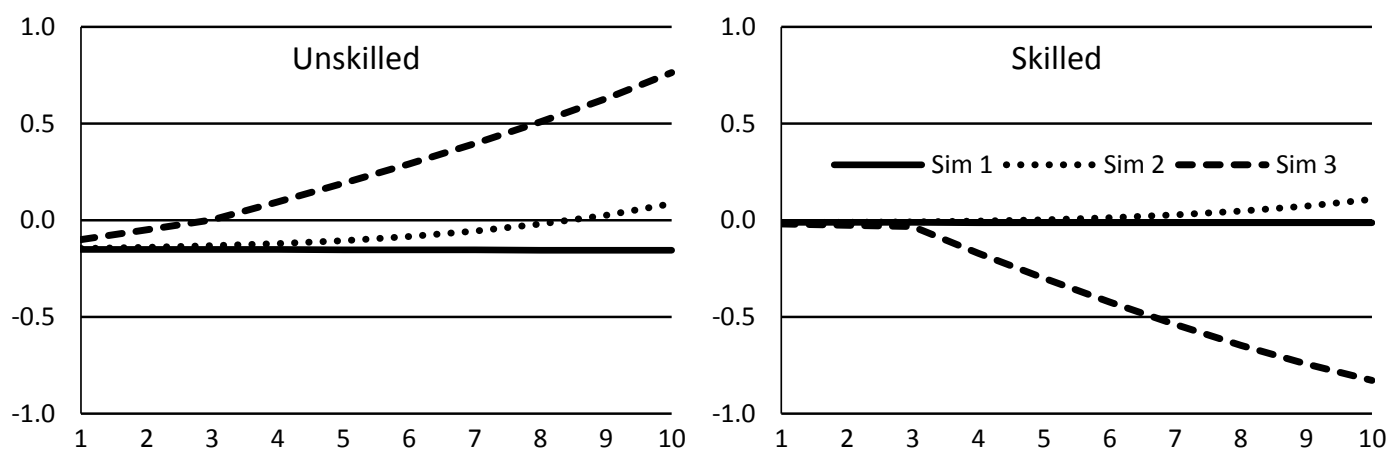
Figure A29: GDP and GNP with dep = 0. 05 [Deviation from BAU, \% Change]
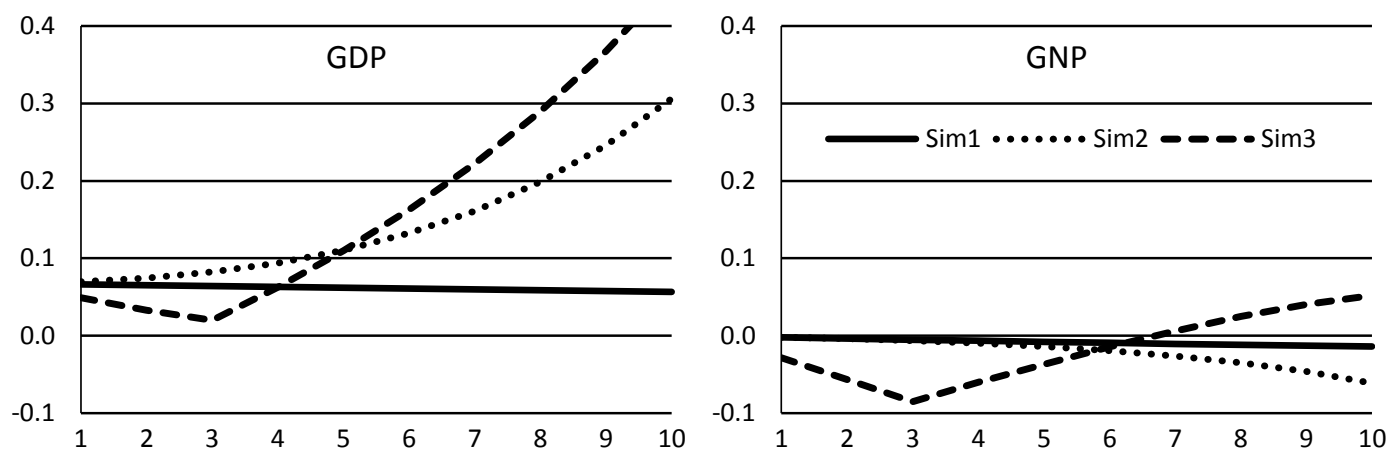

Figure A30: Household Welfare with dep $=0.05[E V$ in Billion BDT]
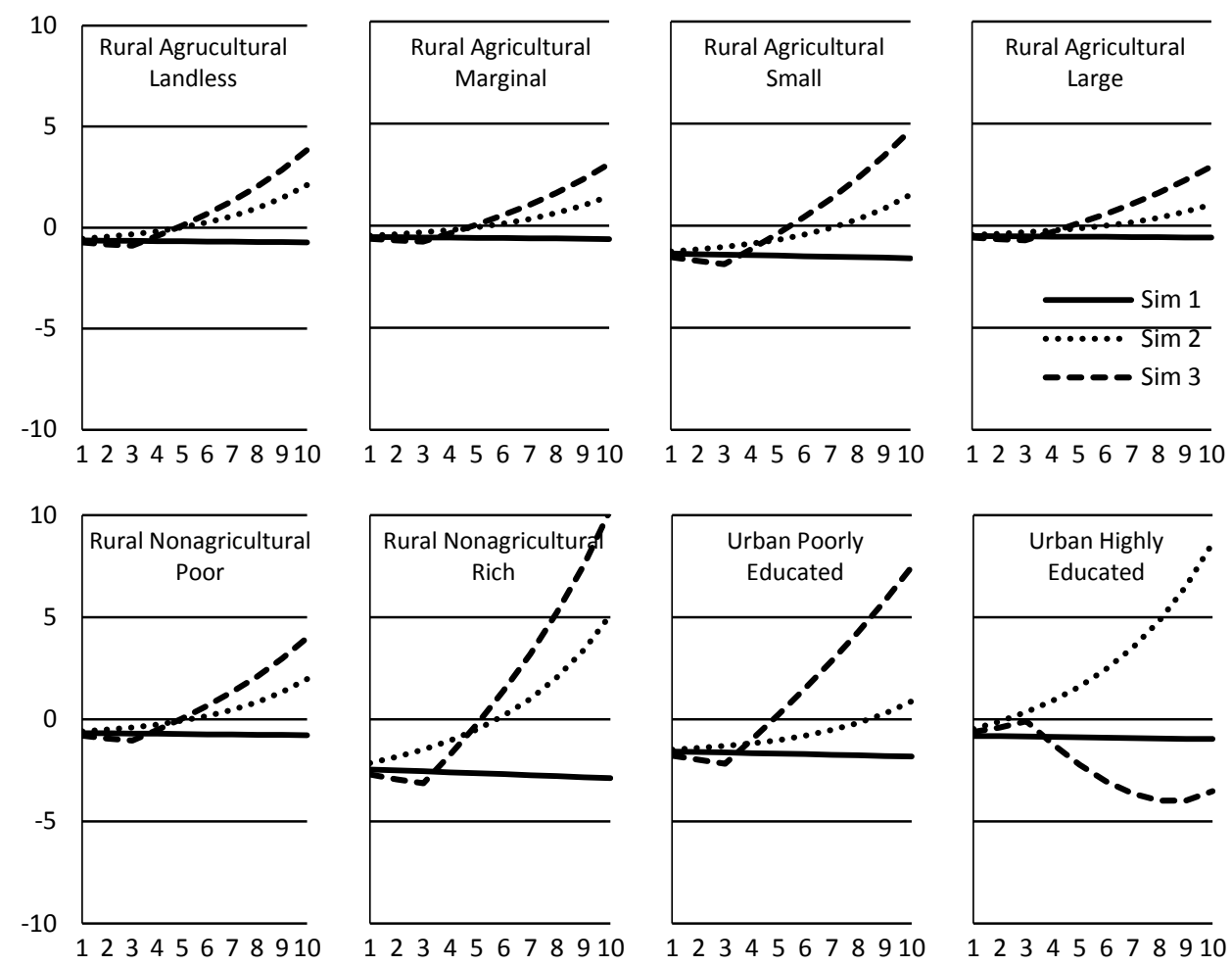
Figure A31: Output with pop $=0.006$ [Deviation from BAU, Billion BDT]

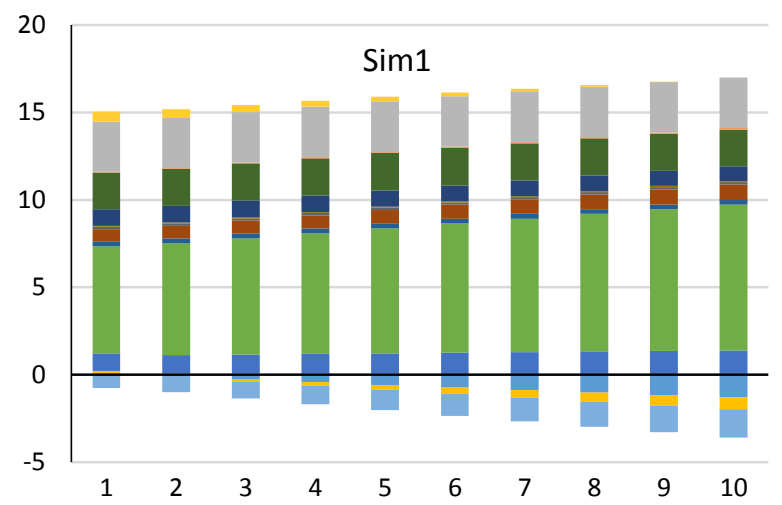

Agriculture

Cotton cultivation

Mining \& quarring

Food products

- Textile

Ready-made garments hosting local firms

Ready-made garments hosting MNEs

- Yarn industry

Paper, printing \& publishing

Basic chemical

Metal, Machinery \& equipment

- Other manufacturing

Constraction

Power

Trade, transport \& communications

Services

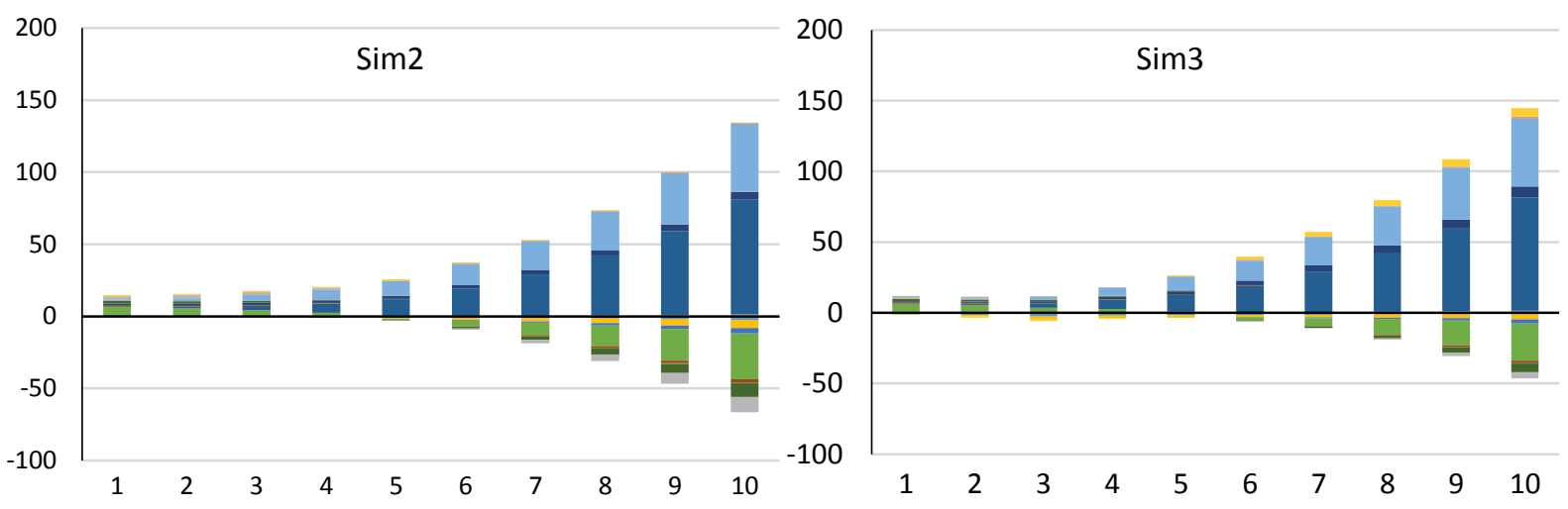

Figure A32: Domestic and Foreign Employment, and Leisure of Unskilled Workers with pop $=0.006$ [\% Change from BAU Total Endowment]
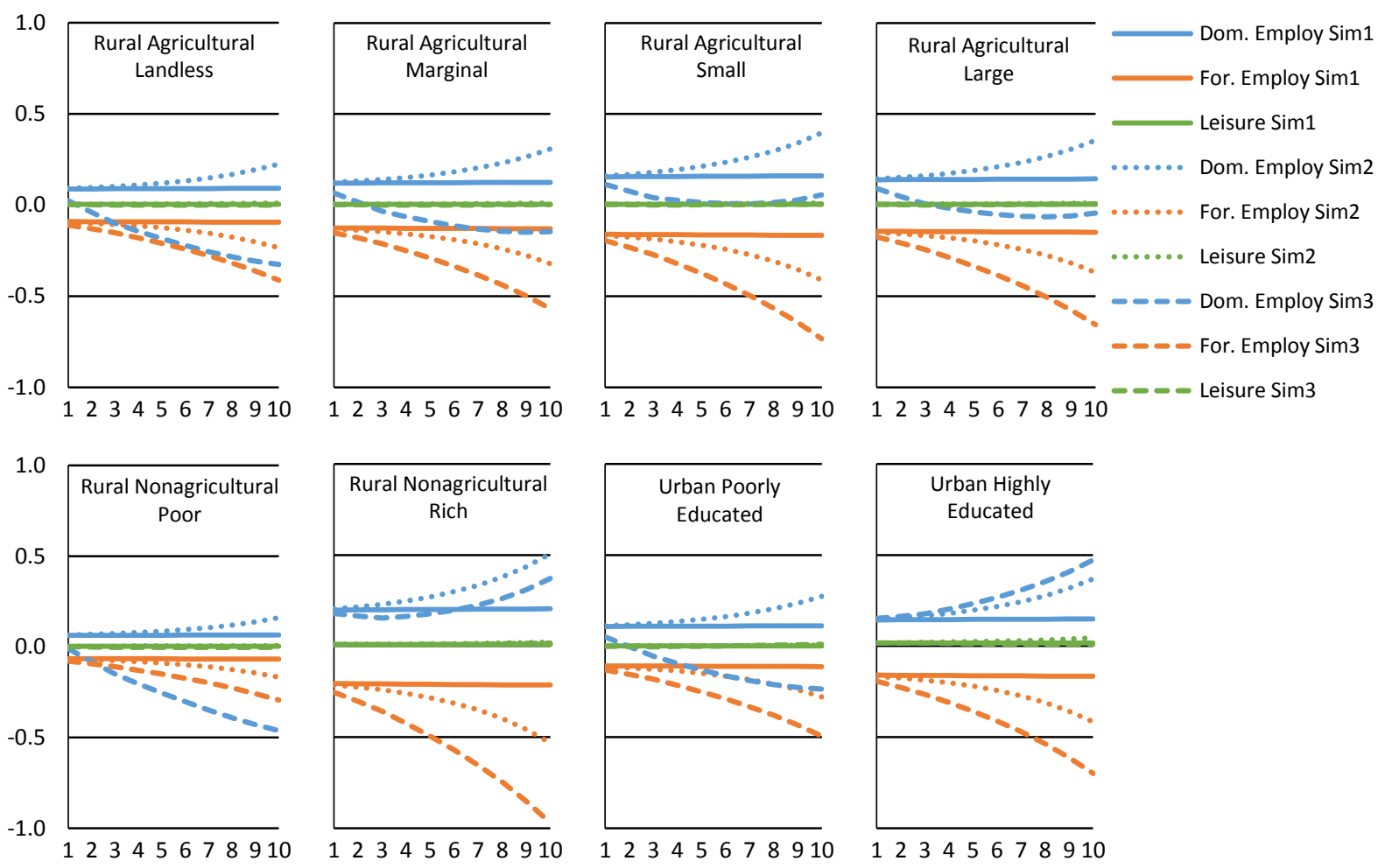
Figure A33: Domestic and Foreign Employment, and Leisure of Skilled Workers with pop $=0.006$ [\% Change from BAU Total Endowment]
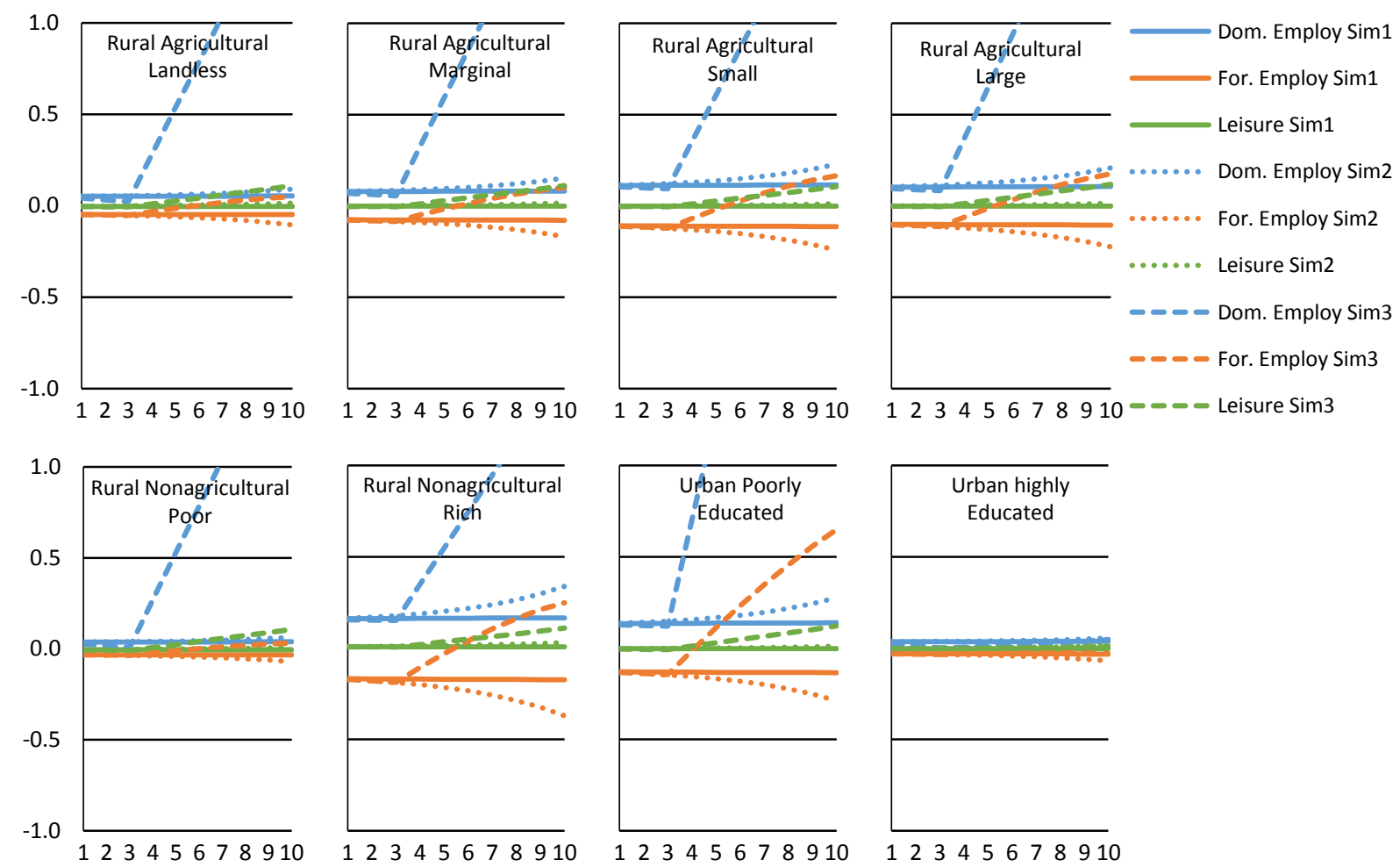

Figure A34: Changes in Domestic Labor Wage with pop $=0.006$ [Deviation from $B A U, \%$

\section{Change]}
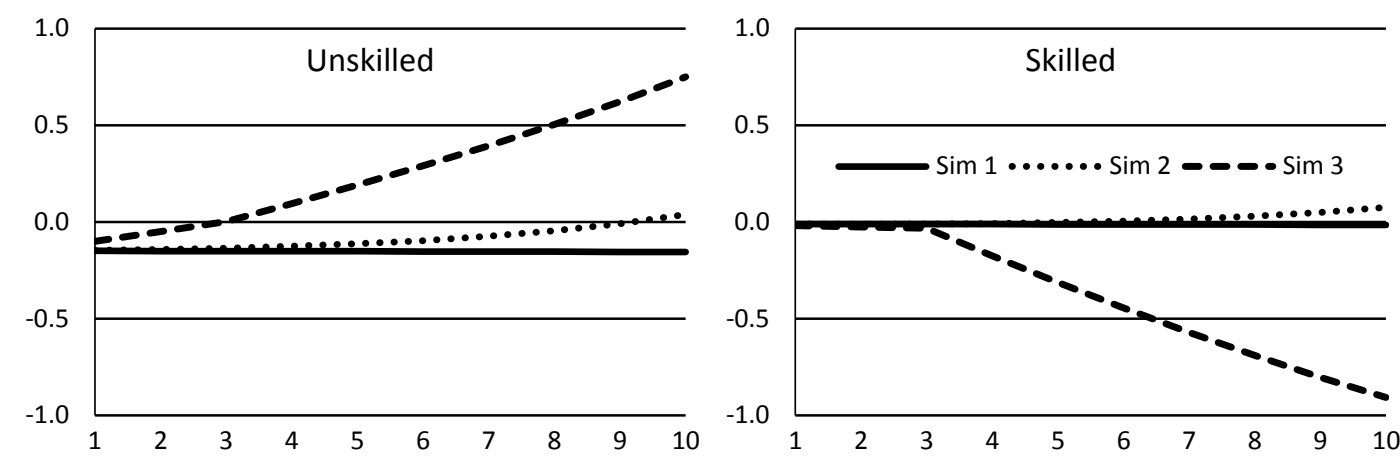
Figure A35: GDP and GNP with pop $=0.006$ [Deviation from BAU, \% Change]
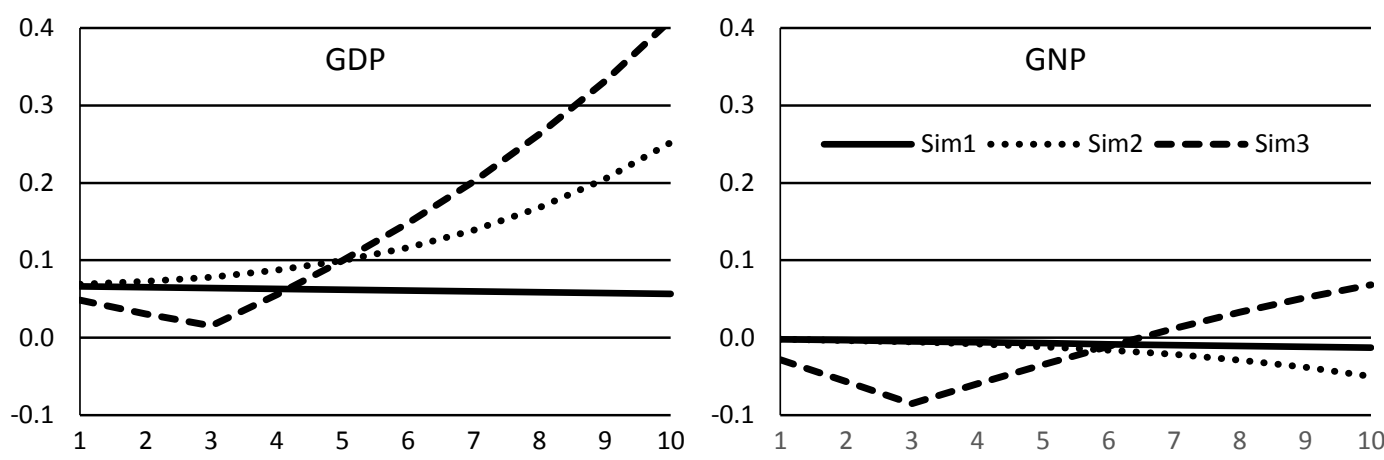

Figure A36: Household Welfare with pop $=0.006$ [EV in Billion BDT]
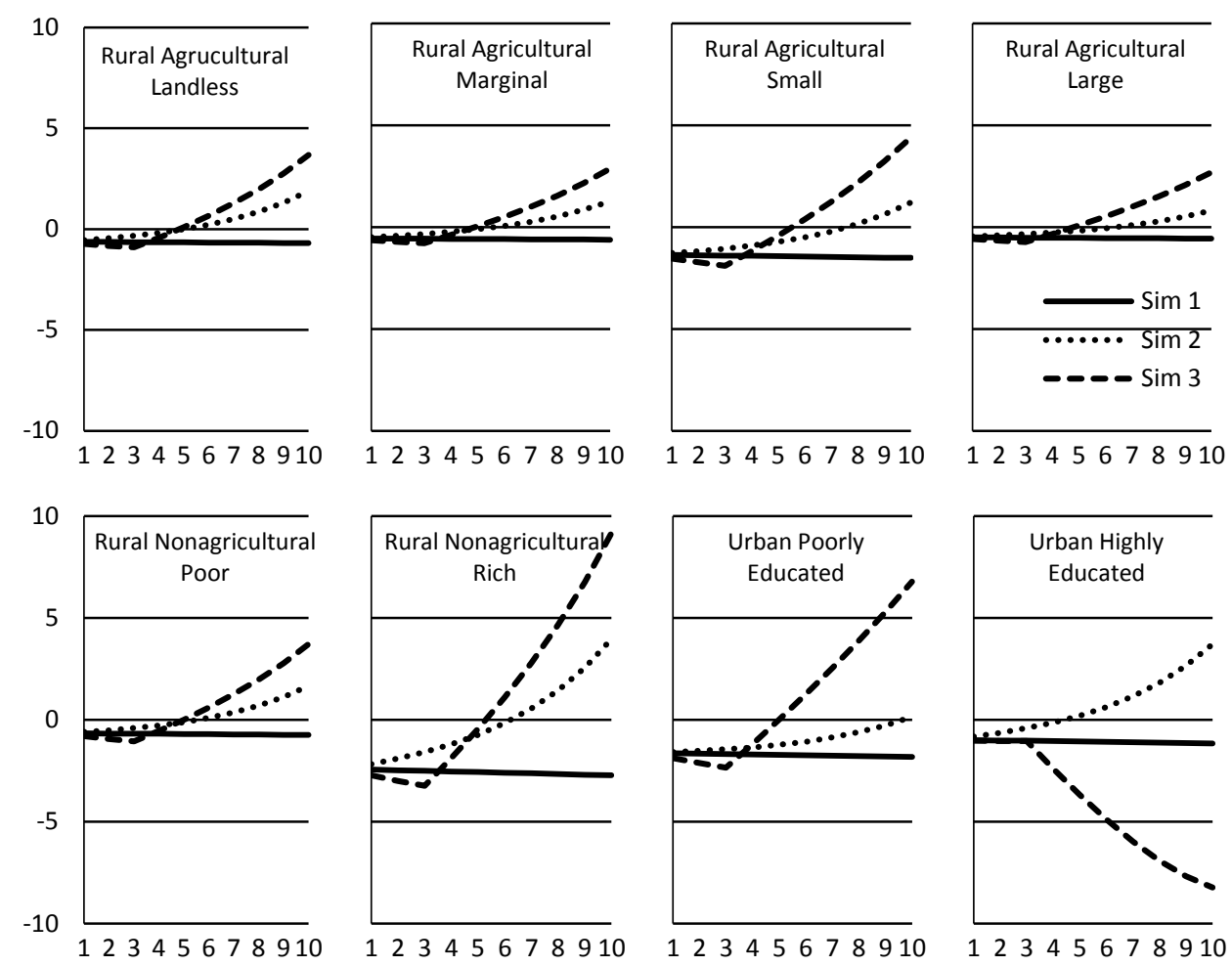
Figure A37: Output with Double Unemployment Rate [Deviation from BAU, Billion BDT]
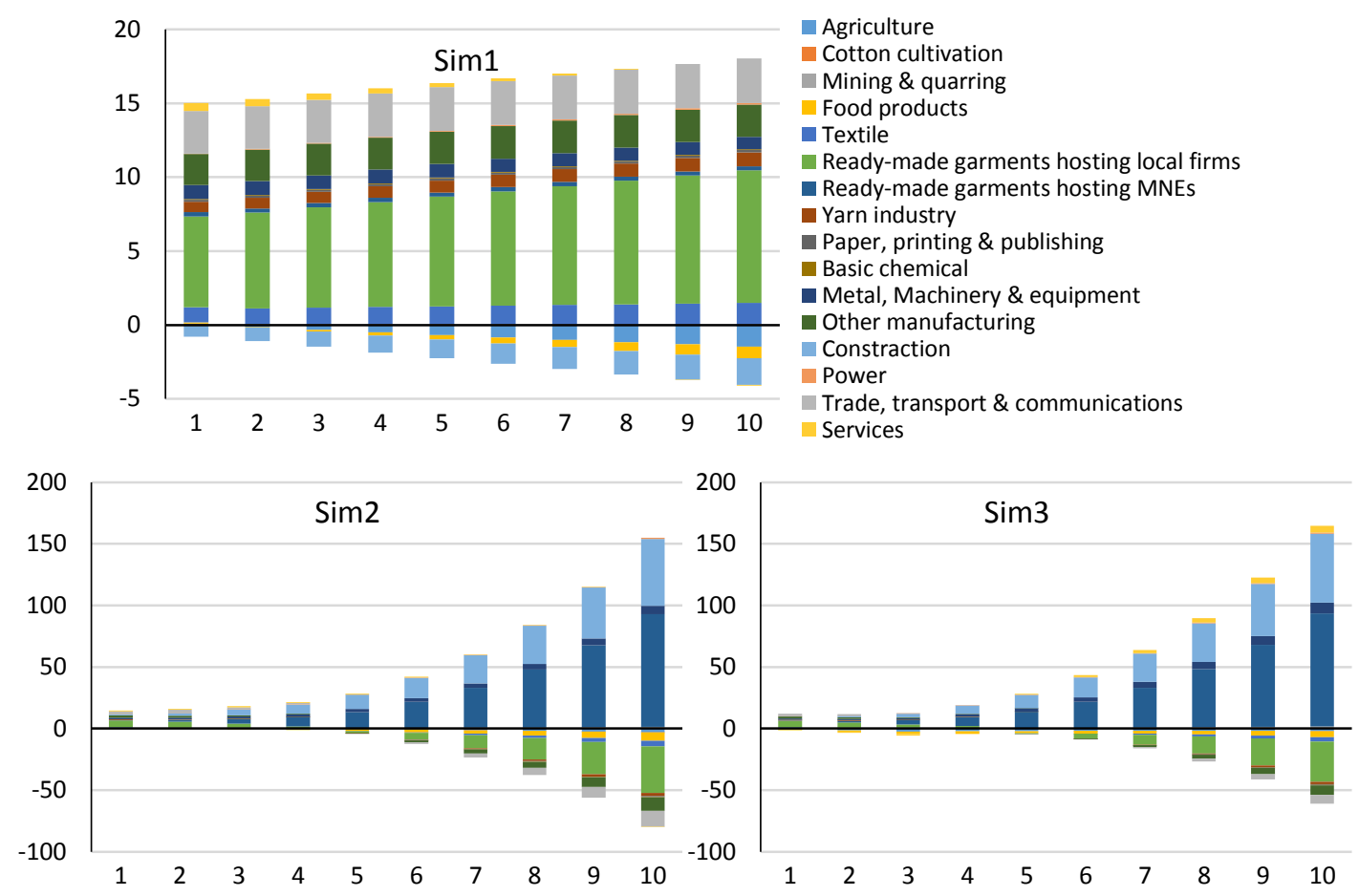

Figure A38: Domestic and Foreign Employment, and Leisure of Unskilled Workers with Double Unemployment Rate [\% Change from BAU Total Endowment]
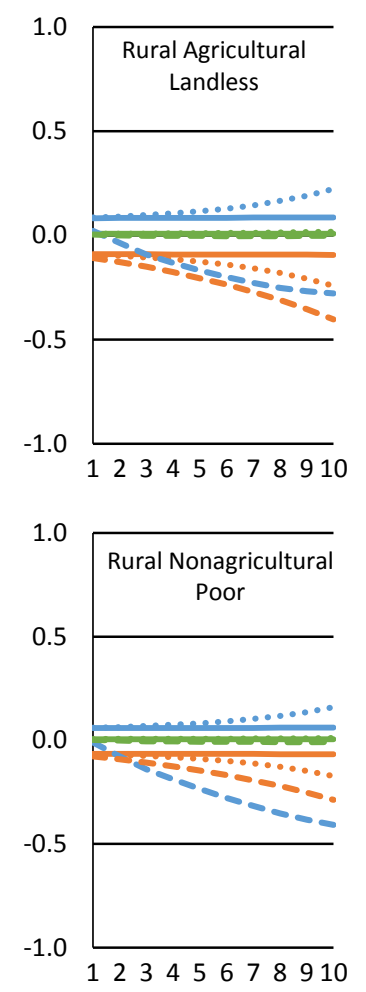
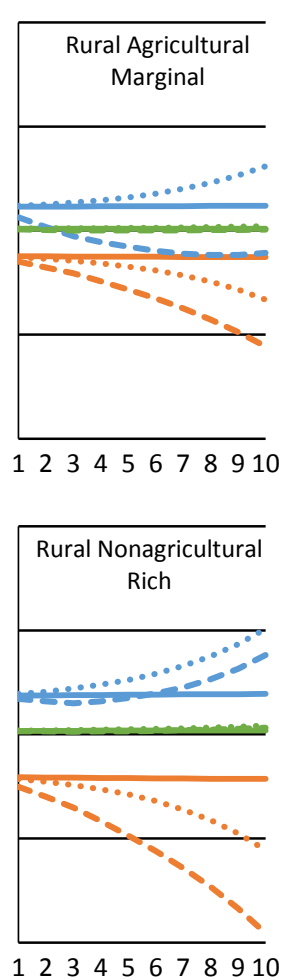
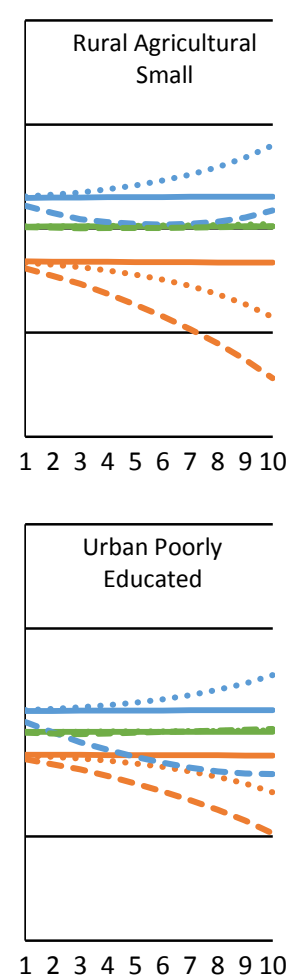
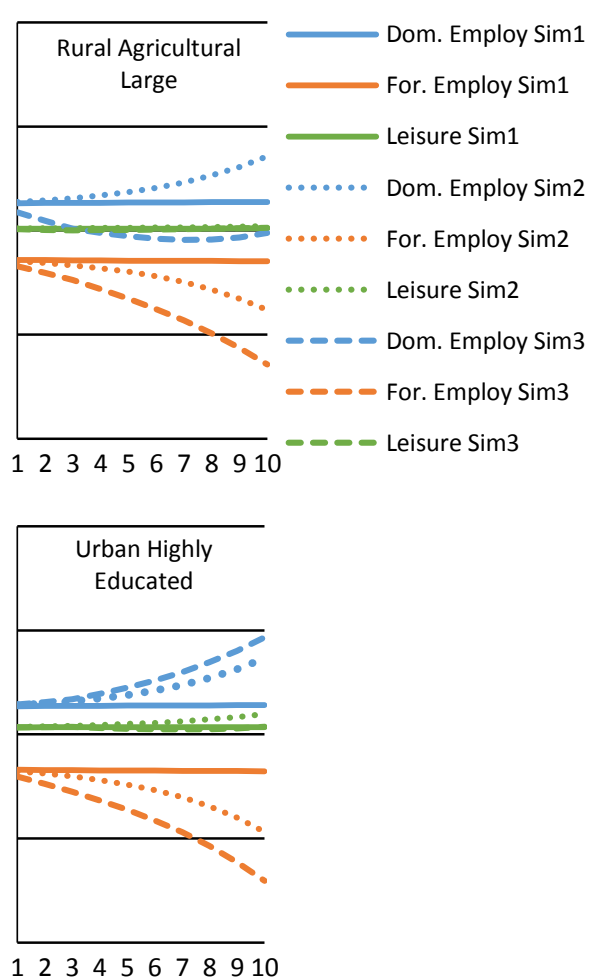
Figure A39: Domestic and Foreign Employment, and Leisure of Skilled Workers with Double Unemployment Rate [\% Change from BAU Total Endowment]
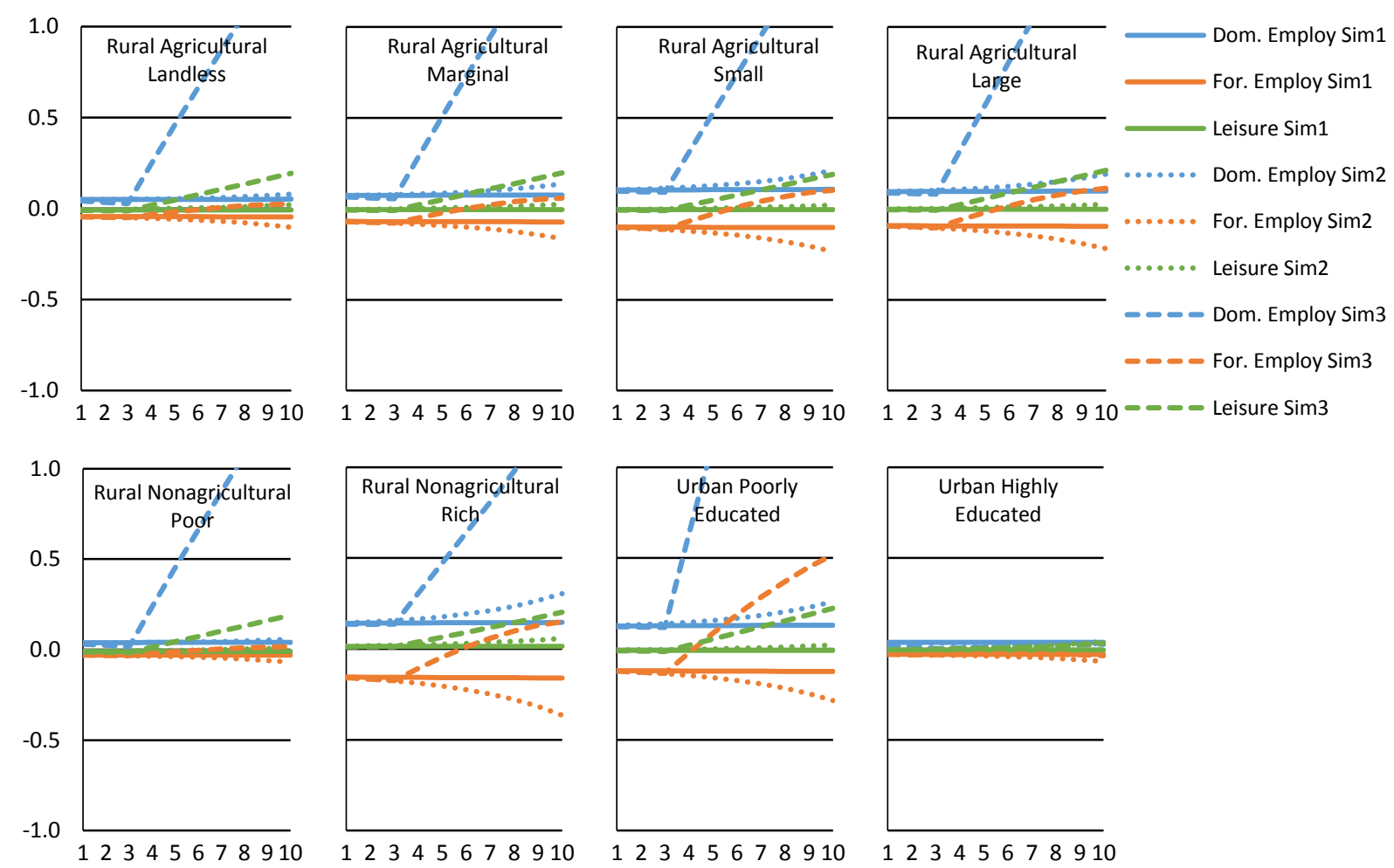

Figure A40: Changes in Domestic Labor Wage with Double Unemployment Rate [Deviation from $B A U$, \% Change]
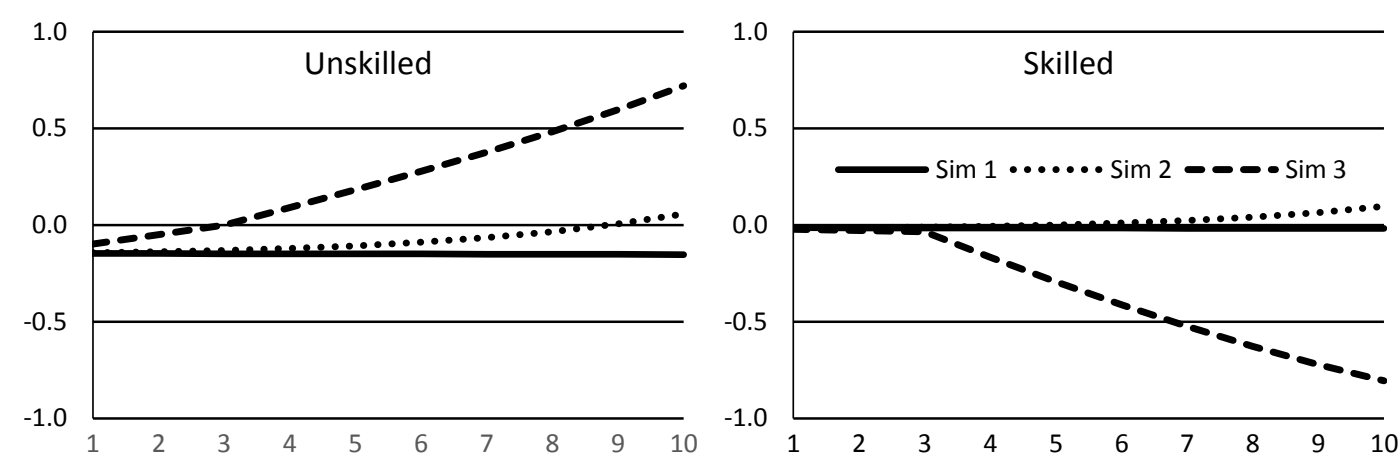
Figure A41: GDP and GNP with Double Unemployment Rate [Deviation from BAU, \% Change]
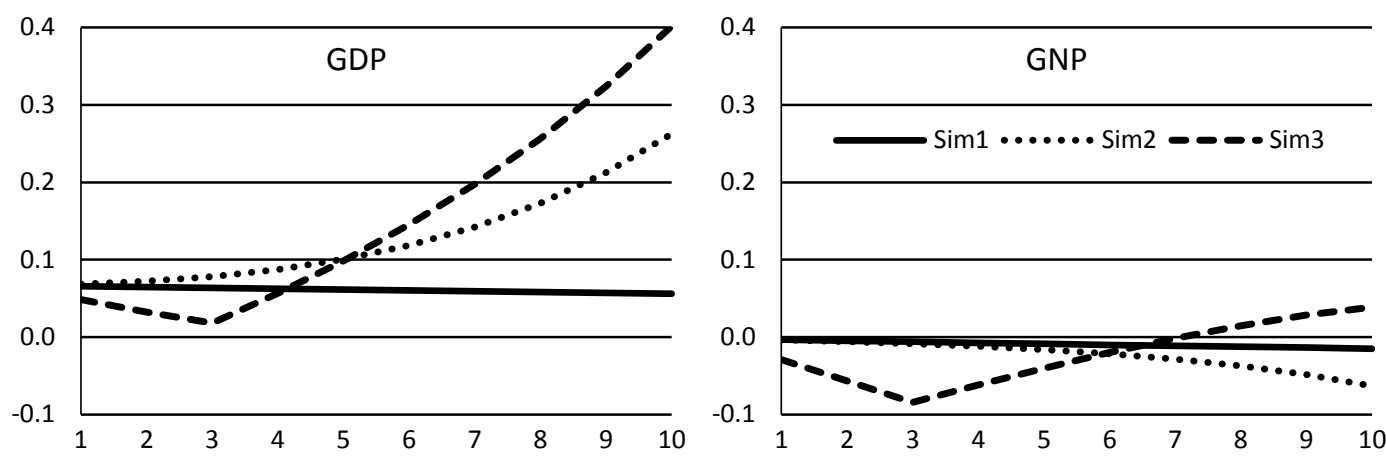

Figure A42: Household Welfare with Double Unemployment Rate [EV in Billion BDT]
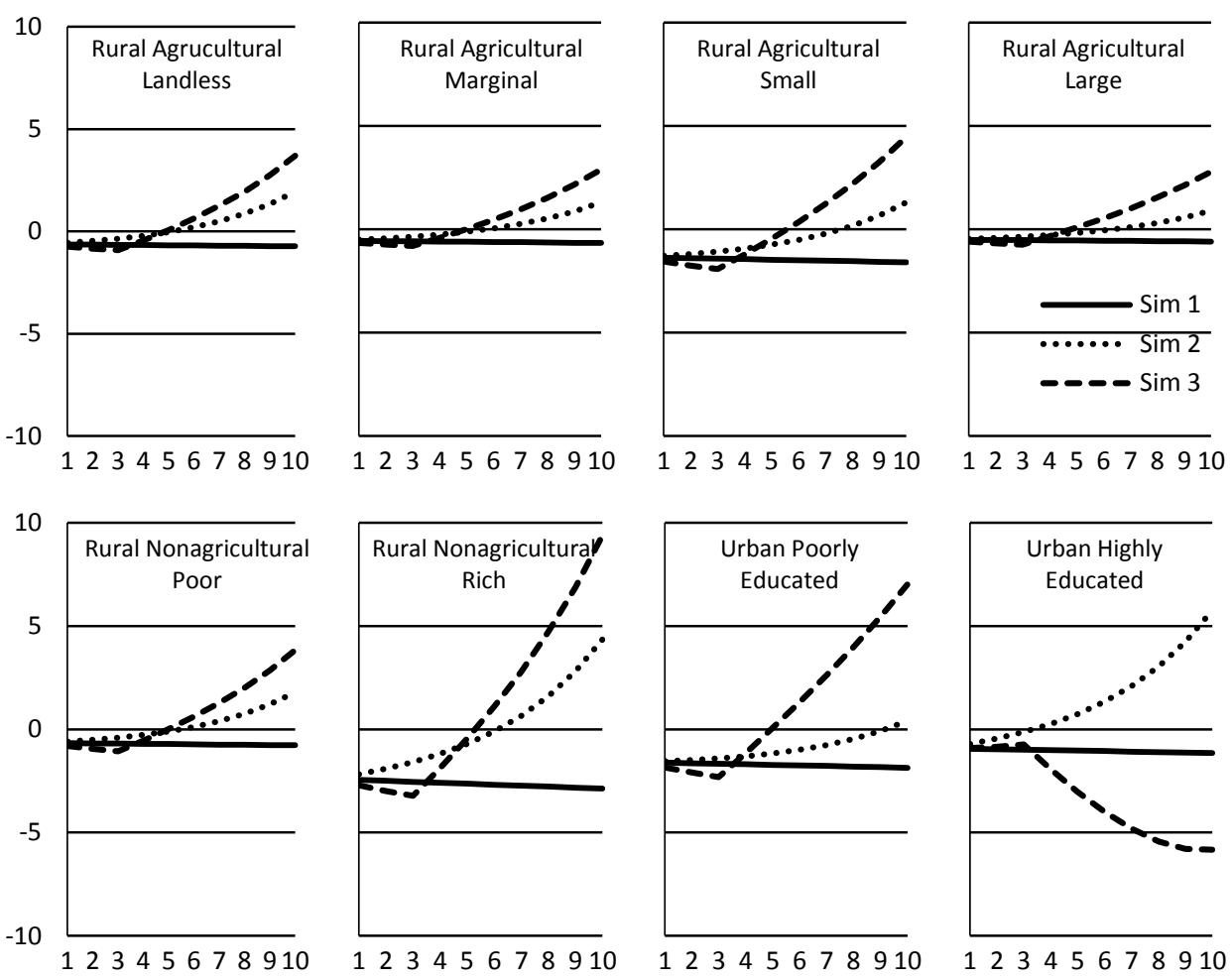


\section{Appendix B: Functional form of Bangladesh Dynamic CGE Model}

We do not show the time period index $t$ in our dynamic model for simplicity unless there is no confusion.

\section{Sets}

i_all,j_all

$i, j \quad$ sectors not hosting MNEs

$i_{-} M N E, j_{-} M N E \quad$ sectors hosting MNEs

$h, k \quad$ factors of production

$h 1, k 1$

$h 2, k 2$

$r, s$

$r 1, s 1$

$\mathrm{r} 2, \mathrm{~s} 2$

$t$ all sectors

capital

labor

institutions (households and corporations)

households

corporations

time period $(0,1,2, \ldots . .10)$

\section{Endogenous variables}

$Y_{j \_a l l}$

$F_{h, j_{-} a l l}$

$X_{i \_a l l, j \_a l l}$

$Z_{j_{-} a l l}$

$X_{i}^{p}$

$X_{i}^{v}$

$E_{i \_a l l}$

$M L O C_{i}$

$M M N E_{i \_a l l, j \_M N E}$

$Q_{i}$

$D_{i \_a l l}$ composite factor (value added)

factor input used by all sectors

intermediate inputs

gross domestic output

household consumption

investment demand

exports

imports for local firms' intermediate and final uses

imports for MNEs' intermediate uses

Armington composite goods

domestic goods produced by all firms 
$D L O C_{i}$

$D M N E_{i \_a l l, j \_M N E}$

$T F_{r, h 2}$

$F F_{r, h}$

$R F_{r, h 2}$

$L_{r, h 2}$

$F F F_{i \_M N E, h}$

$R_{r}^{m}$

$P_{h, j_{-} \text {all }}^{f}$

$P_{r, h 2}^{t f}$

$P_{r, h 2}^{f f}$

$P_{r, h 2}^{r f}$

$P_{j \_a l l}^{y}$

$P_{j_{-} a l l}^{Z}$

$P_{i}^{q}$

$P_{r}^{c c}$

$P_{i-q M N E}^{q M N}$

$P_{-} a l l, j_{-} M N E$

$P_{i \_a l l}^{e}$

$P_{i}^{m L O C}$

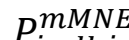

$P_{i \_a l l, j \_M N E}$

$P_{i \_a l l}^{d}$

$P^{k}$ domestic goods used for Armington composite goods

domestic goods used for composite intermediate inputs for MNEs

labor endowment of households employed in domestic and foreign

labor markets

factor endowment of households and corporations employed in domestic market

labor endowment of households employed in foreign labor market

unemployed labor force of households

primary factors owned by foreigners

remittance income of households

factor prices in domestic industries

composite labor wages of households

labor wages of households in domestic market

labor wages of households in foreign labor market in local currency

composite factor prices

supply prices of gross domestic output

Armington composite goods prices

households' composite consumption good prices

Armington's composite goods prices of MNEs' intermediate goods

export prices in local currency

import prices for local firms' intermediate and final goods in local currency

import prices for MNEs' intermediate goods in local currency

domestic goods prices

composite investment goods (or new capital goods) price 
foreign exchange rate (domestic currency/foreign currency)

$S_{r}^{p}$

$S^{g}$

$T_{r}^{d}$

$T_{j \_a l l}^{Z}$

$T_{j}^{m L O C}$

$T_{i_{-} a l l, j \_M N E}^{m M N E}$

$T^{m}$

$T_{j \_a l l}^{S}$

$T_{j \_a l l}^{x}$

$G_{r}^{t}$

$K K_{j \_}$all

$I I_{j \_a l l}$

III

$C C_{r}$

$U U_{r}$

SW private savings by households and corporations

government savings

lump-sum direct tax revenue

production tax revenue

import tariff revenue from local firms' imported inputs, and final demand

import tariff revenue from MNEs imported inputs

total import tariff

production subsidies

export subsidies

government transfers

capital stock (exogenous at the beginning of each period)

sectoral investment

composite investment goods

composite consumption goods (or felicity)

households' utility

social welfare

\section{Exogenous variables}

$X_{i}^{g}$

$L F_{r, h 2}$

$S^{f}$

$P_{h 2}^{w r f}$

$P^{w k}$

$P_{i \_a l l}^{\text {we }}$ government consumption

total labor force of households

current account deficits in foreign currency (foreign savings)

labor wages of households in foreign labor markets in foreign currency

prices of foreign capital goods in foreign currency

prices of exported goods in foreign currency 


$\begin{array}{ll}P_{i}^{\text {WmLOC }} & \text { prices of imported goods in foreign currency } \\ P_{i_{-} \text {all } j_{-} M N E}^{\text {WMMNE }} & \text { prices of imported goods in foreign currency } \\ P R I C E & \text { price index } \\ \tau_{r}^{d} & \text { household share of direct tax } \\ \tau_{j_{-} a l l}^{Z} & \text { production tax rates } \\ \tau_{i}^{m L O C} & \text { import tariff rates on local firm's inputs } \\ \tau_{i_{-} \text {all } j_{-} M N E}^{\text {mMNE }} & \text { import tariff rates on MNEs intermediate goods } \\ \tau_{i_{-} a l l}^{S} & \text { production subsidy rates } \\ \tau_{i_{-} a l l}^{x} & \text { export subsidy rates } \\ \tau_{r}^{g} & \text { government transfer rates to households }\end{array}$

\section{Parameters}

$\begin{array}{ll}a x_{i_{-} a l l, j_{-} a l l} & \text { input requirement coefficients of intermediate inputs } \\ a y_{j_{-} a l l} & \text { input requirement coefficients of composite goods } \\ \alpha_{i, r} & \text { share parameters in composite consumption production function } \\ a_{r} & \text { scale parameter in composite consumption function } \\ \alpha 1_{r} & \text { share parameter in utility function } \\ \alpha 2_{r, h 2} & \text { share parameter in utility function } \\ \beta_{h, j_{-} a l l} & \text { share parameter in production function } \\ b_{j_{-} a l l} & \text { scale parameter in production function } \\ \mu_{i} & \text { share parameter of government consumption } \\ \lambda_{i} & \text { share parameter of investment demand } \\ \delta m L O C_{i}, \delta d L O C_{i} & \text { input share coefficients in Armington composite goods production } \\ & \text { function } \\ \delta m M N E_{i_{-} a l l, j_{-} M N E}, & \text { input share coefficients in Armington composite intermediate input } \\ \delta d M N E_{i_{-} a l l, j_{-} M N E} & \text { production function for MNEs }\end{array}$


$\gamma L O C_{i}$

$\gamma M N E_{i \_a l l, j \_M N E}$

$\sigma_{i \_a l l}$

$\eta_{i \_a l l}$

$\xi d_{i \_a l l}, \xi e_{i \_a l l}$

$\theta_{i \_a l l}$

$\phi_{i \_a l l}$

$\psi_{i_{-} a l l}$

$\omega d_{r, h 2}, \omega e_{r, h 2}$

$\kappa_{r, h 2}$

$v_{r 1, h 2}$

$\chi_{r, h 2}$

$\rho_{r, h}$

l

$\zeta$

$s s_{r}^{p}$ scaling coefficient in the Armington composite goods production function

scaling coefficient in Armington composite intermediate input production function for MNEs

elasticity of substitution in the Armington composite goods production

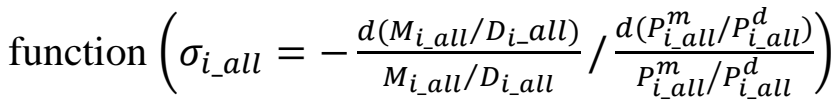

parameter defined by the elasticity of substitution

$$
\left(\eta_{i_{-} a l l}=\frac{\sigma_{i \_a l l}-1}{\sigma_{i-a l l}}, \sigma_{i_{-} a l l} \leq 1\right)
$$

share parameter in the gross domestic output transformation function scale parameter in the gross domestic output transformation function parameter defined by the elasticity of transformation of gross domestic $\operatorname{output}\left(\phi_{i \_a l l}=\frac{\psi_{i \_a l l}+1}{\psi_{i \_a l l}}, \psi_{i} \geq 1\right)$

elasticity of transformation in the gross domestic output transformation function $\left(\psi_{i_{-} \text {all }}=-\frac{d\left(E_{i \_a l l} / D_{i \_a l l}\right)}{E_{i \_a l l} / D_{i \_a l l}} / \frac{d\left(P_{i \_a l l}^{e} / P_{i \text { all }}^{d}\right)}{P_{i_{-} \text {all }}^{e} / P_{i_{\text {a all }}}^{d}}\right)$

share parameter in the labor transformation function

scale parameter in the labor transformation function

parameter defined by the elasticity of transformation in the labor

transformation function $\left(v_{r 1, h 2}=\frac{\chi_{r, h 2}+1}{\chi_{r, h 2}}, \chi_{r, h 2} \geq 1\right)$

elasticity of transformation in the labor transformation function

$$
\left(\chi_{r, h 2}=-\frac{d\left(R F_{r, h 2} / F F_{r, h 2}\right)}{R F_{r, h 2} / F F_{r, h 2}} / \frac{d\left(P_{r, h 2}^{r f} / P_{r, h 2}^{f f}\right)}{P_{r, h 2}^{r f} / P_{r, h 2}^{f f}}\right)
$$

factor shares of households

scale parameter in composite investment good production function

price sensitivity parameter of investment allocation

average propensity for savings by households 


\section{MODEL}

\section{i. Domestic Production Block}

$$
\begin{array}{ll}
Y_{j_{-} a l l}=b_{j_{-} a l l} \prod_{h} F_{h, j_{-} a l l}^{\beta_{h, j} a l l} & \forall j_{-} a l l \\
F_{h, j_{-} a l l}=\frac{\beta_{h, j_{-} a l l} P_{j_{-} a l l}^{y}}{P_{h, j_{-} a l l}^{f}} Y_{j_{-} a l l} & \forall h, j_{-} a l l \\
X_{i_{-} a l l, j_{-} a l l}=a x_{i_{-} a l l, j_{-} a l l} Z_{j_{-} a l l} & \\
Y_{j_{-} a l l}=a y_{j_{-} a l l} Z_{j_{-} a l l} & \forall i_{-} a l l, j_{-} a l l \\
P_{j}^{Z}=a y_{j} P_{j}^{y}+\sum_{i} a x_{i, j} P_{i}^{q} & \forall j \_a l l \\
P_{j_{-} M N E}^{Z}=a y_{j_{-} M N E} P_{j_{-} M N E}^{y}+\sum_{i_{-} a l l} a x_{i_{-} a l l, j \_M N E} P_{i_{-} a l l, j_{-} M N E}^{q M N E} & \forall j \\
\underline{i i . \text { Government }} & \forall j_{-} M N E
\end{array}
$$

\section{ii. Government}

$$
\begin{aligned}
& T_{r}^{d}=\tau_{r}^{d}\left(\sum_{i} p_{i}^{q} X_{i}^{g}+\sum_{r} G_{r}^{t}-\left(\sum_{j_{-} a l l} T_{j_{-} a l l}^{z}+\sum_{i} T_{i}^{m}-\sum_{j_{-} a l l} T_{j_{-} a l l}^{s}-\sum_{j_{-} a l l} T_{j_{-} a l l}^{x}\right)\right) \\
& \forall r \\
& T_{j_{-} a l l}^{Z}=\tau_{j_{-} a l l}^{Z} P_{j_{-} a l l}^{Z} Z_{j_{-} a l l} \\
& \forall j \_a l l \\
& T_{i}^{m}=\tau_{i}^{m L O C} P_{i}^{m L O C} M L O C_{i}+\sum_{j_{-} M N E} \tau_{i, j_{-} M N E}^{m M N E} P_{i, j_{-} M N E}^{m M N E} M M N E_{i, j_{-} M N E} \quad \forall i \\
& T_{j_{-} a l l}^{S}=\tau_{j_{-} a l l}^{S} P_{j_{-} a l l}^{Z} Z_{j_{-} a l l} \\
& \forall \text { j_all } \\
& T_{j_{\_} a l l}^{x}=\tau_{j_{-} a l l}^{x} P_{j_{-} a l l}^{e} E_{j \_a l l} \\
& \forall j \_a l l \\
& G_{r}^{t}=\tau_{r}^{g}\left(T^{d}+\sum_{j_{-} a l l} T_{j_{-} a l l}^{z}+\sum_{j} T_{j}^{m}+\sum_{j_{-} a l l} T_{j_{\_} a l l}^{s}+\sum_{j_{-} a l l} T_{j_{-} a l l}^{x}\right) \quad \forall r
\end{aligned}
$$

iii. Investment and Savings

$$
\begin{array}{cc}
X_{i}^{v}=\frac{\lambda_{i}}{P_{i}^{q}} p^{k} \sum_{j_{-} a l l} I I_{j_{-} a l l} & \forall i \\
S_{r}^{p}=S S_{r}^{p}\left(\sum_{h 1}\left(\sum_{j} P_{h 1, j}^{f} F_{h 1, j}\right) \rho_{r, h 1}+\sum_{h 2}\left(\sum_{j_{-} a l l} P_{h 2, j_{-} a l l}^{f} F_{h 2, j_{-} a l l}\right) \rho_{r, h 2}+G_{r}^{t}+\varepsilon R_{r}^{m}-T_{r,}^{d}\right) \\
\forall r
\end{array}
$$


$S^{g}=s S^{g}\left(\sum_{r} T_{r}^{d}+\sum_{j_{-} a l l} T_{j_{-} a l l}^{Z}+\sum_{j} T_{j}^{m}+\sum_{j_{-} a l l} T_{j_{-} \text {all }}^{s}+\sum_{j_{-} \text {all }} T_{j_{-} \text {all }}^{x}\right)$

$\underline{\text { iv. Households }}$

$X_{i, r}^{p}=\frac{\alpha_{i, r}}{P_{i}^{q}} P_{r}^{c c} C C_{r}$

$\forall i, r$

$C C_{r}=a \prod_{i} X_{i, r}^{p} \alpha_{i, r}$

$\forall r$

$C C_{r}=\frac{\alpha 1, r}{P_{r}^{c c}}\left(\sum_{h 2} P_{r, h 2}^{t f} L F_{r, h 2}+\rho_{r, h 1} \sum_{h 1, j} P_{h 1, j}^{f} F_{h 1, j}+G t_{r}-T d_{r}-S p_{r}\right) \quad \forall r$

$L_{r, h 2}=\frac{\alpha 2_{,, h 2}}{P_{r, h 2}^{t f}}\left(\sum_{h 2} P_{r, h 2}^{t f} L F_{r, h 2}+\rho_{r, h 1} \sum_{h 1, j} P_{h 1, j}^{f} F_{h 1, j}+G t_{r}-T d_{r}-S p_{r}\right) \forall r$

\section{v. Export and Import Prices and Balance of Payments Constraint}

$$
\begin{aligned}
& \left(1+\tau_{i_{-} a l l}^{x}\right) P_{i_{-} a l l}^{e}=\varepsilon_{t} P_{i_{-} a l l}^{\text {we }} \\
& \forall i \text { _all } \\
& P_{i}^{m L O C}=\varepsilon_{t} P_{i}^{w m L O C} \\
& \forall i \\
& P_{i_{-} a l l, j_{-} M N E}^{m M N E}=\varepsilon_{t} P_{i_{-} a l l, j_{-} M N E}^{W m M N E} \\
& \forall i_{-} a l l, j_{-} M N E \\
& P^{k}=\varepsilon P^{w k} \\
& P_{r, h 2}^{r f}=\varepsilon P_{r, h 2}^{w r f} \\
& \forall r, h 2 \\
& \sum_{i \_a l l} P_{i_{\_} \text {all }}^{\text {we }} E_{i_{\_} a l l}+S^{f}+P^{w k} \sum_{j_{\_} M N E} I I_{j_{\_} M N E}+\sum_{r} R m_{r}=\sum_{i} P_{i}^{w m L O C} M L O C_{i}+ \\
& \sum_{i \_a l l, j \_M N E} P_{i_{-} a l l, j j_{-} M N E}^{w m M N} M N E_{i \_a l l, j \_M N E}+\sum_{h 1, j \_M N E} \frac{P_{h 1, j-M N E}^{f}}{\varepsilon} F_{h 1, j \_M N E}
\end{aligned}
$$

vi. Substitution between Imports and Domestic Goods

$$
\begin{array}{lc}
Q_{i}=\gamma L O C_{i}\left(\delta m L O C_{i} M L O C_{i}^{\eta_{i}}+\delta d L O C_{i} D L O C_{i}^{\eta_{i}}\right)^{\frac{1}{\eta_{i}}} & \forall i \\
M L O C_{i}=\left(\frac{\gamma L O C_{i}^{\eta_{i}} \delta m L O C_{i} P_{i}^{q}}{\left(1+\tau_{i}^{m L O C}\right) P_{i}^{m L C O}}\right)^{\frac{1}{1-\eta_{i}}} Q_{i} & \forall i \\
D L O C_{i}=\left(\frac{\gamma L O C_{i}^{\eta_{i}} \delta d L O C_{i} P_{i}^{q}}{P_{i}^{d}}\right)^{\frac{1}{1-\eta_{i}}} Q_{i} & \forall i
\end{array}
$$


$X_{i \_a l l, j \_M N E}=\gamma M N E_{i \_a l l, j \_M N E}\left(\delta m M N E_{i_{-} a l l, j_{-} M N E} M M N E_{i_{-} a l l, j_{-} M N E}^{\eta_{i_{-} a l l}}+\right.$

$\left.\delta d M N E_{i_{-} a l l, j_{-} M N E} D M N E_{i_{-} a l l, j_{\_} M N E}^{\eta_{i}}\right)^{\frac{1}{\eta_{i \_a l l}}}$

$\forall i_{-} a l l, j_{-} M N E$

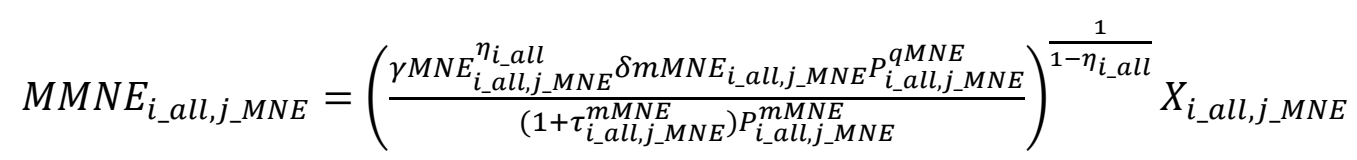

$\forall i_{-} a l l, j_{-} M N E$

$D M N E_{i \_a l l, j \_M N E}=\left(\frac{\gamma M N E_{i \_a l l, j \_M N E}^{\eta_{i} a l l} \delta d M N E_{i \_a l l, j \_M N E} P_{i \_a l l, j \_}^{q M N E}}{P_{i \_a l l}^{d}}\right)^{\frac{1}{1-\eta_{i} a l l}} X_{i \_a l l, j \_M N E}$

$\forall i_{-} a l l, j_{-} M N E$

vii. Transformation between Exports and Domestic Goods

$$
\begin{aligned}
& Z_{i \_a l l}=\theta_{i \_a l l}\left(\xi e_{i \_a l l} E_{i \_a l l}^{\phi_{i} a l l}+\xi d_{i \_a l l} D_{i \_a l l}^{\phi_{i} a l l}\right)^{\frac{1}{\phi_{i} a l l}} \quad \forall i \_a l l
\end{aligned}
$$

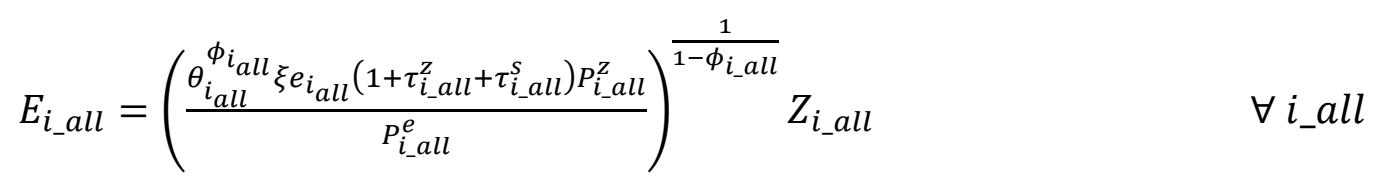

$$
\begin{aligned}
& D_{i \_a l l}=\left(\frac{\theta_{i \_a l l}^{\phi_{i} a l l} \xi d_{i \_a l l}\left(1+\tau_{i \_a l l, t}^{Z}+\tau_{i \_a l l, t}^{S}\right) P_{i \_a l l}^{Z}}{P_{i \_a l l}^{d}}\right)^{\frac{1}{1-\phi_{i \_a l l}}} Z_{i \_a l l} \quad \forall i \text { all }
\end{aligned}
$$

viii. Transformation between Migrant Workers and Domestic Workers

$$
\begin{array}{ll}
T F_{r, h 2}=\kappa_{r, h 2}\left(\omega e_{r, h 2} R F_{r, h 2}^{v_{r, h 2}}+\omega d_{r, h 2} F F_{r, h 2}^{v_{r, h 2}}\right)^{\frac{1}{v_{r, h 2}}} & \forall r, h 2 \\
R F_{r, h 2}=\left(\frac{\kappa_{r, h 2}^{v_{r, h 2} \omega e_{r, h 2} P_{r, h 2}^{T F}}}{P_{r, h 2}^{r f}}\right)^{\frac{1}{1-v_{r, h 2}}} T F_{r, h 2} & \forall r 1, h 2 \\
F F_{r 1, h 2}=\left(\frac{\kappa_{r, h 2}^{v_{r 1, h 2}} \omega d_{r 1, h 2} P_{r, h 2}^{T F}}{P_{r, h 2}^{f f}}\right)^{\frac{1}{1-v_{r, h 2}}} T F_{r, h 2} & \forall r 1, h 2 \\
R m_{r}=\sum_{h 2} P_{h 2}^{r f} R F_{r, h 2} & \forall r
\end{array}
$$

\section{ix. Dynamic Equations}

$I I I=\iota \prod_{i} X_{i}^{v \lambda_{i}}$ 
$P^{k} I I_{j}=\frac{p_{C A P, j}^{f}{ }^{\zeta} F_{C A P, j}}{\sum_{i} p_{C A P, i}^{f}{ }^{\zeta} F_{C A P, i}}\left(\sum_{r} S_{r}^{p}+S^{g}+\varepsilon S^{f}\right)$

$\forall i$

$\underline{x . \text { Evolution of State Variable and Exogenous Variable }}$
$K K_{j_{-} a l l, t+1}=(1-d e p) K K_{j_{-} a l l, t}+I I_{j_{-} a l l, t}$
$\forall j \_a l l, t$
$L F_{r, h 2, t+1}=(1+p o p) L F_{r, t}$
$\forall r, h 2, t$
$X_{i, t+1}^{g}=(1+p o p) X_{i, t}^{g}$
$\forall i, t$
$S_{i, t+1}^{f}=(1+p o p) S_{i, t}^{f}$
$\forall i, t$
$R_{i, t+1}^{f}=(1+p o p) R_{i, t}^{f}$
$\forall i, t$
$R_{i, t+1}^{m}=(1+p o p) R_{i, t}^{m}$
$\forall i, t$

$\underline{x i .}$ Market Clearing Conditions
$Q_{i}=\sum_{r 1} X_{i, r 1}^{p}+X_{i}^{g}+X_{i}^{v}+\sum_{j} X_{i, j}$
$\forall i$
$D_{i}=D L O C_{i}+\sum_{j_{-} M N E} D M N E_{i, j \_M N E}$
$\forall i$
$D_{i_{-} M N E}=\sum_{j_{-} M N E} D M N E_{i \_M N E, j_{\_} M N E}$
$\forall i_{-} M N E$
$F_{h 1, j_{\_} a l l}=$ ror $K K_{j_{-} a l l}$
$\forall h 1, j_{-} a l l$
$\sum_{j_{\_} a l l} F_{h 2, j_{-} a l l}=\sum_{r} F F_{r, h 2}$
$\forall h 2$
$L F_{r, h 2}=T F_{r, h 2}+L_{r, h 2}$
$\forall r, h 2$
$\sum_{j_{-} a l l} I I_{j_{-} a l l}=I I I$
$\sum_{j} P_{h 1, j}^{f} F_{h 1, j} \rho_{r 2, h 1}=T d_{h 1}+S p_{h 1}$
$\forall h 1$

xii. Price Equalization Conditions
$P_{h 2, i_{-} a l l}^{f}=P_{h 2, j_{-} a l l}^{f}$
$\forall h 2, i_{-}$all
$P_{h 2, i_{-} a l l}^{f}=P_{r, h 2}^{f f}$
$\forall r, h 2, i \_a l l$
$P_{r, h 2}^{r f}=P_{s, h 2}^{r f}$
$\forall r, s, h 2$ 


$$
P_{r, h 2}^{f f}=P_{s, h 2}^{f f}
$$$$
\forall r, s, h 2
$$

xiii. Fictitious Objective Function and Social Welfare

$$
\begin{array}{ll}
U U_{r}=C C_{r}{ }^{\alpha 1_{r}} \prod_{h 2} L_{r, h 2}{ }^{\alpha 2_{r, h 2}} & \forall r \\
S W=\sum_{r} U U_{r} & \\
\text { PRICE }=\frac{\sum_{j} P_{j}^{q} Q 00_{j}}{\sum_{i} Q 00_{i}} &
\end{array}
$$

